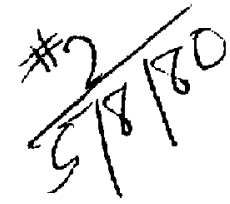

ALO- 53

?
* Printed: Anr11 1980.

\section{MASTER}

UCLA-ENG-7974

DETERMINATION OF OPTIMAL LWR CONTAINMENT DESIGN,

November, 1979 EXCLUDING ACCIDENTS MORE SEVERE

THAN CLASS 8

L. Cave

T. K. Min

$\therefore$
$\therefore \quad:$
$\therefore \quad 1$ 
ALO-68

UCLA-ENG-7974

\title{
DETERMINATION OF OPTIMAL LWR CONTAINMENT DESIGN, EXCLUDING ACCIDENTS MORE SEVERE THAN CLASS 8
}

\author{
L. Cave \\ T. K. M1n \\ Prepared by \\ Chemical, Nuclear and Thermal Englneering Department \\ School of Engineering and Applied Science \\ University of California \\ Los Angeles, California 90024 \\ Prepared for \\ U. S. Department of Energy \\ IIght Water Reactor Safety Technology Management center \\ Sand la National Laboratorles \\ Albuquerque, New Mexico 87185 \\ Sponsored by \\ U. S. Department of Energy \\ Division of Nuclear Power Development \\ Washington, D.C. 20545 \\ Work performed under DOE/ALO Contract No. ET-78-S-04-5450
}

Submitted: November 1979

Printed: April 1980

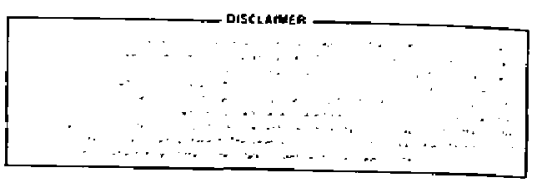


TABLE OF CONTENTS

Page

Summary

1

(1) Introduction .....................66 6

(2) The restrictive effect of existing NRC requirenents . . . . 15

(2,1) Description of the NRC requirements ........ 15

(2.1.1) Regulatory Guide $1.4 \quad$.......... 15

$(2.1,2)$ Accident Assumptions for Envi ronmental

Reports .............. 16

(2.2) Discussion of the conservatism in NRC

requirements $\ldots . . . . . . . . .20$

(2.2.1) Introduction ............. 20

(2.2.2) Source terms .............. 20

(2.2.3) Containment leak rates . . . . . . . . . 20

(2.2.4) Isotope removal process .......... 28

(2.2.5) Atmospheric dispersion .......... 31

(2.2.6) Dose calculation ............ 36

(2.2.7) Extent of conservatism in 10 CFr 100 Guide-

lines for radiological consequences . . . . . 38

(2.3) The extent of the conservatism in NRC requirenents .40

(2.3.1) Dry PliR Containgents .......... 40

(3) Definition of possible targets for containment

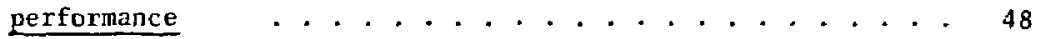

(3.1) Nature of problem ............... 48

(3.2) Definition of assumptions for a "No significant

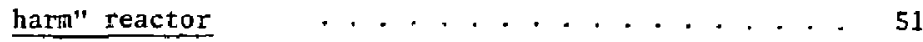


(3.3) Comparisor of containment requirements to meet

NRC and "No significant harm" criteria . . . . . . . . 54

(3.4) Summary of containment performance requirenents

to be considered in optimization studies . . . . . . . 56

(4) Possible containment systems for LWR . . . . . . . . . . . . 61

(4.1) Elements of a containment system . . . . . . . . . 61

(4.1.1) Shielding structure .... . . . . . . . . . 61

(4.1.2) Vented shielding structure with filtration... . 61

(4.1.3) Shielding building structure as $10 \mathrm{w}-1 \mathrm{eak}$

containment ............... . . 62

(4.1.4) Specially designed very low leak rate single

she11 contaimments. . . . . . . . . . . 63

(4.1.5) Doub1e containment concept . . . . . . . . . 64

(4.1.6) Pressure suppression concept . . . . . . . . 66

(4.1.7) External expansion vessel concept . . . . . . . 69

(4.1.8) Application of the "Post-Accident Filtration

Systen" (PAFS) to LWR containment systen . . . 71

(4.2) Performance requirements for Lin containments . . . . 72

(4.2.1) Minimum performance required from the containment

for a $1100 \mathrm{MH}(\mathrm{e})$ LHR $\quad . . . . . . . . . .472$

(4.2.2) Whole body dose due to rare gases as an

indication of the maximum acceptable leak 74

rate ................. 74

(4.3) Performance characteristics of some possible containment

systems for PlW's . . . . . . . . . . . . . . . 76 
(5) Optimization of containment design for classes 3 through

o accident (PWR) . . . . . . . . . . . . . 79

(5.1) Factors affecting the optimization . . . . . . . 79

(5.2) Performance requirements .......... 79

(5.3) Cost of the basic elements of containment systems . . 80

(5.4) Possible means of reducing containment costs . . . 83

(G) Estimated casts of some possible containment arrangements for Phir relative to the standard dry containment system . . . 89

(6.1) Introduction . . . . . . . . . . . . . 89

(6.2) Relative cost of licensed alternatives to the Teference design . . . . . . . . . . . . . . . . 89

(6.2.1) Containment system used in PWR's new operation, or under construction in the U.S. ....... 89

(6.2.2) Relative costs of the various "dry" containnent

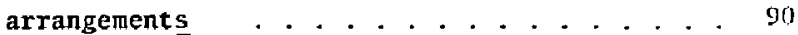

(6.2.3) Relative costs of "Ice-condenser" containments ............ 91

(6.3) Minor modifications to licensed designs which could Iead to higher standard of performance and/or lower cost ................ 93

(6.3.1) Double shell systems with inproved cont rol over annular leakage ........... . . 93

(6.3.2) Double shell systems with lined inner and outer shelis .............. 93

(6.3.3) Partial dual conta $\bar{c}^{i}$ ment systems . . . . . . 94 
[6.3.4) Relaxation of leak rate requirements for mild steel liners . . . . . . . . . . . 95

(6.4) Some foreign containment systems with potential for cost reduction . . . . . . . . . . . . . 95

(0.4.1) Double containments using unlined inner and auter shells ................ 95

$[6,4,2)$ Use of low pressure systems incorporating a

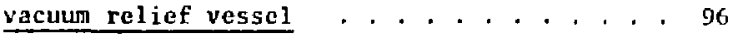

(6.4.3) Use of rapid dousing systens for pressure

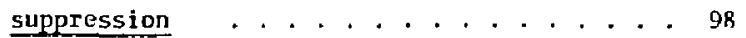

(6.5) Estimated costs of some simple containment systems

(6.5.1) Shiclding structure with no retention capability . . . . . . . . . . 99

(6.5.2) Vented containatrt (unfiltered) . . . . . . 99

(6.5.3) Pressure suppression systems $\ldots . . .100$

(6.5.4) Further exploitation of double shell concept at iow cost . . . . . . . . . . . 101

(6.6) Spray cooling capacity as a factor in containment optimization ......................

(6.7) Effect of the "Post-accident Filtration" concept on containment costs ............. 102

(6.8) Summary .................. . . 103

(7) Estimated costs of BWR containment . . . . . 107

(8) Discussion of results .......... . 110

(9) Conclusions ................ 119 
Appenơix

Appendix 1. Assumptions used in Reg. Guide 1.4 for evaluating

the potential radiological consequences of a loss

of coolant accident for PHR , . . . . . . . . . 121

Appendix 2. Accident assumptions used in discussion of accidents in Environmental reports . . . . . . . . . 129

Appendix 3. Fission product gas release from thermal reactor fuel ...................... 137

Appendix 4. Nature of realistic leakage calculation. . . . . . . 165

Appendix 5. Theoretjcal and experimental models of spray

washout of airborne cuntaminants . . . . . . . 188

Appendix 6. Atmospheric dispersion . . . . . . . . . . . . . 214

Appendix 7. Review of estimate dose for C.ass 8 accident . . . - 233

Appendix 8. Effects of internal diameter and design pressure

on containment cost . . . . . . . . . . . . . 237 
The study described in this report was commenced some months before the accident to the Three Mile Island No. 2 plant (TMI 2). As the ful1 analysis of that accident has not yet been completed, no attempt has been made to include any detailed consideration of its implications on contajument design. However, where it appears that it may have a significant effect on the assumptions made in this report, or on the conclusions reached, this has been indicated in the text.

The first stage in the study was to attempt to define realistically the performance required from a containment in accident classes 3 through 8. This definition presents some difficulties as the existing main documentary guidance (Nuclear Regulatory Commission Regulatory Guides 1.3 and 1.4$)$ contain assumptions about the extent of damage to the fuel which, prior to the TMI 2 accident would have been considered unduly conservative for an accident in classes 3 to 8 . It should be noted that throughout this study it has been assumed that the accidents remain within the "design basis" (i.e. all the engineered safety systen function correctly'). For convenience, these are described as "rell conditioned" accidents. There are also a number of other aspects about which conservative assumptions have been made However, the documentary guidance contains assumptions about the level of radiation exposure, to the public, on which containment designs should be based that might be regarded as unduly high for accidents which are within the design basis envelope.

This preliminary study of the requiremente led to two conclusions:

(a) That, if the source terms in the Regulatory Guide were retained, there was little scope for a reduction in containment performance 
from that required in current plants and thus, at first sight, little scope for reducing cost.

(b) That, if an attempt was made to reduce the conservatism in the source terms and elsewhere, this would need to be accompanied by a re-consideration of the acceptable levels of radiation exposure to the public.

Thus, the second stage in the study was to review systematically all the possible sources of conservatism in the assumptions and methods described in the relevant guidance documests. It was found that the methods and assumptions in the appropriate Regulatory Guides gave rise to an overall factor of conservatism in the estimated dase of order 10 , apart from the source term; including the source term this factor may be as large as order $10^{4}$. However, if the assumptions and methods used in the Environmental Report Models were used, this factor was considerably smaller, about unity, apart from the source term, and of order $10^{2}$ including this term.

The third stage in the study was to formulate an alternative set of radiation exposure criteria, suitable for use with a "best-estimate" set of assumptions and methods for assessing the radiation exposures from Class 3 through 8 accidents. Clearly there is an almost infinite variety of criteria that could be proposed. For the purposes of this study, however, it was sufficient to develop a set which was likely to be the most severe that would be required by any of the interested parties. The set of criteria proposed has been developed from the concept that it would be desirable to show that, for accident Classes 3 through 8, there would be no interruptions of the fublic's activities 
due to faults on the reactor. It so happens that the particular set of criteria chosen for this limiting case proved to be so restrictive that they virtually orfset the overall conservatism estimated to be present in the assumptions $a d$ methods of the Regulatory Guides. Consequently, if this set of criteria were adopted, there would again be little scope for reducing the performance required in current containment designs.

Although a simple cost/benefit approach, based on the "expectation of loss" principle, indicated that there was a case for dispensing with containment, this line was considered to be so unlikely to be acceptable that it was not pursued further and attention was focussed on the possibility of meeting current performance standards at lower cost.

The fourth stage of the study, therefore, was an analysis of the rather limited data available for the cost of the main elements in typical containment systems and an investigation of the cost/performance relationship. From these studies it appeared that the most promisino method of reducing the cost of containment for PWRs lay in the exploitation of the pressure suppression concept, since this could lead to lower design pressurer and the possibility of dispensing with low leak rate steel liners. Estimates of the cost of the Westinghouse "ice containment" indicated that this should be about 15 percent lower than that of the conventional "dry" containment system. Estimates of the cost of the CANDU-PHWR containment system, based on the very rapid condonsation of steam by the use of a rapid dousing system and the replacement of the conventional steel liner by a plastic coating, indicated that a reduction of 25 percent in the cost of the contaigment system for a 1100 Mh'(e) PWR. In principle the ice containment system could be developed further to permit the use of plastic liners, which should lead to an 
overall saving similar to that estimated for the Canadian system. However, although PWRs using the ice-condenser concept are already in use, it is not entirely clear that the difficulties encounte ed with the system are due to remediable design errors or to more generic problems; moreover, the acceptability in the US of the Canadjan system has not yet been zested. Thus it is not yet cortain that these potential reductions in containment cost can be achieved in practice.

The analysis of costs indicated also that, if an improvement over present standards of performance were required, this could best be achieved by the use of the double containment concept, with "pump back" from the aindlar space into the inner vessel. By the use of plastic lined pre-stressed concrete shells, together with the pressure suppression concejt, the overall cost should be about the same as that of the Reference Design.

In the case of BlWR, as a pressure suppression system was used in the Reference Design, there is less scope for a reduction in cost. However, the Reference Design, for a BWR containment system appears to contain some unduly expensive features and reductions of between 7 and $1 j$ percent might be achievable by adopting the same approach as that proposed above for PWR containment systems. Similarly, the performance could be improved at little extra cost by an application of the doublecontainment concept.

Savings of up to $S_{I} \mathrm{~m}$ (at 1979 prices) per PIIR appears to be attainable;development work (e.g., on the reliability and performance of some pressure suppression systems and on the testing of plastic liners) would be necessary to achieve these savings. However, it is not clear 
that, in the aftermath of the TMI-2 accident, utilitics would be interested in making savings of this order, it it were necessary to depart from accepted design solutions in order to achieve them; nor is it clear whether changes in containment perforsance requirements will be formulated by NRC, or the utilities themselves, (e.g.. there may be requirement to cater for core meltdown situations). If major changes in requirements are proposed these may inter-act with the nethods visualized for reducing containment costs. Thus there are two areas in which more work is required before a decision could be made to embark on a deveiopment program aimed at reducing the cost of contaimment. If it vicre decided to go ahead with a program of development to support cost reduction, the main itemswould be:

(a) Investigation of the reliability of pressure suppression systems, as compared with pressure retention systems

(b) Analysis of all available experience with ice containments, to determine whether the system is subject to any unresolved generic problens

(c) Investigation of the performance of the Canadian rapid dousing pressure suppression system

(d) Review of data relating to the leak rates of unlined and plastic lined pre-stressed concrete shells

(e) Continuation of passible methods for reducing the cost of protecting interior concrete structures of BWR containments. 


\section{(1) Introduction}

For many years the retention performance of contaisment systems for LiW's has been determined largely by the requirements set out in Regulatory Guides 1.3 and 1.4 (Ref. 1 and 2). These requirements are discussed in detail later, it is only necessary for the moment to note that they require the applicant for a license to asswe that large proportion of the gaseous and volatile fission products have been released from the fuel; these proportions are, in fact, so large that they could only occur as a result of prolonged heating of the fuel at temperatures greater thas $1500^{\circ} \mathrm{C}$ or of core melt dowi. However, for accidents in Classes 1 through 8 , as defined in Ref. 3 for the purposes of preparing Environmental Reports, the amounts of activisy released ere consistent with fuel cladding failure accompanied by only a small increase in fuel temperature, far short of melting.

Preliminary calculations, based on recent FSAR's for PHR's with "dry" containments, have shown that if the conservative assumptions required by Regulatory Guide 1.4 are employed, there is relatively Iittle margin of safety in the containment performance (factors of 1.6 to 3,3 , according to reactor design). Thus there would be little opportunity for modifying the containlest design in order to reduce the cost.

However, if a situation is visualized in which the Regulatory Guides were revised and less conservative assumptions were used for accidents in Class I through 8 , then there could be scope for changes in the contaimment system. Nevertheless, in this more realistic situation it wotud probably be necessary to revise downwards the 
maximum dose delivered to members of the public and to consider other possible restrictions on containment design such as the need for the structure to resist seismic forces.

Thus three necessary stages in the first part of this study are as follows:

(a) An evaluation of the degree of conservatism in the requirements of Reg. Guides 1.3 and 1.4 ,

(b) Consideration of appropriate dose 1 imits for members of the public, taking account into the expected irequencies of the accidents in Classes 3 through 8 .

(c) Consideration of the constraints imposed on the containgent design by other factors, such as the need to withstand external hazards.

The performance and cost of a variety of containment designs fo: water reactors, some of which have not yet been used for commercial reactors in the United States, have heen examined. In addition some possible ways of reducing costs, while meeting either the Reg. Guide requirements for radiation exposure of the public, or some other hypothetical requirements, have been examined in more detail to establish the extent of the saving which might be made.

This repcrt is divided into eight sections. Following this introduction, Section 2 reviews and evaluates the extent of the conservatism in NRC requirements. Sertion 3 defines the possible targets for containment performance and summarizes containment performance requirements to be considered in optinization studies. Section 4 outlines the possible contaiment systems for Light Water Reactors (LWR's). 
Section 5 gives the optimization of containment design for Classes 3 through 8 for Pressurized liater Reactors (Pl'R's). Section 6 describes the estimated costs of some possible arrangements for PWR relative to the standard dry contajnment system (Ref. 4). Section 7 also gives the estimated costs of Boiling Water Reactors (BW's's), Sections and 7 contair the conclusion of this study. More detailed expianations for cach section are presented in Appendices at the end of this report. The more important types of containment considered in this study are illustrated in ligures 1.1 through 1.5 . 
(1). U.S. Nuclear Regulatory Guide 1.3, "Assumptions used for evaluating the potential radiological consequences of a loss of coolant accident for boiling water reactors," Revision 2, June, 1974.

(2). U.S. Nuclear Regulatory Guide 1.4, "Assumptions used for evaluating the potential radiological consequences of a loss of coolant accident for pressurized water reactors." Revision 2, Junc, 1974.

(3). U.S. Nuclear Regulatory Guide 4.2, "Preparation of Environmental Reports for Nuclear Power Stations,"NUREG-0099, Revision 2, $\mathrm{July}, 1976$.

(4). "Capital Cost: Pressurized Nater keactor P1ant," NUREG-0241, C002477-5, June, 1977. 


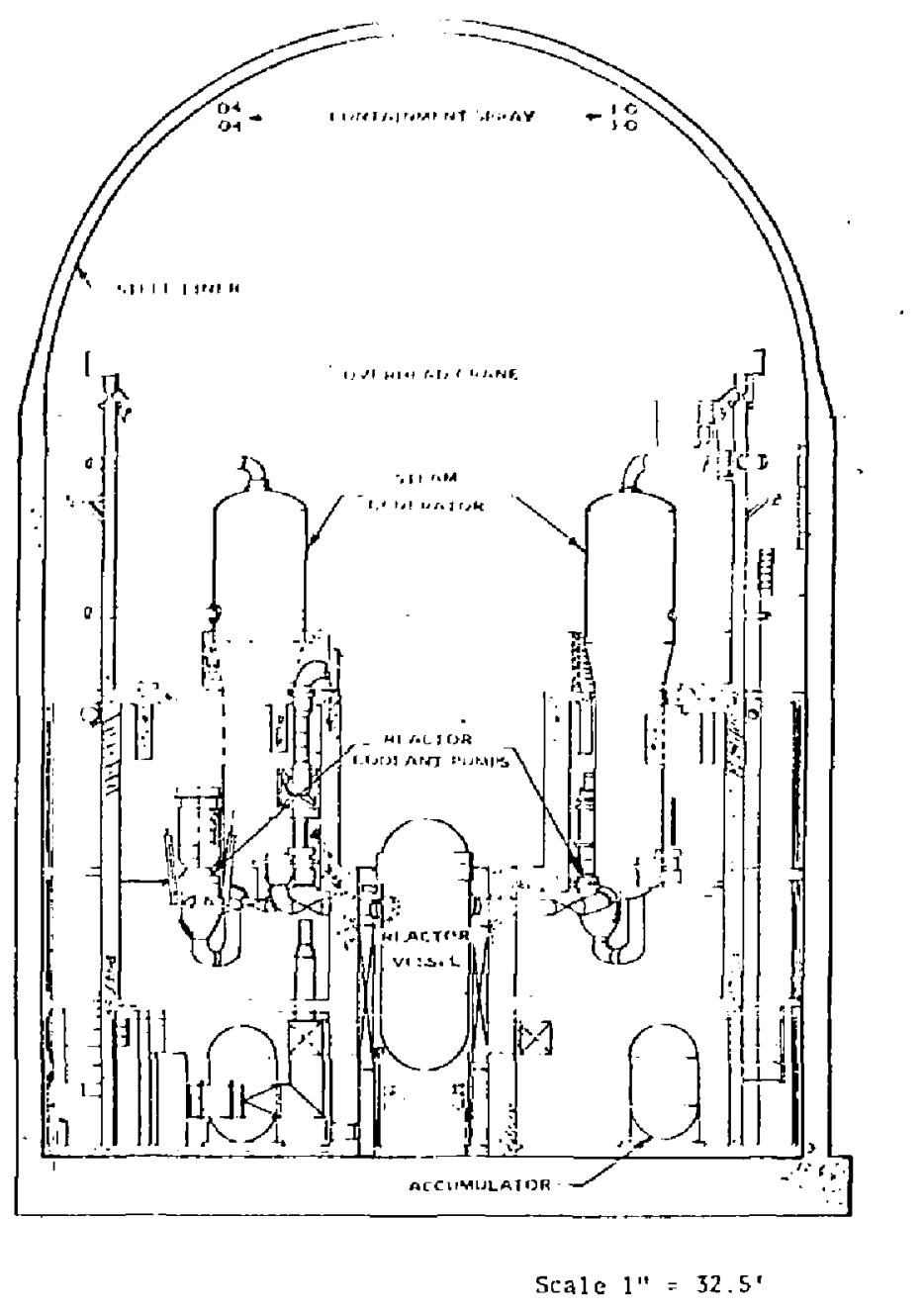

Figute 1.1 Typical PIR 'ity containment. 


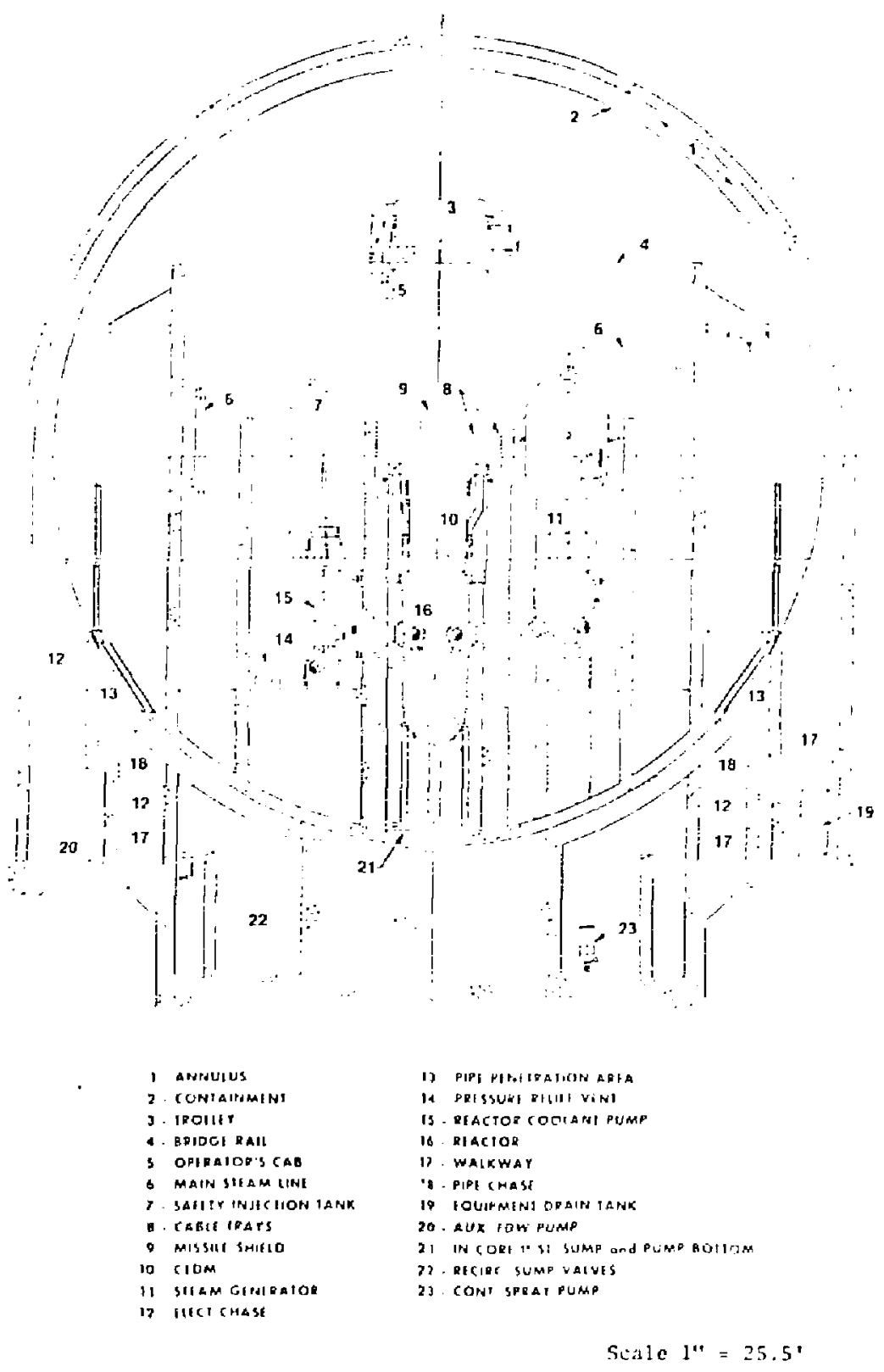

Figure 1.2 Elevation view of a typical spherical PliR containment. 


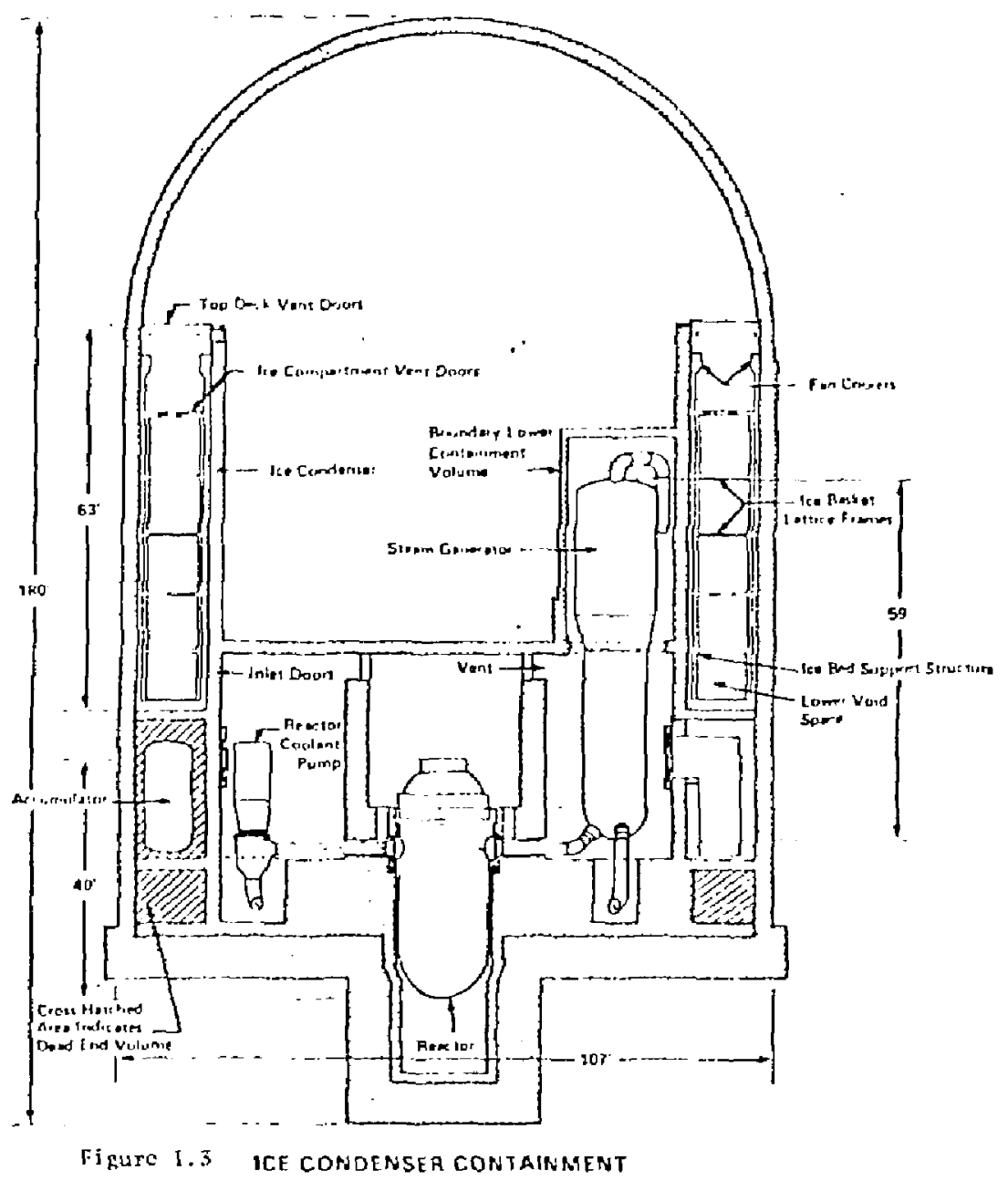




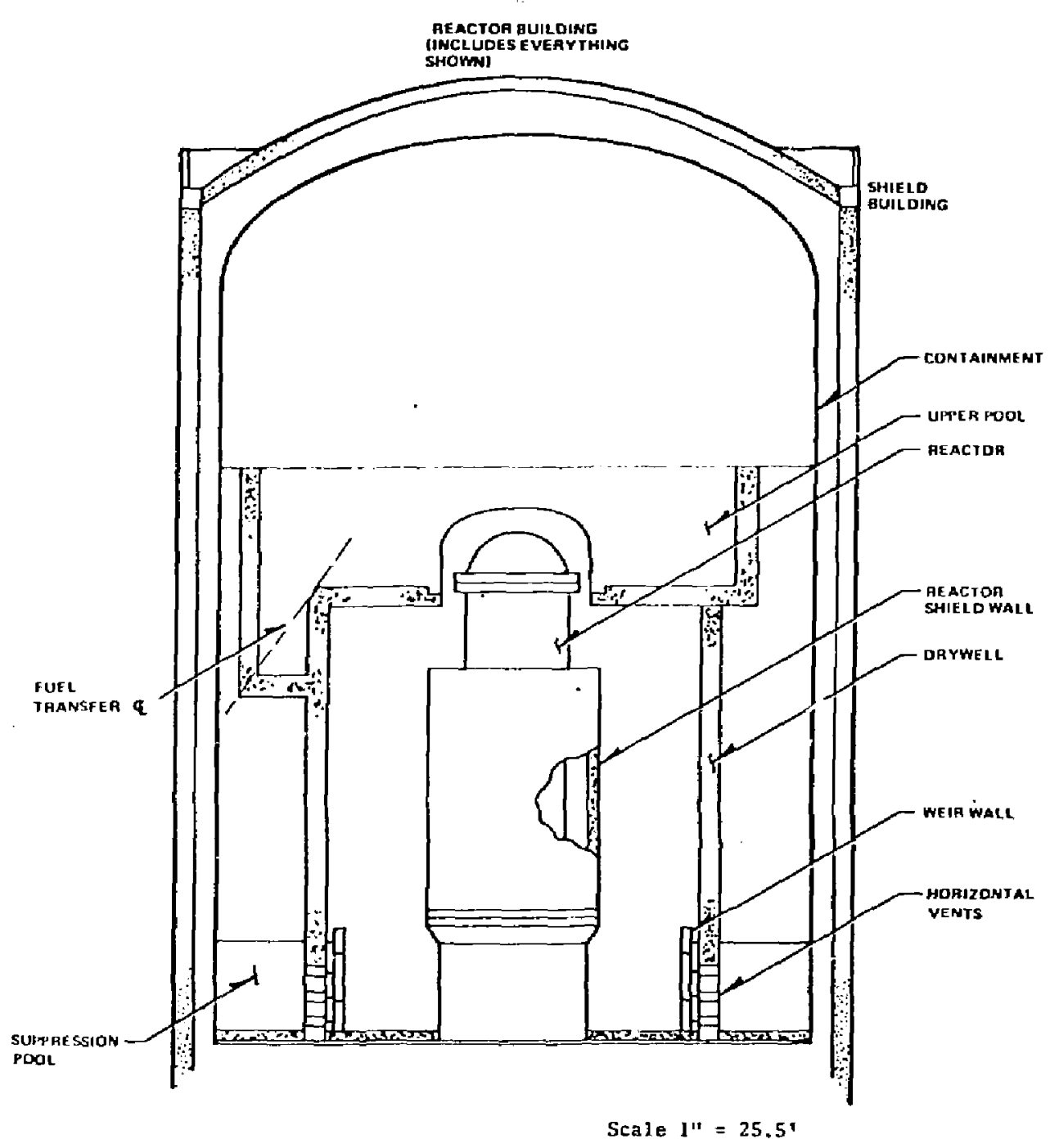

Figure 1.4 Mark III BWR Reactor Building 


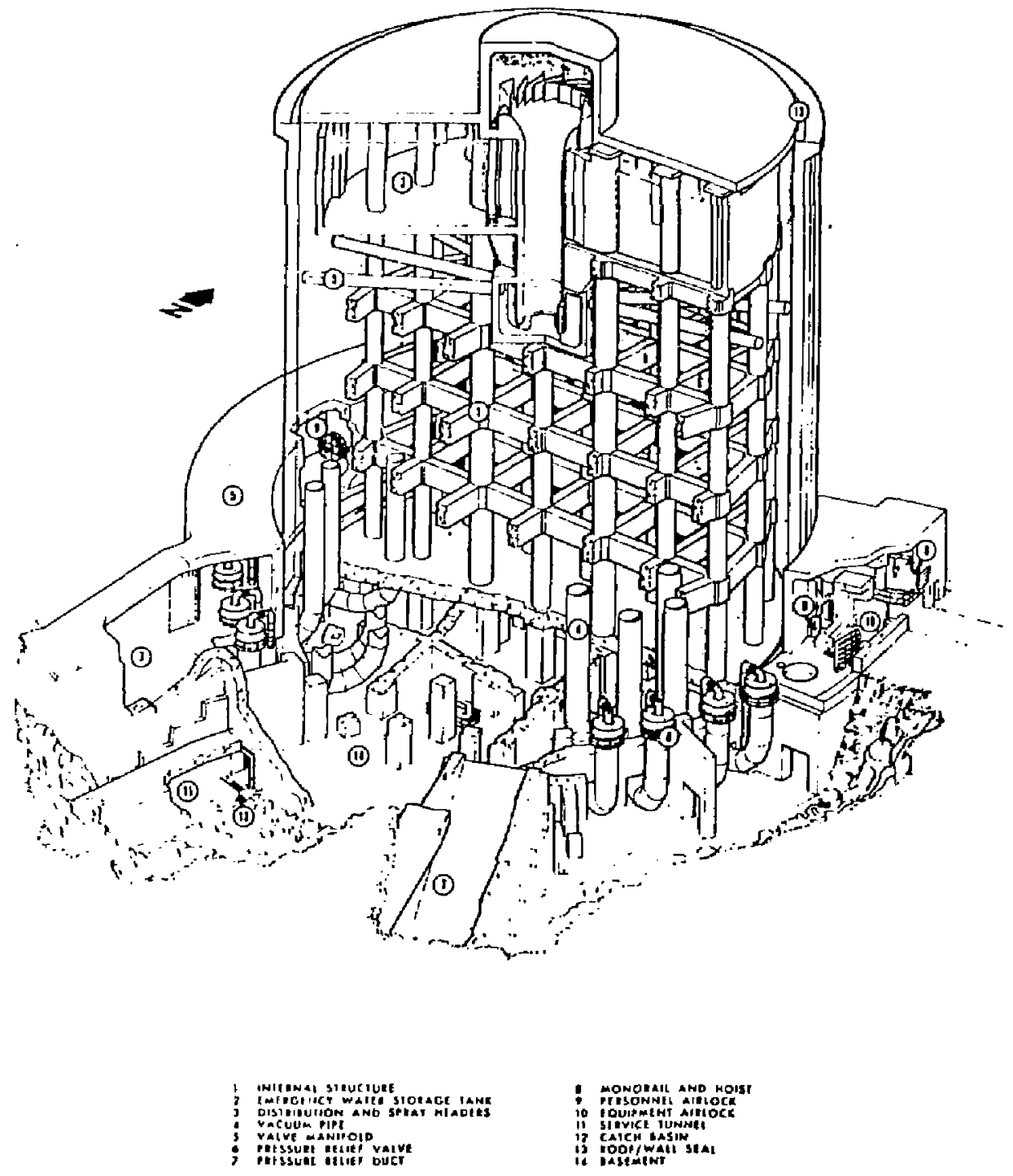

Figure 1.5 Cutaway view of vacuum building and valve manifold. Pickering (CANDU) 
(2). The restrictive effect of oxisting NRC requirement

(2.1) Description of the NRC Requireaents

$<2.1 .1\rangle$ Requlatory Guide 1.4: Assugptions used for eveluating the

potentis1 radiological consequences of a LOCA for PWRs

\section{(2.1.1.1) Introduction}

Section 50.34 of 10 CFR Part 50 (Ref. I) requires that each applicant for a construction permit or operating license provide an analysis and evaluation of the design and performance of structures, systems, and components of the facility with the objective of assessing the risk to public health and safety resulting from operation of the facility. ihe design basis loss of coolant accident (LOCA) is one of the postulated accidents used to evaluate the adequacy of these structures, systems, and components with respect to public health and safety. Ref. 1 requires that the methods and assumptions described in two Regulatory Guides (1.3 and 1.4) should be used in this evaluation. In some cases, unusual site characteristics, plant design features, or other factors may require different assumptions which will be considered on an individual basis. (2.1.1.2) Regulatory Posicion

Reg. Guide 1.3 and 1.4 require a demonstration that the offsite dose consequences will be within the guidelines of I0 CFR Part 100. (Ref.4) The Reg. Guides require that during the construction permit review, lower guideline exposures, of $20 \mathrm{rem}$ whole body and 150 ren thyroid, should be used rather than the values given in 5100.11 of $10 \mathrm{CFR}$ (Ref. 4) in order to allow for (a) uncertainties in final design details and meteorology or (b) new data and calculational techniques that might influence the final design of engineered safety features or the dose reduction factors allowed for these feetures. 
For the convenience of readers, the assumptions related to the release of radioactive material from the fuol and containment which are specified tn Reg. Guide 1.4 (Ref. 3) are geproduced in Anpendix 1 co this report.

For evaluating the potential radtological consequence of a LOCA for boiling water reactors (BhR), Regulatory Guide 1.3 (Ref. 2) requires very similar assumptions to those of Regulatory Guide 1.4(Ref. 3)

\section{<2.1.2> Accident Assumptions for Environmental Reports}

\section{$[2,1,2.1]$ Introduction}

Prior to the issuance of a construction permit as an operating license for a nuclear power station, the Nuclear Regulatory Commission (NRC) is required to assess the potential environmental effects of that facility to ensure that issuance of the permit or license will be consistent with natural environfental goals which are expressed by the National Enviroumental Policy Act (NEPA) of 1969 (Public Law 91-190, P3 Stat. 852). In order to obtain inforwation essential to this assesswent, the NRC requires each applicant for a permit as a licensee to submit a report on the potential environmental impacts of the progosed station and associated facilities. The NRC's implementation of NEPA is containcd in 10 CFR part 51," Licensing and Regulatory Policy and Procedures for Enviءonmental Protection." (Ref. 5)

The spectrum of accidents to be considered in preparing the section of Environmental Reports dealing with accidents is divided into aight classes, some of which have subclasses. It is stipulated that where assumptions are not specified, or where those specified are deemed unsuitable, assumptions as realistic as the state of knowledge permits 
shall be used, taking into account the specific design and operational characteristic of the plant under consideration. For each class, except class 1 because of its trivial consequences, the environmental consequences should be evaluated as indicated.

Owing to their highly conservative nature, the assumptions and calculations used in NRC safety evaluations are not suitable for environmental risk evaluation, because their use would result in a substantial overestimate of the environmental risk. For this reason, class 2 to 8 accidents need to be evaluated realistically. Consequences predicted in this way will be far less severe for some events than those given, for example, in safety analysis reports, where more conservative assumptions are usually enployed.

In this report, we have deemed it necessary to consider only ciass 8 events, which are design basis accidents that establish the performance requirements of engineered safety features, including the containment system.

\subsubsection{Accident Assumptions}

Since containment requirements are determined mainly by the potential consequerces of class 8 accidents, it is of interest to compare the conditions postulated by NRC for PWR Environmental Reports with those postulated in the Regulatory Guides. The forner are reproduced below. Those for accidents classes 2 through 7 are reproduced in Appendix 2. Accident Class 8.0. Accident initiation events considered in design basis evaluation in the safety analysis report.

\section{B.1 Loss-of-coolant accidents} Srall Pipe Break ( 6 in. or less)

(a) Source term: the average radioactivity inventory in the primary coolant shall be assumed. (This inventory shall be based on operation with $0.5 \%$ failed fue1). 
(b) Filter efficiencies shall be 954 for internal filters and 994 for external filters.

(c) $50 \%$ building mixing for bolling water reactors shall be assumed.

(d) For the effects of plateout, sprays, decontamination factor in pool, and core cprays, the following reduction factors shall be assumed:

For pressurized water reactors -0.05 with chemical additives in sprays, 0.2 for no chemlcal additives.

(e) A realistic bujlding leak rate as a function of time shall be assumed.

(f) Meterology assumptions: $x / Q$ values shall be $1 / 10$ of those given in NRC Safety Guide No. 3 or 4.

(g) Consequences should be calculated by weighting the effects in different directisils by the frequency the wind blows in each direction.

\section{Large Pipe Break}

(a) Source term: The average radioactivity inventory in the primary coolant shull be assumed. [This inventory shal] be based on operation with 0.5 failed fuel), plus release into the cuolant of:

For pressurized water reactors.2\% of the core inventory of halogens and noble gases.

For boiling water reactors-0.28 of the core inventory of halogens and noble gases.

(b) Filter efficiencies shall be 956 for internal filters, and $99 \%$ for external filters.

(c) 50 building mixing for boiling water reactors shell be assumed.

(d) For the effucts of plateout, containment sprays, core sprays 
(values based on 0.5 of halogens in organic form), the following reduction factors shall be assumed:

For pressurized water reactors -0.05 with chemical additives in sprays, 0.2 for no cinemical additives.

(e) A reajistic building leak rate as a function of time and including design leakage of stamline valves in gh's shall be assumed.

(f) Hetea: ology assumptions: $x / Q$ values shall be $1 / 10$ of those given in NRC Safety Guide No. s or 4 .

(B) Consequences should be calculated by weighting the effects in different directions by the frequency the wind blows in each direction.

\section{2 (a) Rod ejection accident (pressurized water reactor)}

(a) 0.28 if the core inventory of noble gases and halogens shall be assumed to bu eleased into the primary soolant plus the average inventory in the primary coolant basec on operation with 0.5 failed fuel.

(b) Loss-of-coolant accident occurs with break size equivalent to dianeter of rod housing (see assumptions for Accident 8.1).

(c) The mechanical vacuum pump shall be assumed to be auromatically isolat ad by high radiation signal on the steamline.

(d) Radisactivity shall be assumed to carry over to the condenser where lot of the halogens shajl te assumed to be available for leakage from the condenser to the environment at $0.5 \% /$ day for the course of the accident (24 hours).

(e) Meterology assumptions: $X / Q$ values shall be $1 / 10$ of those given in Mic Safety Guide No. 3 .

(f) Consequences should be calculated by weighting the effects in different directions by the frequency the wind blows in each direction. 


\section{<2.2> Discussion of the Conservatism in NRC Requirements}

\section{(2.2.1) Introduction}

In this Section the extent of the conservatism in the NRC Regulatory Guide 1.4 (Ref. 3) and in the "Requirements for Esvironmental Reports" (Reg Guide 4.2) is evaluated, on the basis that no accidents more severe than Class 8 (as defined in the previous section) has to be considered. This evaluation provides an indication of the additional, and possibly unnecessary, severity of the requirements imposed on PWR containment design by Reg. Guide 1.4 and by the "Requirenents for Environmental Reports". Hence it is appropriate to quantify the extent of the conservatisn in the existing NRC requirements not only in relation to the source term (i.e., the fraction of the various isotopes released from the fuel) in accidents up to and inciuding class 8 accidents, but also in relation to the assumptions which have to be made concerning zeruaval processes within the containment, leak rates, atmospheric dispersion and doses to the problic. This quantification of the conservatisn in the assumptions required by NRC can then be used to provide an indication of the maximum scope for reducing the performance required from the containment. The assessments of conservatism of the NRC assumptions have made in relation to the following areas:

(a) source terns

(b) Jeak rate and effect of containment pressure

(c) isotope renoval processes within the containment

(d) atmospheric dispersion

(e) calculation of dose due to external soubes and to inhalation.

\section{(2.2.2) Source terms}

During the normal operation of light water reactors(LWR's) fission products are generated within the fuel elements. Most of these fission 
products are radioactive and would be a hazard to public health if allowed to disperse in the environments. Releases of the gaseous and the more volatile radioactive isotopes, referred to as "source terms," can be postulated to occur as the result of a spectrum of potentlal accidents in LWRs.

1л Reg. Guide 4.2 the postulated accidents are categorized according to "the class 1 through class 9" designations described in Appendix I of that document. They include eight accident types in class 3 through 8 for BWRs and ten types in classes 3 through $B$ for PWRs. The design basis "loss of coolant accident" (LOCA) is one of the postulated severe accidents in classes 3 through 8 used to evaluate the adequacy of power plant structures, systems, and components with respect to the public health and safety (in Reg. Guide 4.2).

In Regulatory Guide $1.4^{(3)}$ the initiating event is not stated specifically but a set of assumptions are listed that should give an acceptably conservative source term. These assumptions are as follows:

(a) Twenty-five per cent of equilibrium radioactive iodine inventory developed from maximum full power operation of core should be assumed to be imediately available for leakage from the primary reactor containuent. Ninety-one per cent of this twenty-five per cent is postulated to be in the form of elemental iodine, 5 per cent of this 25 per cent in the form of particulate iodine, and 4 per cent of this 25 per cent in the form of organic iodide,

(b) One hundred per cent of the equilibriur radioactive noble gas inventory developed from maximum full power operation of the core should be assumed to be inmediately available for leakage from the reactor containment. 
The realistic "source term," which can be used to prepare "Environmental Reports" by applicants for construction permits for PWR power plants, is described for LOCA in Appendix I of Reg. Suide 4.2 as follows:

(a) The primary coolant activity is based on $0.5 \%$ failed fuel, plus the release of $2 \%$ of the core inventory of halogens and noble gases as a result of cladding failure during the LOCA. The cladding failure is assumed to occur after containment building isolation. The reactor is assured to have operated at full powcr for 620 days prior to the accident.

(b) All of the primary wolant is assumed to be released to the contaisment building.

During the last two decades knowledge of the basic physical processes concerned in fission product gas release from thermal reactor fuel has increased significantly. However, the exploitation of this knowledge to produce becter practical methods of predicting fission gas release during accidents has not proceeded at a similar pace. There are two approaches to predict the fission product release during an accident; one is the use of analytical techniques which rely on the fully detailed physical model, the other is the use of a broad 'guide-line' type of correlation which provide interpretation of experimental release data for making gas release estimates. Detailed descriptions of the above approaches are given in Appendix 3 .

In sumary, the amounts of stable and long-lived isotopes that are released during the Lh' Loss of Coolant Accident as calculated from each postulated rodel, assuming failtre of all fuel rods but excluding the effects of previous fuel damage are compared in Table 2,1 . 
The comparison between the source terms of Reg. Guide 1.4 , the Environmental Report Madel and two more recent models, contained in Table 2.1, shows that the value of the Reg. Guide 1.4 model is one order of magnitude larger than those of the Environnental Report and HASH$1400^{(7)}$ models for iodine and nearly two orders of magnitude larger for noble gases. Another comparison of the source terms between the Reg. Guide 1.4 and the most recent ORNL model from Table 2.1 shows that the values of the $\mathrm{Reg}$. Guide $1.4^{(3)}$ model are three orders of magnitude greater for noble gases and iodine than those of the ORNil model.

liowever, the validity of the ORNL model is questionable, particularly for trausients in which the fuel is maintained at a high temperature for Innger times than those used in the experiments on which the model is based (e.g. as in the case of the TMI Z aceident). Nevertheiess, they do provide a further indication that the source terms proposed in the NRC's Regulatory Guides 1.3 and 1.4 are highly conservative for "well-conditioned" Class accidents, as defined in the NRC's instructions for the preparation of Environmental Reports (Ref, 6), even if all the rods burst. Sinee the Standard Technical Specification for a PliR (Ref. 9] permits operation with up to $1.0 \mathrm{HCi} 1-131$ per gm of coolant (corresponding to about 0.5 percent of the fuelbeing defective), it is necessary to consider whether the presence of this defective fuel can slgnificantly incresse the amount of activity released into the containment during accidents in Classes 3 through 8 .

Two factors have to be considered:

( ) The amount of equilibrium activity in the coolant.

(b) Any additional release mechanism associated with the existence

That is, an accident in which all the safety systems perform as expected. 
of defects in the fuel existing prior to the accident.

It is shown in Appendix 3 that the contribution due to the first term is insignificant compared to that which would the expected from failure of the remaining rods in a LOCA e.g. At the limit imposed by the Standard Technical Specification, the amount of $I^{131}$ in the coolant would be about $400 \mathrm{Gi}$ as compared with the lower limit estimate of $3 \times 10^{4}$ Ci due to bursting of all rods, .

However, it is necessary to consider also the effects of "iodine spiking". These are reviewed in Appendix 3 and it is show that the somewlat limited data indicate that, for a $1100 \mathrm{MH}(\mathrm{e})$ PWR, the additional contribution in a large LOCA could amount to about $1 \times 10^{4} \mathrm{CI}{ }^{131}$ which is about 30 percent of the lower limit value estimated from the most recent ORNL $\operatorname{model}$.

Thus, the total additional contribution is not negligible at the lower limit level, assuming that all rods fail. However, if the more conservative value of 1 percent release from the failed fuel were used, this additional contribution would be insignificant.

A further possible factor of conservatism in the source term for LOCA's is the proportion of rods which fail as a result of the accident, It can be claimed that, if all the sefety systems function as designed, no additional rods would fail. Thus the most "realistic" source term would be the activity due to rods which had failed prior to the accident (See, for example Section 15.1.4 of the FSAR for the Virgil sumner NPP). Prior to the realization of the importance of splking, this implied that the release of $\mathrm{I}^{131}$ into the containment, for example, would be about $200 \mathrm{ci}$, or about $3 \times 10^{-4}$ percent of the total inventory. However, 
it follows from the preceding discussion that the contribution due to "spiking" could be of about the same order of magnitude as the lower limit for the "all rods failing" case, (i.e.0.04 percent). Consequently, the source terms described as "realistic" in, for example, the FSAR referred to above are probably highly opt imistic. N1though it would probably be realistic to asstme that not more than 10 percent of the rods fail in a "we]1-conditioned," large JOCA, nevertheless this "realistic" source term would still be an order of magnitude too small.

In the case of a BWR, the additional contribution due to "spiking" appears to be a factor of 10 smaller than in PWR (See Appendix 3) and is therefore insignificant.

Table 2.1. Fission Product Release in an LKR Loss of Coolant Accident, Excluding Effects of Previously Damaged Fuel

\begin{tabular}{|c|c|c|c|c|}
\hline \multirow[b]{2}{*}{ Element } & \multicolumn{4}{|c|}{ Release as Percent of Total Inventory } \\
\hline & $\begin{array}{l}\text { Reg. Guides } \\
1.3 \text { \& } 1.4 \text { Models }\end{array}$ & $\begin{array}{l}\text { Environmental } \\
\text { Repart Model }\end{array}$ & $\begin{array}{l}\text { WASH-1400 } \\
\text { Model }\end{array}$ & $\begin{array}{l}\text { ORNL Model(a) } \\
\text { (Lorentz et al) }\end{array}$ \\
\hline $\mathrm{Kr} \& \mathrm{Xe}$ & 100 & 2. & 3 & 0.9 \\
\hline Cs & - & - & 5 & 0.07 \\
\hline I & 25 & 2. & 1.7 & 0.04 \\
\hline
\end{tabular}

Notes: (a) These data have been modified from the original data for our own purpose, based on their assumptions ${ }^{(3)}$ as follows;

(1) The gap inventory and total reiease of 131 and 133 xe would be 3 to 9 times lower.

(2) An additional amount of fission gas, approximately $1.5(8)$ of the total inventory, would be released during heatup.

(b) In the case of a PWR the presence of previously damaged fuel is 
estimated to increase the amounts of $\mathrm{Cs}$ and $\mathrm{I}$ by about 30 percent (i.e. to 0.07 percent of $C s$ inventory and 0.04 percent of I inventoryj, if the reactor is operating within the levels imposed by the Standard Technical Specification. In the case of a BWR the corrections would be insignificant,

\section{(2.2.3) Containment leak rates}

Once the pressure transients associated with design basis accidents (DBA's) have been detertained, coritainment strength requirements can be set so that structural failure leading to the release of containment atmosphere to the environment will not occur. However, because of inevitable structural imperfections and defects in sea1s, the containment will not have a zero leak rate. As the leak rate will vary with pressure, this maximum rate must be related to some specific pressure. A value for the maximum containment leak rate for a light water reactor,at the peak calculated internal containment pressure, is incorporated as a Technical Specification requirement. A typical value is $0.2(\%)$ volume of containnent atmosphere per day. Reg. Guide 1.4 (Ref. 3) requires that this leak rate should be assumed to persist for the first 24 hours anct that leakage should continue at 50 percent of this rate for the remaining duration of the accident.

For the accidents defined in the Environmental Report Model, it appears at first sight that it would be unduly conservative to assume that the leakage rate remains constant at the design value for the first 24 hours, since the primary containement pressure would decrease after the first few minutes. However, the relationship between pressure and leak rate is very dependent on the type of flow through the leaks. A detailed evaluation of the relationship between pressure and leak rate for various possible flow regimes, is given by Appendix 4 to this report. 
It is show that, of the fur flow regtmes considered lorifice flow, turbulent flow (rough passage), turbulent flow (smooth passage) and laminar flow], the leak rate is more sensitive to pressuro.in the case of laminar flow and least sensitive for orifice flow. In practice there is no means of determining, prior to construction, what proportion of the Jeakage will be attributable to each type of flow. Consequently it has to be assumed in design that the relationship between leak rate and pressure will be the least favorable (i.e. orifice flow). It will be seen from Fig. 4.7 of Appendix 4 that, for a typical PHR "dry" containment. the leak rate due to orifice flow would be reduced by 50 percent when the absolute pressure has fallen to $1.1 \mathrm{~atm}$. from an initial value of about 5 atm; whereas, if the flow were entirely lmaminar it would have fallen to 50 percent at about 2.7 atm.

Using the data given by Bechtel in Ref. 10 for the pressure/time relationship, for a typical PHR "dry" containment, in conjunction with the results obtained in Appendix 4 , it is found that (with the unavoidable assumption that all the leakage is due to orifice flow) the average leak rate over the first 24 hours is 84.3 percent of the initial value; the rate at 24 hours is about 75 percent of the initial value, i.e. the assumptions required by Reg. Guide 1.4 , in this instance, do not necessarily contain any conservatism. However, testing of a containment, as built, at design pressure and at some fraction of design pressure would provide a more representative indication of the actual pressure/ leak rate relationship and might well reveal some measure of conservatisa in the assumptions, for that structure. 


\section{(2.2.4) I sotope removal process}

There are bssically two concepts of fission product removal used in containment systom design; they are removal within the primary contajnent structure boundary and removal outside of that houndary, but within a secondary contaimient boundary.

For those containment systems using internal fission product removial mechunisms, the following mechanisms have been employed:

(a) removal by air recirculation through charcoal filter beds.

(b) removal through the containment spray process.

(c) removal through natural deposition ("plate out") on containnent surfaces

The charcoal filter removal system was used fairly extensively in the 1966 to 1970 virtage PHR plants. This system made use of the existing containment fan coolers, and simply added a HEPA/charcoal adsorber filter train in series. This method relies on fan forced recirculation of the virtually 100 of humidity post-accident containment atmosphere through the adsorber beds to remave radioactive halogens, particularly iodine. The removal rate is dependent on the rate of containment air recirculation through the filters, as well as the filtor renoval efficiency. This results in the following requirements ${ }^{[1]}$;

$f_{a}$ very large fan motors qualified to operate in the post-accident environment conditions of temperature, pressure, and hamidity;

(b) large additions to difsel generator capacity requirements;

(c) seismic category I containment duct systens to assure fairly uniform sweeping of the containment atmosphere; and

(d) charcoal filter material with high filter efficiencies at high humidity for both organic and inorganic forms of iodine. 
Despite development efforts, charcoal filter efficiencies for elenental iodine drop off dranatically at $100 t$ humidity conditions, and at lower humidities for organic iodines, especially if there is a possibility of filter wated logging. These factors make this method of fission product removal very expensive and the last choice of most designers.

A more popular methad of internal fission product removal from pirR's uses the containment spray system (CSS). A very fine mist is produeed by sprays, which tend to adsorb both airborne particulate and gaseous iodine. The extent of adsorption depends upon droplet size, free fall height, and $\mathrm{pH}$. Solution $\mathrm{pH}$ also affects the capabiliry to retain the adsorbed iodine in solution in the containment sump.

The water used in PWR ECCS has to be borated to maintain reactivity shutdown margin in the reactor core. Borating increases iodine adsorption to some extent but the addition of either sodium hydroxide or sodium thiosulfate has been found to greatly enhance the iodine-getter properties of the spray systems, with the hydroxide giving a somewhat higher renoval rate. For econony, it is convenient to use the same stored water for refueling operation and for emergency core cooling system (ECCS) and containment spray functions, but for the refuelling role hydroxide additions would be uлacceptable. Thus if an hydroxide additive is used as an iodine getter, it aust be stored in a separate container and mixed with the spray solution when it is called upon for LOCA conditions.

The mechanism of natural deposition of particulate is dependent mainly on impaction processes, since the containment atmasphere circulates as is result of natural convection generated by temperature differences between bulk gas and containment wall. In the case of gaseous halogens, 
the mechanism of plateout is surface adsorption. Several models have been proposed to describe fission product removal for particulates and halogen gases due to surface deposition and adsorption.

The more detailed theoretical and experimental work on models of spray removal and natural deposition are described in Appendix 5.

fission product removal systems external to the primary pressure containment bousdary generally consist of a secondary containment structure enclosing the primary one. This kind of system is usually referred to as a "double barrier" PWR containment. Leakage from the primary boundary is permitted at a low rate, of the order of 18 per day. The secondary volume is maintained at a slightly negative pressure with respect to the outer atmosphere thorugh operation of a fan system. This far system exhausts to the atmosphere via a filter system.

As far as isotope removal process is concerned, the Reg. Guide ${ }^{(3)}$ 1.4 does allow case-by-case evaluation of the removal factor so that, in principle, this may not be treated very conservatively. From various FSAR and NRC Safety Evaluation Reports, it appears that both the NRC and applicants have used a value for the removal factor which was established several years ago. If the NRC were to choose the more recent realistic spray removal coefficient value ${ }^{(12)}\left(\lambda=17.0 \mathrm{hr}^{-1}\right)$, which is in good agreemert with the Containment Sycten Experiment (CSE) tests instead of the ald Stagnant Film model value $\left(\lambda=10 \sim 12.55 \mathrm{hr}^{-1}\right)$, then the spray removal for elemental iodine would be calculated to be 35 70 percent more efficent than before. Thus there is, at present, a factor of conservatism of about 1.5 in the evaluation of the spray systems. 


\section{[2.2.5] Atmospheric dispersion}

In order to assess the radiological inplication of radioactive material release, it is necessary to determine the distribution of radiaactive species released to the atmosphere and their subsequent transfer to biological system. For a fixed release quantity, the magnitude and duration of exposure to a given dose level, depends upon the characteristic of the transport medium (i.e., the atmosphere) during the time of release.

An analytical method based on generalized three dimensional, timedependent diffusion equation including suurces can be used to describe the turbulent diffusion of radioactive pollutants released to the atmosphere. A detailed discussion of this method is given in Appendix 6. However, most workers in the area of atmospheric dispersion prefer to make use of the method devised by Taylor, "13] which is based on statistical theory. In this method, the concentration, $x$, of gas or aerosols (less than about 20 micron diameter) at $x, y, z$ from a continuous source which has an effective emission height, $\mathrm{H}$, is given by Equation ( 1 ) as follows:

$$
\begin{aligned}
X(x, y, z, H) & =\frac{Q}{2 \pi \sigma_{y} z^{\bar{u}}} \exp \left[-\frac{1}{2}\left(\frac{y_{y}}{\sigma_{y}}\right)^{2}\right]\left\{\exp \left[-\frac{1}{2}\left(\frac{Z-H}{\sigma_{z}}\right)^{2}\right]\right. \\
& \left.+\exp \left[-\frac{1}{2}\left(\frac{Z+H}{\sigma_{z}}\right)^{2}\right]\right\} \quad \text { (1) }
\end{aligned}
$$

where $X$ = concentration of a given radioactive material at position $(x, y, z)$ in Curies $/ m^{3}$,

$Q=$ magnitude of the instantaneous release of radioactive paterial in curies/sec,

$\overline{\mathrm{u}}=$ mean wind speed affecting a plume in $\mathrm{m} / \mathrm{sec}$, 


$$
\begin{aligned}
\sigma_{y}, \sigma_{z} & =\text { standard deviations of plume concentration distribution in } \\
& \text { the horizontal and vertical direction respectively in meter }{ }^{2} .
\end{aligned}
$$

The main assumption for Eguation (1) are;

(1) the plume spread has a Gaussian distribution in both horizontal and vertical planes,

(2) toral refjection of plume takes place at the earth"s surfacc, j.c., there is no deposition or reaction at surface,

(3) the diffusion of the plume travel is assumed to be neglected, i.e., no diffusion in $x$-direction.

If the receptor is located at the ground level $(z=0)$, then

$$
X / Q=\frac{1}{\pi \sigma_{y} \sigma_{z} \bar{u}} \exp \left[-\left(\frac{y^{2}}{2 \sigma_{y} z}+\frac{h^{2}}{2 \sigma_{z}}\right)\right]
$$

which is the form of the Gaussian plume model most usually used.

The Regulatory Luide 1.4 for evaluating dispersion for class 3 through $\&$ accident used Equation (1) with the following assumptions: concontrations are calculated at grourd level, i.e., $z=0$, along the centerline plume $(y=0)$, and for a ground-1evel source with no effective plume rise $(H=0)$. Equation (1) then takes the simpler form

$$
x(x, 0,0,0)=\frac{Q}{\pi \sigma_{y} \sigma_{z} \bar{u}}
$$

For time period of greater than 8 hours, the plume is assumed to meander and spreat uniformly over a $22.5^{\circ}$ sector. The resultant equation is

$$
x(x, 0,0,0)=\frac{2.0320}{\sigma_{2} \bar{u} x}
$$

where $x$ = distance from point of release of the receptor.

Material released from bujlding vents, from short stacks or at graund level may be subject to enhanced dispersion due to the turbulent 
wake caused by air flow around the building. Building wake corrections are generally considered only for ground level release.

Regulatory Guides 1.4 suggests use of the bullding wake correction model presented by slade ${ }^{[14]}$. This nodel is to be applied only to ground Ievel releases of eight hours or less duration. The dispersion correction factor is 1 imited to the range of $1 / 3$ to 1 . The Guussian dispersion equation for a normalized concentration at ground level with building wake correction becomes

$$
X / Q=\frac{1}{\Pi \Sigma_{y}, \Sigma_{z}, \bar{v}}
$$

where $E_{y^{\prime}}=\left(\sigma_{y^{2}}{ }^{2}+0.5 A / \pi\right)^{1 / 2}$

$$
\Sigma_{z^{\prime}}=\left(o_{z^{2}} 2+0.5 \mathrm{~A} / \mathrm{II}^{1 / 2}\right.
$$

$A=$ the minimum cross sectional area of reactor building $\left(M^{2}\right)$

These equations are believed to give "best estimate" values of the concentration at this axis, i.e. the actual concentration is as likely to be larger as smaller than the estimated value. However, NRC slas introduced some conservatism in their assumptions concerning the atmosphere stability conditions assumed to exist during the post accident period. In Reg. Guides 1.3 and 1.4 it is assumed conservatively that Category $F$ weather conditions are present for the whole of the first 24 hours and for 66 per cent of the time in the rext 3 days. An indication of the effect of this assumption on the value of the diffusion factor is :rovided by Fig. 2.1. This shows that the assumption of 100 per cent persistence of Category $F$ would lead to a 3 fold increase in the dilution factor, as compared with 30 percent persistence. The factor of conservatism has been estimated for an average U.S. Site by evaluating the weighted mean diffusion factor for the average meterological conditions 
(taken over 33 sites) which are given in Table VI-3 of Ref. 15. This method indicates that the factor of conservatism in the diffusion factor computed according to Reg. Guide 1.4 is about 3 .

The Envi ronmental Report Model allows the use of dilution factors which are ten times as large as those used in the Reg. Guide 1.3 and 1.4 (See Sec. 2.1.2.2, above). Consequent1y, in terms of realistic values for the average US sites considered above, the Environmental Report Model is non-conservative by a factor of about 3 . Thus the predicted doses (given the speciried source terms) are higher by a factor of 3 than can readily be justified.

One omission from Regulatory Guide 1.4 relates to deposition of active isotopes from the plume. The Guide does not require this potential source in radiation exposure to be considered. However, for completeness the appropriate choice of the main parameter, the deposition velocity is discussed in Appendix 3. 

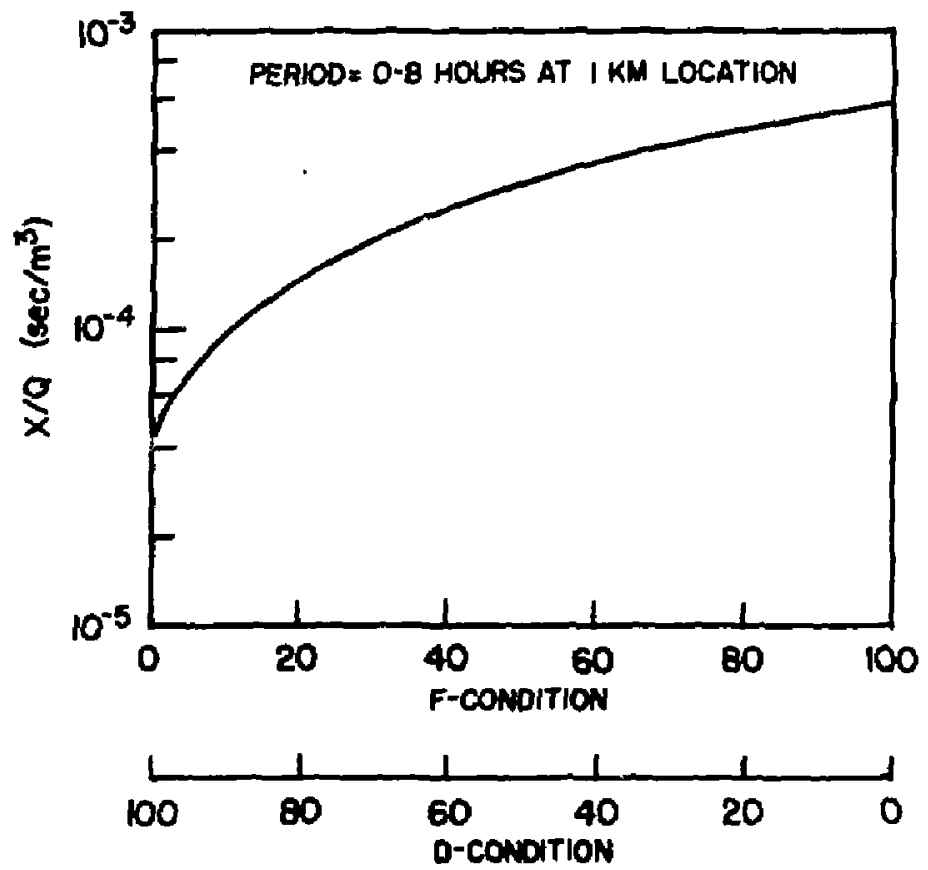

FRACTION OF WEATHER CONDITION (\%)

Fig. 2.l Variation of Average Dilution with Fraction of time for which highly stable conditions persist. as compared with category ' $D$ ' conditions.

35 
$\leq 2.2 .6\rangle$ Dose Calculations

\section{$\leq 2.2 .6 .1\rangle$ Introduction}

offsite radiological analysis required for an accidental release of radioactivity to the environment consists of determining the inhalation and external whole body doses resulting from exposure to the airborne radioactive materials. The methods for calculating the inhalation and whole body dose given in Reg. Guide $1.4^{(3)}$ are based mainly on the recommendations of the International Comnission on Radiological Protection (ICRP), but some unduly conservative assurptions are made; the overall effect of these is discussed below.

2.2.6.2 Externat Whole Body Dose

Reg. Guide 1.4 requires that these should be calculated on the basis that the cloud is of semi-infinite extent. This is unnecessarily con* servative, particularly for points relatively close to the sourcel(e.g. at the exclustive area boundary (EAB) and for very stable conditions.

The extent of the conservatism arising from this assumption can be estimated from the results given by Beattie and Bryant in Ref. 18. (Their Fig. 6). Assuming, as in the previous section, that highly stable conditions persist for 50 percent of the time, it is found that there are factors of conservatism of 3 at $1 \mathrm{~km}$ and 2 at $5 \mathrm{~km}$.

\subsubsection{3> Dose to thyroid from inhalation of iodine}

Reg. Guide 1.4 requires that a breathing rate approximately 50 per cent higher than nortal should be used for the first 8 hours after the release. This seems to be unnecessarily conservative for members of the public. 
Reg. Guide 1.4 specifies that the factors for converting the intike ut active iodine to thyroid dose should be based on those given in "ICRP Publication 2" (Ref, 16). However, these values were calculated some 20 years ago. Sore recent ealculations, using more refined models shoh a considerable variation from the JCRP values, as shown in Table 2.3. It will be seen from the Tabje $2+3$ that for the two important isotopes (I ${ }^{131}$ and $1^{133}$ ) the use of the ICRP Publication 2 values over-estimates the dose per curie inhaled by a factor of at least 1.5. Combined with the conservatism in the breathing rate for the first 8 hours this leads to a factor of conservatism of about 2 .

Table 2.2 Breathing Rates Specifjed in Reg. Guide 1.4 (3)

\begin{tabular}{|l|c|}
\hline Time after accident & $\underline{m}^{3} /$ sec. \\
\hline 0 to 8 hours & $3.47 \times 10^{-4}$ \\
8 to 24 hours & $1.75 \times 10^{-4}$ \\
1 to 30 days & $2.32 \times 10^{-4}$ \\
\hline
\end{tabular}

Table 2.3 Iodine Dose Converșion Factors

\begin{tabular}{|c|c|c|}
\hline \multirow{2}{*}{ I sotopes } & \multicolumn{2}{|c|}{ Ren-thyroid/curies inhaled } \\
\cline { 2 - 3 } I-131 & Reg. Guide $1.4^{(3)}$ & WASH-1400 (17) \\
I-132 & $1.48 \times 10^{6}$ & $1.1 \times 10^{6}$ \\
I-133 & $5.35 \times 10^{4}$ & $6.6 \times 10^{3}$ \\
$1-134$ & $4.00 \times 10^{5}$ & $1.8 \times 10^{5}$ \\
$1-135$ & $2.50 \times 10^{4}$ & $1.1 \times 10^{3}$ \\
& $1.25 \times 10^{5}$ & $4.4 \times 10^{4}$ \\
\hline
\end{tabular}


$\langle 2.2 .7>$ Extent of conservatism in 10CFR 100 guide-1ines for radiological consequences

\subsubsection{1.> Cancer risk from exposure to the "guide-1 inle" consequences}

It is usually accepted that the chance of a fatal, delayed, cencer developing during a life-time, due to whole body exposure to radiation is about $1 \times 10^{-4}$ per rem. The corresponding chance for thyroid cancers of any sort is about $0.1 \times 10^{-4}$ per rem, due to inhalation of active iodine (App. 6 of Ref.7 ). However, only a small percentage of these should prove fatal; a conservative estimate of the proportion of fatal thyroid cancers, given adequate medical surveillance and care, is 10 percent. The probability of a fatal, delayed thyroid camcer due to external radiation is approximately 10 tintes greater than for the case of $I^{131}$ inhalation. Thus, the overall probability of a fatal cancer from exposure to the $10 \mathrm{CFR} 100$ "guide line" consequences (i.e. 25 Iem whole body and 300 rem to the thyroid due to iodine inhalation) is about $3 \times 10^{-3}$, if both components have their maximum value.

In principle a somewhat higher value should be taken to allaw for the effects of other volatile isotopes, notably $C_{S}^{137}$, which would be expected to accompany the iodines. The correction can be estimated as follows: assuming that the proportion of $\mathrm{C}_{\mathrm{s}}^{137}$ released into the containrent is twice that of $I^{13 I}$ (APp. 7 of Ref.7) and that the subsequent removal processes are equally efficient for both, it is found that the probability of fatal delayed cancers due to $C_{5}^{137}$ would be approxinately 30 percent of that due to $I^{131}$. Thus the additional contribution to the probabilicy of total delayed cancers, due to $C_{S}^{137}$, is less than 5 per cent of the total and can be neglected. 
From an economic point of view the probability of an accident leading to severe darage to the furel would need to be kept below $10^{-4}$ per year, owing to the heavy cost of the prolonged outage of a nuclear power plant (e.g. see Ref, 19). Thus, the combined probability of the event visualized in Reg. Guide 1,4 accuring and of any ore individual within the LPZ (low population zone) developing a fatal cancer later in life, as a direct result, is conservatively estimated to be less than $3 \times 10^{-7}$ per year. This is substantially lower than the probability of immediate death from accidents due to causes that are virtually unavoidable in u.s. society (about $1 \times 10^{-4}$ per year, Ref. 20). Thus, on a simple "comparability of risk" basis the "guide line" consequences could be regarded as reasonabty conservative. However, as discussed in sec. 3 below, from some points of view, they might not be regarded as sufficiently restrictive.

It should be noted that if we were concerned only with accidents in Classes 3 through 8 , as defined in Sec. 2.1 .2 , above, the actual maximur radiation exposures should be lower than the "guide line" values, due to the smaller source terms. Taking account of the reduction in source terms anly, the prabability of delayed fatal cancers due to the most severe class 8 accident would be reduced by a factor of at least 30 (i.e. to less than $1 \times 10^{-8}$ per year), It can be shown, as in the лext Section, that the elimination of other factors of conservatisn in Reg. Guides 1.3 and 1.4 would reduce this probability by another order of magnitude. 


\subsection{The extent of the conservatism in NRC requirements}

\section{(2.3.1) Dry PWR Containment}

\section{(2.3.1.1) Introduction}

Since the ARC requirements determine the performance and design parameters for the containment systen, the various factors of conservatisn identified in the preceding Sections are summarized below. For completeness, the factors of conservatism, both in Reg. Guides 1.3 and 1.4 and in the Environmental Report Maiel, ${ }^{(6)}$ have been stmarized.

There is a possibility that Reg. Guides 1.3 and 1,4 might be revised in the future; the available information as to the nature of the changes is discussed in Sec.2.3..1.3, below.

\subsubsection{Sumary of factors of conservatism in Reg. Guides 1.3 and 1.4 .}

The various factors of conservatism in the approach adopted in Reg. Guide 1.4 and in the Environmental Report Model which have been discussed in the preceding Sections are sumarized in Tables 2.4 (a) and 2.4 (b). This summary is based on the dominant accident in $\mathrm{Class} 8$, namely the large Loch.

For ease of comparison,the effects of che conservatism in the estimates of whole body dose and thyroid dose have been combined by estimating the probability of an individual developing a delayed fatal cancer as a result of the joint effects of the doses which have been estimated using the assumptions specified in the Reg. Guides and those which would be received if these were reduced by the factors of conservat ism.

In view of the degree of uncertainty about the source terms the comparisons have been made for two sets of assumptions:

(a) That the releases of rare gases and iodines into the con- 
tainment are in accordance with the estimates given in the

Environmental Report Model (i.e. 2 per cent for rare gases and 2 per

cent for iodine); assuming failure of all of the rods.

(b) That the releases are in accordance with the latest ORNL mode1 (assuming failure of all of the rods), corrected for the effects of "iodine spiking" as discussed in Sec. 2.2.2.

The effect of assuming that only 10 per cent of the rods fail in the LOCA lis also been examined. Tuble 2.5 contains the results of this comparison.

Table 2.5 Evaluation of conservatism in Reg. Guide 1.4 in tems of reduction in probability of delayed fatal cancers.

\begin{tabular}{|c|c|}
\hline Source term used in comparison & $\begin{array}{l}\text { Apparent reduction in probability } \\
\text { of deleyed fatal cancer }\end{array}$ \\
\hline $\begin{array}{l}\text { Environmental Report Model, } \\
100 \text { per cent rod failure }\end{array}$ & 300 \\
\hline $\begin{array}{l}\text { Environmental Report ModeI, } \\
\text { I0 per cent rod failure }\end{array}$ & 3000 \\
\hline $\begin{array}{l}\text { ORNL model, plus spiking, } \\
100 \text { per cent rod failure }\end{array}$ & 1000 \\
\hline $\begin{array}{l}\text { ORNL madel, pius spiking, } \\
10 \text { per cent rod failure }\end{array}$ & 7000 \\
\hline
\end{tabular}

Thus, providing that it were unnecessary to consider accidents worse that a "well-conditioned" large LOCA (i.e. one in which the pratection system behaved in accordance with design) it is possible that the performance requirements for the containment of a large PWR could be reduced by factors of at least 100 , without actually exceeding the radiological consequences specified in Reg. Guide 1.4. Thus it could be argued that a much lower standard of performance should be sufficient. The minimum standard repuired is discussed in Sec. 4.2 .1 below.

Subject to the same provision, a similar relaxation in the containment requirements for a large BWR should also be possible.

However, in practice, relaxations of this magnitude may not be 
possible on account of:

(a) The unexpectedly high release of fission products from the fuel in the Three Mile Island reactor accident, even though the fucl did not melt.

(b) There are other arguments, which are discussed in the next Section, that suggest it might be desirable to retain the current standards of performance, or even to improve upon them. Consequently the re-optimization of containment-design has had to be considered on a wide basis (See Section 6, below).

\section{(2.3.1.3) Possible Revisions of NRC Requirements}

The revision of Reg. Guide 1.3 and 1.4 is currently under review by NRC. (Ref. 21). One form of revision, which has been suggested by the Director, Office of Nuclear Reactor Regulation (NRR) would increase the present source terms, by changing the amount of radioactive iodine available for release from the primary containment to 50 percent of the inventory, as zompared with the present value of 25 percent, and in addition one percent of other non-gaseous fission products would be assumed to be released into the primary coolant. However, credit would still be given for reduction in the iodine concentration by plateout, using suitably conservative estimates and credit could be taken for reduction of containment pressure 2 hours after the start of the release, instead of 24 hours later.

In general, it seems that a more flexible attitude towards the use of engineered safeguards to reduce the iodine concentration is visualized but the reliability of such systems would be subject to the usual NRC requirements concerning the incidence of single failures.

For PWRs with conventional 'dry' containments the ather requirements of the proposed draft Reg. Guides would be similar to those in 
the oxisting one. In eddition, specific proposals are marle for the treatment of secondary containments, where these are provided.

A further conservatisu in the proposed Reg. Guide is that, at the application for a construction permit stage, significant theertainties in the estimated doses should be taken into account by an appropriate reduction in the $10 \mathrm{CPR} 100$ values.

Overall, it appears that the draft proposals put forward by DONRR would be sonewhat less conservative than the existing Reg. Guide but revertheless the fundamental difficulty remains, namely that the source terms correspond to accidents more severe than any of those defined in classes 3 through $B$ in Ref. 3. However, in view of the large fractions of gaseous and volatile products raleesed in the TMI aceident, without meltdown of the fuel (i.e. short af a Class 9 accident) it could be arguted that these large source terms are not unduly conservative. This sspect will be the subject of further study by UCLA. 
Table 2.4 Factors of conservatism in NRC Reg. Guides 2.4 and 4.2, for dominant Class 8 Accident (I.arge LOCA)

Table 2.4(a) Parameters other than the source terms

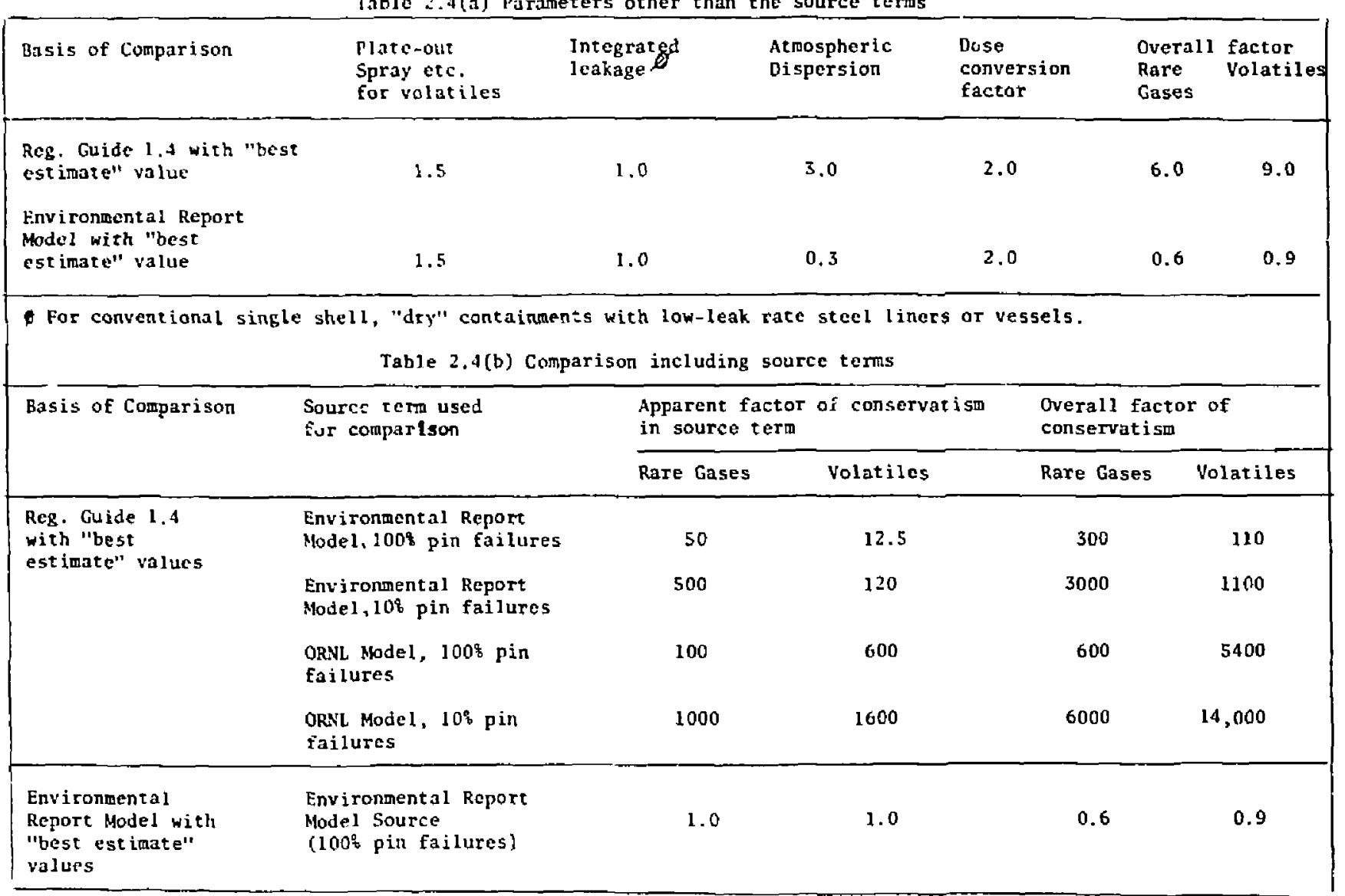


Table 2.4(a) cont intied

\begin{tabular}{|c|c|c|c|c|c|}
\hline \multirow[t]{2}{*}{$\begin{array}{l}\text { Basis of } \\
\text { Coipurison }\end{array}$} & \multirow[t]{2}{*}{$\begin{array}{l}\text { Source rern used } \\
\text { for comparison }\end{array}$} & \multicolumn{2}{|c|}{$\begin{array}{l}\text { Apparent factor of conservatis } \\
\text { in source term }\end{array}$} & \multicolumn{2}{|c|}{$\begin{array}{l}\text { Overall factor of } \\
\text { conservatis. }\end{array}$} \\
\hline & & Rare Gases & Volatiles & Rare Gases & Volatiles \\
\hline \multirow{2}{*}{$\begin{array}{l}\text { Finvirongental } \\
\text { Report Model with } \\
\text { "best estinate" } \\
\text { values }\end{array}$} & $\begin{array}{l}\text { ORNL Model } 100 t \\
\text { pin failures }\end{array}$ & 2.2 & 50 & 1.3 & 45 \\
\hline & $\begin{array}{l}\text { ORNL Hodel } 106 \\
\text { pin failures }\end{array}$ & 22 & 500 & 13 & 450 \\
\hline
\end{tabular}




\section{References of Section 2}

(1) 10 CFR Part 50, "Licensing of production and utilization facijitics."

(2) U.S. vuclear Regulatory Guide 1.3, "Assumptions used for evaluating the jotential radjological consequences of a loss of coolant accident for :niling water reactors," Revision $2,1974$.

(3) U.S. Nuclear Regulatory Guide 1.4, "Assumptions used for evaluating the, otential radiological consequences of a loss of coolant accidene for fressurized water reactors," Revision 2, 1974.

(4) 10CFi Part 100, "Reactor Site Criteria."

(5) 10CFr Part 51, "Licensing and Regulatory Policy and Procedures for Envi mmental Protection."

(6) U.S. Vuclear Regulatory Guide 4.2, "Preparation of Environmental Repo: ts for Nuclear Power Stations," NUREG-G099, Revision 2, July. 1976.

(7) WASH-1400 (NUREG-75/014) Appendix VII, "Release of Radioactivity in Reac' Jr Accidents," October, 1975.

(8) R. A. Lorenz, J. 1.. Collins, and A. P. Salinauskas, "Fission Product Source Terms for LHR LOCA," NUREG/CR-009i, ORNL, June 1978.

(9) Techrical specification for PH'R.

(10) R. W. Braddy, J. W. Thiesing, and P. S. Lowery, "Performance and Sizijg of Dry Pressure Containments," BN-TOP-3, (Revision 4) Bechtel Corperation, October, 1977.

(11) Haro 1 Oslick, "Safety Aspects of Containment System Design for Nuc1 ir Power Plants", Nuclear Power Safety, edited by J. H. Rust and L. L. Neaver, July, 1976, Pergammon l'ress [Progress in Nuclear Energy, New Serias, Series .V].

(12) A. K. Postma, R. R. Sherry, and P.S. Tam, "Technological Bases 
for Models of Spray Washout of Airborne Containments in Containment Vesse1," NUREG/CR-0009, October, 1978.

(13) Taylor, G. I., "Diffusion by Continuaus Movements," Proc. London Soc., 20, P 196 (1921).

(14) Slade, D. H., "Metorology and Atomic Energy," U.S. AFC, Washington, D.C., [1968).

(15) WASH-1400 (Draft) Appendix VI, "Calculation of Reactor Accident Consequences," August, 1974.

(16) "Report of ICRP Committee II, Permissible Dose for Internal Radiation (1959)." Health Physics, 3, P 30, 146*153, 1960.

(17) Table VI D-2, Appendix VI of WASH-1400, U.5. ARC, October, 1975.

(18) J. R. Beattie and Pamela M. Bryant, "Assessment of Environmental Hazards from Reactor Fission Product Releases," NHSB(S) 8135, 1970.

(19) L. Cave, "The Relattonship between Reliability and Safety in Nuclear Power Plants", IAER-SM-195/54, IAEA, Vienna, 1975 ,

(20) MASH-1400 (NUREG-75/014), Main Text, "keactor Safery Study", Oct., 1975.

(21) Denton, H. R., 7-18-78 ietter to Minogue, R. B., "Request for Initiation of Change Actions to Regulatory Guides 1.3 and 1.4," July 18, 1978. 


\section{Definition of possible targats for containment performance}

(3.1) The nature of the problem

Containment performance depends partly on the leak rate of the containment structure, at its design pressure, and partly on the effectiveness of the system provided for functions such as decreasing the containnent pressure (in order to reduce the leak rate) and removing volatile fission products fron the containment atmosphere. There is sone scope for design aptimization since, for example, improvement of the efficiency of a sp-y syster, to reduce the iodine vapor concentration, may be considerably cheaper than attempting to reduce the design leak rate of the structure as a means of achieving the same overall effectiveness.

In the past, the NRC Iequirements as stated in Reg. Guide 1.3 and 1.4 have provided an adequate basis for design optimization, within the narrow limits which are feasible for such seeningly conservative requirements, in an era wher no specific reliability requirements had to be met.

In the future it is possible that a more "risk-oriented" approach to design might be required in which the performance and reliability of the reactor protection systems, combined with that of the containment system, kould be require? to give either a constant or diminishing level of risk (i.e., probability $x$ consequence) as the potential consequences of an accident increased. 
It may be noted that an sppronch of this nature hes recently been adopted in the United Kingdon; the 1atest draft of the "Safety Principles" document (Ref. 1), which the Chief Inspector of Nuclear Installation (CINI) is about to issue for public comment, contains the following proposals:

(i) If the probability of an accident is greater than 0.03 per reactor year (i.e. about onee per reactor life time), the dose to a member of public should not exceed $1 / 30$ of the annual dose 1 imit for the general public. (i.e. about $17 \mathrm{~m} \mathrm{rem}$ )

(ii) If the probability of ar accident is greater than $3 \times 10^{-4}$ per reactor year (i.e. about once in 30 years for a national program of 100 renctors), the dose to a nember of the public should not exceed the ennual dose $1 \mathrm{indt}$. (i.e. 0.5 rem)

(iii) If the consequences of a more severe accident would give to a nember of the public a dose greater than an Evergency Reference leve1* [ERL) dose, the probability of such an accident must be made as "low as rensonubly achievable." The combined effect of proposals (i) and (ii) should be to avoid any accident exposure of the public greater than the limits which are appropriate to noral operation, during the reactor program; the sffect

*An ERL is defined as that level of dose from an accident above which counter-measures (e.g. evacuation) should be undortaken, if by those means a suistantial reduction in the potential dose is 11 kely to be achieved. The various ERLs, which are specified by the U.K. are specified by the U.K. Hedical Council, are approxinately twice the occupational cose levels to the same organ, e.g. the ERL for whole body doses $12 \mathrm{rem}$. 
of (iii) should be to reduce the risk from the more severe accidents to a level considerably lower than that which the LfK Health and Safety Executive (to whom the CINI is responsibie) would consider acceptable for other potentially hazardous industries.

The Three Mile IsIand accident has denonstrated that the U.S. public is extremely sensitive to nuclear accidents which appear to present the slightest hazard to their health. Thus an approach similar to that adopted by the U.K. regulatory body might be attractive to U.S. utilities as a basis for a design specification, since this means it should be able to maintain a very low "safety profile" througlout the theral reactor progran, except in the event of severe but undjkely accidents leading to consequences greater than those expected in accident classes 3 through 8 of Reg. Gutde 4.2. It is convenient to define such a combination of reactor and containment as a "ho significant harm reactor".

Thus it should be a useful exercise to determine whether the containment requirements to meet a set of "No significant harm" criteria, such as those described above, far accidents in classes 3 through 8 wotld be substantially less onerous than those required to meet existing, or anticipated, NRC requirements. If the requirements were substantially less anerous it would then be worth while to determine whether any significant savings in cost could be made by modifications to current design specifications (e.g. by relaxation of the leak rate requirenent and a reduction of the high quality currently needed for the containment liner), possibly by the greater use of engineered safety systems.

Given that a worthwhile saving in cost appeared to be feasible it 
would then be necessary to determine the reliability which could be expected from the simplest version of the revised system and to consider whether it would be adequate. If not, the increased piant requircments would, of course, reduce the expected cost savings.

The next step, to provide a basis for negotiation with NRC, would then be to determine how large a source term could be accepted, or how much accident severity could extend beyond class 8 , before the limits of 10 CFR 100 were exceeded.

1t should be noted that, if the concept of a "lo significant harm" containment design were adopted, it would aiso be necessary to consider the extent to which the "uncontajned accidents" in classes 3 to $B$ (c.g. fuel handling accidents, radwaste accidents and failure of stean pipes outside the containment) would necessitate additional protection, firstly on simple deteministic grounds and secondly an the grounds of comparative risk. However, this aspect of the problem has been considered to be outside the scope of the present study.

\section{(3.2) Definition of assugptions for a "no significant harm" reactor}

For the purpose of defining the reactor containment specification for a "no significant harm" response, if the reactor were subject only to accidents in classes 3 through 8 , the assumptions defined below have been made initially; the sensitivity of the containment requirements to these assumptions is explored later. The initial assumptions are as follows:

(a) Source terms

The source terms are those specified originally in the Annex to Appendix $D$ of 1OCFR 50 (Ref. 2), except that equal fractional releases 
of cesiun isotopes have been assuned to be released in all situations where specific reference is made to iodine releases, and the "spiking" effect on iodinc and cesiur isotopes releases have been taken jnto account.

(b) Atmospheric dispersion

The dispersion conditions assumed are those for the average of 33

U.S. sites (as discussed in Sec. 2.2.5, above) which leads to a three fold reduction in the diffusion factor as compared with Reg. Cuide 1.4.

(c) Acceptablo limits on dose

For a "no significant harm" situation some specific limits on dose have been assumed. These limits, which are based on the radiation exposure at the EAB, and the reasons for their selection, are as follows:

(i) thole hody $\gamma$-dose incurred during the first 48 hrs of the relcase, at EAB-30 arem (Notej. This dose is assumed to be made up of components due to:

- external dose from rare gases is cloud

+ external dose from other isotopes in cloud

- external dose from deposited material

- internal dose from inhaled material

(ii) Whole body $\gamma$-dose accumulated in first year at EAB-50 mrem (Note) This dose is assumed to be made up of components due to:

- dose in first 48 hours, as in (i)

- additional dose from deposited material (mainly C5137) this component is Iimited to $20 \mathrm{mren}$

(iii) Dose to child's thyroid incurred during the first 18 hrs of the release, at $\mathrm{EAB}-0.5$ rem. 
(Note) This dose is assumed to be made up of components due ta:

- inhaled isotopes of iodine

- external i-radiation with appropriate factors

(as in appendix VI/H of KASH-1400)

(IV) Dose to child's thyroid due to consumption of contaminated milk

$-0.5 \mathrm{ram}$.

(Note) This dose is assumed to be due to be entirely to iodine deposited on herbage. It is assuned that the active iodine content of milk consumed by any one child would represent the average contamination in a sector 1 kor wide, extending downwind from the EAB, in the most heavily contaminated direction.

The bases for the limits suggested above are as follows:

The radiation exposure of individuals at the EAB who are NOT evacuated is proposed as a basis for a "no significant harm" design, since any need for evacuation could give rise to widespread anxiety and adverse effects on public opinion.

. Whole body $\gamma$-dose incurred during the release (30 mrem). This is $1 / 17$ th of the maximus dose allowed for the general public in normal operation of the plant; any contained accident likely to give rise to a dose of this size would almost certainly necessitate an outage of more than 2 months (i.e. 1/6th year) for repairs. Thus the reduction in dose during the enforced ourage should offser the dost received as a result of the accident.

- Whole body $\gamma$-dose accumulated in first year. The incremental dose due to deposited material in the first year would continue at a reduced level in the secand and subsequent years but, due to weathering, would probably not exceed $10 \mathrm{mrem}$, i.e., there would be no significant addition to natural background, due to the 
deposited material or to the nuclear power plant itself, if the reactor were restarted.

- Dose to child's chyroid; In accidents where thyroid effects are likely to be limiting, the dominant contribution to the dose would be intaled iodine. Taking a ratio of $10: 1$ for the thyroid cancer risk from external $\gamma$-radiation as compared with iodine deposited in the thyro:d itef. 4), a thyroid dose of about $500 \mathrm{mrem}$ would be equivalent to 30 raren whole body in terms of risk of cancer.

- Thyroid dose from milk; so few cows could be grazing at the FAB that it would be unrealistic to take the herbage dose at the EAB as the limiting figure. The average value for a sector between $E A B$ and $(E A B+1 \mathrm{kr})$ is considered to be a more realistic basis for the degree of contamination.

(d) Site condition

The EAB is assumed to be at a distance of $1 \mathrm{~km}$ fron the reactor. The wind directions are assumed to be uniformly distributed.

\subsection{Comparison of containment requirements to meet NRC and "No signi-}

\section{ficant harm" criteria}

\subsubsection{Method of Comparison}

The containment requirements to meet the SRC exposure 1 imits defined in Reg. Guides 1.3 and 1.4 and those to meet the "no significant harm crituria" defined in the previous Section can be compared initially in a simple, approxisate way by consideration of the whole body doses received at the EAB due to external radiation from the rare gases and volatile fission products and the tintoid doses due to iodine. A nore exact comparison can be made by comparing the probabilities of fatal delayed cancers in the two cases, taking into account the other possible components discussed in the previour Section. 


\subsubsection{Quantitative comparison of requirements}

Table 3.1 provides a comparison of the whole body doses due to external radiation (1.e., to the rare gases and volatile fission products) and of the thyroid doses due to iodine, at the EAB, which would be acceptable in terms of Reg. Guides 1.3 and 1.4 and in terms of the "no significant hazard" requirement discussed in Section 3.2. In the latter case the doses due to the external radiation and to the iodines should be reduced to some extent, in order to allow for the other possible contributions to the health hazards.

Table 3.1 Approximate quantitative comparison of requirements imposed by the criteria of Reg. Guides 1.3 and 7.4 and by the "No significant harm" (NSH) concept.

\begin{tabular}{|l|r|r|c|}
\hline \multirow{2}{*}{ Source of hazard } & \multicolumn{2}{|c|}{ Type of Criterion } & Ratio("Reg. Guide't) \\
\cline { 2 - 4 } & Reg. Guides & "No significant harm" & NSH \\
\hline $\begin{array}{c}\text { Whole body dose } \\
\text { (extermal } \\
\text { radiation) }\end{array}$ & $25 \mathrm{ren}$ & $50 \mathrm{mram}$ & 500 \\
\hline \begin{tabular}{l} 
Thyroid dose \\
\hline
\end{tabular} & $300 \mathrm{rem}$ & $500 \mathrm{mrem}$ & 600 \\
\hline
\end{tabular}

It has been shown in Section 2 that the overall factor of conservatism in the evaluation of the hazard in Reg. Guides 1.3 and 1.4, as compared with a "best estimate" evaluation, is about 600 for the whole body dose if this is attributed to rare gases alone)and about 5,000 for the thyroid dose due to iodine, if, in the best estimate evaluation, the most favorable interpretation of the recent experimental data on gas releases from ORNL, is employed. (See Table 2.4) However, if the more conservative data on gas releases, which are summarized in WASH 1400 (Ref. 3), are used, these factors of conservatism are reduced to 200 and 130 respectively. The degree of conservatism has also been assessed in terms of the probability of fatal delayed cancers by taking into account also the exrernal doses to thyroid and whole 
body due to the volatile fission products. On this basis the factors of conservatism for these 2 sets of estimates are 1000 and 190 respectively. It must be remembered that the "no significant harm" criteria are based on continuous exposure at the EAB for 48 hours, whereas the Reg. Guide criteria assume only 2 hours exposure. With this reservation, it will be seen from Table 3.1 that even on a "best estimate"has is and with the assumption that, although a high proportion of the rods may fail, there is no prolonged heat up of the core in Class 3 through 8 accidents, the containnent performance required to meet the "no significant harm" criteria is at least as high as that required to meet the Reg. Guide eriteria, i.e., the more conservative assumptions used to evaiuate the releases in the Reg. ruide are offset by its less severe criteria for the radiological consequences.

Thus a utility wishing to order a "no significant harm" reactor would have no incentive to seek any relaxation of the present Reg. Guide requirements unless it believed that only a small proportion of the rods would fail in Class 8 accidents.

3.4 Sumnary of containment performance requirements to be considered in optimization studies

An examination has been made of the dose calculations for Class 8 accidents in a number of FSARs and NRC Safety Evaluation Reports. As might be expected, it has been found that when the doses at the EAB and at the I.PZ boundary have been calculated by the methods presented in Reg. Guides 1.3 and 1.4 they are ustrally relatively close to the criteria laid down in the Reg. Guides (See Appendix 7).

Thus, if it were required that containment performance in Class 3 
through 8 accidents should be such that either:

(a) The requirements of Reg. Guides 1.3 and 1.4 should be get in ful1, retairing all the prosent factors of conservatism,

or

(b) The requirements of the "no significant harm concept" should be met, using "best estimate" calculations,

then there would be little possibility of reducing the performance below that claimed for current designs. However, it was conceivable before the "Three Mile Island" accident, and perhaps might be conceivable again in some years time, that a case could be made for a lower standard of performance. This case could have been made on the premise that the Reg. Guide requirements were unduly conservative for "well-conditioned" accidents in Classes 3 through 8 and that they were leading to substantial expenditure that was not cost effective.

Thus, the optimization of containment systems has been treated in two ways in this study:

Firstly, on the basis that the containnent should be cost effective and, if necessary, a lower standard of performance should be accepted in order to achieve cost-effective designs. Secondly, on the basis that the present standard of performance should be maintained.

A possible method of assessing the cast effectiveness of a containment system is as follows:

(a) The probabilities of the various fault sequences leading to releases of activity are estimated.

(b) The consequences of the sequences, in terns of harm to health and of property damage are estimated. 
(c) The overa]l expectation of loss (or "risk") is computed.

(d) Comparison of the expectation of loss with the cost of the containment system will then show whether the latter can be considered cost cffective.

Some prelininary calculations for typical IJ. $\varsigma$. sites based on kef. a sugpests that, if fault selquences more severe than "well-conditjoncd" Class 3 through a accidents could he jpored lon the grounds of very low probability) and expectations of inss are assessed on a "best estimate" basis, then the present standards of containment could Not be regarded as cost effective. Moreover, if a reasonable allowance wers made for the uncertaintios $i$ : the bost estinate values the present standards would still seen to be non cost effective. Thus if containment wert optimized on a cost/benefit basis, using expectation of loss for risk! as a criteria, the correct decision would be to dispense with containment. This conclusion is, in fact consistent with the results of the Rasmussen study (Ref. 3): Analysis of the results presented in Table $12-1$ of WASH-1400 shows that in the case of the jodines released to atmosphere, for example, the "expectation of release" is only decreased by a factor of 10 by the provision of the contaiment; the risk to the public from nuclear power, as estimated in bisll-1400, is so low compared with the otlier risks to which they are subjected that a tenfold increase due to the anission of the contaisment would lot be significant.

However, if the cost/benefit analysis were conducted on some other recognized basis (e.g. on the "Minis-Max" principle, which requires the designer to minimize the maximum consequences of accidents) a different conclusion would be reached about the need for containment. As it is highly unlikely that decisions on containment based on a cost henefit analysis founded on the 
"expectation of 10ss" criteria, would be acceptable to the U.S. public, this approach to containment optimization has not been pursued any further in the present study. However, if should be noted that although the notion of an uncontained power reactor is unacceptable in the $\mathrm{U} . \mathrm{S}$., this attjtude js not universal; in the U.K., for cxample, it is intended to continue the construction of Advanced Gas Cooled Rezctors without conventional containment systems. 
References of Section 3 .

(1) "Safety Assessment Principles for Nuclear Power Reactors", lealth and Safery Executive liM Nuclear Installations inspectorate, U.K., Revised Sor, $197 \mathrm{R}$.

(2) JI.S, NRC, Regulatory Guide 4.2 (lkevision 2), "Preparatien of Environmental Reports for Nuclear Power Station" NUREG-0099, July, 1976.

(3) WASH-1400 (NISREG 75/04) Appendix vIS, "Release of Radioactivity in Reactor Aceidents", October, 1975.

(1) Wall, I, B, Yaniv, S.S. et al. "Overview of the Reactor Safety Study Con.uqiance wode1", NUREG-0340, Septemher 19:7. 
4. Yossible containment systems for LWR

\subsection{Elements of e containment system}

\subsubsection{Shielding Structure}

In order to meet current requirements for resistance to external hazards such as tornados, a reactor in the U.S. must be protected by a substantial shield wall. Even if it were argued that a containment in the conventional sense (i.e. a structure to hold up the escaping primary coolant) were not required, the shielding structure woul: have to be built as a relatively strong enclosed structure to provide tornadu protection. Moreover, since its collapse could endanger vital reactor plant, jt wouid also have to have a seismic resistance comparable to that of the reactor itself. However, in its most primitive form this "containment" could be vented, so that its design pressure need only be as high as required to meet the tornado requiremest (about $3 \mathrm{psig}$, and it could be allowed to have a substantial leak rate.

\subsubsection{Vented shielding structure with filtration}

In a typical water reactor the primary coolant would contain some active material and, in loss of coolant accidents, some bursting of fuel rods, leading to the release of gaseous and volatile fission products, is to be expected.

Thus one possible step in the evolution of a containment system would be to arrange to vent the primary coolant through some form af filter, thereby removing the immediately available activity and ensuring that the pressure within the shielding structure did not rise beyond its design pressure which, as noted above, could be quite low.

Dwing to the very large flow that would have to be accomodated ir the even: of a large LOCA, it is unlikely that any type of solid filter 
(e.g. HEPA or sand-bed) could be devised that would be economically feasible (Sce Ref. 1). However, in principle, there should be no difficulty in arranging for the coolant to vent through a deep pond of chemically treated water, which could remove a substantial proportion of the volatile and particulate activity.

Nevertheless any rare gas fission products entering the pond would be releasei and activity released after the initial depressurization could lcak out fron the shie!ding structure subsequently. Clearly with one additianal refinement of design, namely the provision of a low leak rate shielding structure, some control over the later releases could be achieved. The refinement of design would have to include some provision of resealing the vents. In addition some provision for the removal of heat transferred from the reactor to the shielding structure might be necessary to preserve the integricy of the structure.

\subsubsection{Shielding building structure as low-leakage containnent}

As an alternative to venting the shielding structure it could be used as the basis of a low leakage containment structure, This would necessitate:

i) Large increase in design pressure, typically this would have to be increased to about 50 psig.

ii) Provision for removal of heat fron the contairtent to avoid over-pressurization and/or deterioration of materials

iii) Additional features (e.g. double penetration seals) to achieve a sufficiently low leak rate to make the expenditure on the other additional features worthwhile.

The inclusion of a low leak rate liner in the design night not be 
essential. It has been showi in the U.S. that by care in construction a leak rate of less than 1 percent per day (by volume) at a design pressure of about 15 psig can be achieved in a reinforced concrete structure (Ref. 2G3). It has also been shown in France that by the use of a prestressed design, instead of a conventional reinforced one, much lower leak rates should be achievable, down to about 0.5 percent per day, by volume at design pressures up to 5 atm, at least. (Ref, 4). It should be roted that in principle the development of cracks leading to a significant increase in leak rate during service should be much less likely in a prestressed structure, since the concrete should be in compression throughout the structure. As discussed in Sec. 5, it is unlikely that there would be a significant difference in cost between a pre-stressed and a reinforced concrete structure built to similar standards of quality and designed to weet the same requirements.

4.1.4 Specially designed very low leak rate, single shell contajnments

On some sites, in areas of relatively high population density, it is possible that a $1000 \mathrm{M}(\mathrm{N})$ PHR would require an overall leak rate of less than 0.1 percent per day (at design pressure) from the containment, in order to meet the requirements of Reg. Guide 1.4. This would be beyond the capability of a single unlined structure, unless the pressure within the containment could be reduced very rapidly and/or the concentrations of airborne fodine and other volatile isotopes could also be reduced very rapidly.

As discussed in Sec. 5, the cost of the liner required to reduce the leak rate of the structure to 0.1 or 0.2 percent per day is a substantial component [about 20 percent] of the cost of the systern. The cost of a system to reduce pressure and/or jodine concentration rapidly is also significant. (In typical us designs it is about 10 percent of the total 
cost of the system. See Sec. 5); devices to 1 imit the leak rate at the various penetrations to an acceptable leve] would also add to the car: Nevertheless, in spite of these sources of additional costs, the single-shell, lined, containment vessel, provided with spray systens to condense stear and to remove iodine, and with internal rectrculatinf. cooling and filtration systems has proved to be one of the most popular design solutions for PHR containment in the U.S. Hawever, in arder to make use of sites with small distances to the EAB F LPZ, a higher performance may be recessary (See Sec, 6.3).

As indicated in the previous section, it is not expected that trere world be much difference in cost betheen reinforced or pre-stressed, lined chllarete shells. It also appears that, subject to certain restrjctions I ce Sec. Ej, a free-standing stcel shell, capable of withstanding the ane design pressure, and surrounded by a separate shielding structure, of pre-stressed or reinforced concrete, which would simply fill the role defined in Sec. 4.1 .1 above, would also cost about the same. A structure of this type is described fuly in Ref. 5: it can have the advantage of providing more room for equipment at no greater cost. This similarity in costs makes foasible a further refinement in system design which could lead to significant savings, as discussed in the next section.

\section{1 .5 Double containment concepts}

It was appreciated in the early 1960's that, if very :ow leak rates were requir.d, an aiternative to achieving these by further development of 1 iners and penetration seals hould be to use two separate vessels, onc enclocirat the other, each with a moderately low leak rate and with provision for controlling the activity leaking from the inner vessel iato the annular space between the two. 
Two methods of controlling the activity in the annular space have been used:

a) In the first method, the annular space is kept at a slightly negative pressure, so that any leakage through the outer vessel is inwards, by continually pumping the leakage (from both shells) into the inner vessel. In order to avoid over pressurizing the inner vessel in an unaccoptably short time, it is necessary for the outer vesscl to have a low leak rate, which may add substantially to the cost.

b) In the second method, the annular sface is also kept at a slight negative pressure, but in this case, that is achieved by exhausting air from the inter-space to the atmosphere, via an efficient filtration system. To improve the control, a recirculating filtration system in the interspace may also be provided.

It was shown in the FSAR for the Kewaunee, wiscons in PWR (Ref. 5) that the combination of a free standing steel inrer vessel with a design leak rate of 2.5 percent per day, an outer building of medium quality reinforced concrete and a re-circulating filtration system in the interspace (with a capacity of $5,400 \mathrm{Cfm}$ ) should be sufficient to limit the overajl leak rate to less than 0.1 percent per day, at the design pressure (46 psig) of the inner vessel. A similar system was provided for the Prairie Island, Minnesota, PHR. So far as can be ascertained, the design objective was demonstrated during the start-up tests and has been confirmed by tests during service. As discussed in Sec. 5 , the use of an inner vessel with a leak rate of 2.5 percent per day as compared with, say, 0.2 percent should lead to a significant reduction in cost. However, the precedent set by the Kewaunee and Prairie Istand plants for using double containment to justify a higher design leak rate for the 
primary containment does not appear to have been followed in more recent designs. Although the same concept has been ased, it has only been claimed as a further, unquantified safety margin when applied in conjunction with primary containment vessels having design leak rates of 0.2 percent per day at design pressure.

\subsubsection{Pressure suppression concepts}

The rise in pressure within a containment due to the retease of stean or of water flashing to stear, can be reduced rapidly by condeasing the stear. In the case of boiling water, direct-cycle reactors, the absence of large steam generators external is the reactor pressure vessel (RPV) makes it relatively easy to pass stean released as the result of a primary circuit failure to a static water pool at the bocton of a chamber (the primary contaigment) containing the RPV and those parts of the feed and steam mains which cannot be isolated rapidly by valves. The escaping steam is bubbled through the water; thereby condensing the greater part of it. The primary containment is housed within a low leak rate structure so that any activity carried over with the uncondensed steam can be held up and treated as in the "drw" double containnent system described in the previous section.

This type of pressure suppression has been used for virtually all commercial BhR's and, as described in Sec. 7, probably Iepresents the chcapest way of securing even a moderate containment perfomance for this type of reactor. If a decision is made to use this type of pressure system at the start of conceptual design, the only parameters which can achieve a significant increase in performance are the leak rate of the secondary containment and the capacity of the plant for treating the air/steam, mixture in the annular space. As discussed in Sec. ', the cost of the "standard" designs for U.S. comnercial BWR's could be 
reduced significantly, if a somewhat higher leak rate for the secondary containment were acceptable.

Two other forms of pressure suppression containment have been used for comperical, indirect cycle water reactors. These are:

i) Rapid dousing by spray, as in some CANDU HKRs.

ii) Use of an "ice-condenser" as in some PWRs.

In principle, the pool type of suppression systen could also be used for indirect cycle reactors and a commcicial design for small "integral" PWRs (up to $1200 \mathrm{MHe}$ ) has been proposed which uses this type of pressure suppression (Ref. 6).

In the dousing system, as used in the CANDU reactors, the containment structure is a pre-stressed concrete shell, which also embadies a large water storage tank (about $10^{5}$ cu. $f t$ ) is in the roof of the building. In the event of a LOCA this is rapidly discharged without delay through spray nozzles, so that the design pressure is substantially lower than in a typical 'dry' PWR containment. Typically, the design pressure is 3 psig as compared with 50 psig (Ref. 7). The pressure is reduced almost to atmospheric so rapidly that a steel liner is not required. This system may be used in conjunction with an external "expansion chamber", of the type described in the next section, in order to reduce the design pressure stili further.

In the "ice condenser" system a large volute of ice, in which flow passages are formed, is maintained in an insulaced section of the primary containment structure, which is divided into 3 sections viz:

a) A loser "collecting chamber" into which all the steam/water mixture from a breach in the primary circuit would pass initially

b) The "ice condenser section"

c) An upper receiving chamber in which aif displaced from the 
collecting chamber, any uncondensed steam, and the air-borne activity released from the primary circuits are collected.

In practice it lad hoen foastble ta so arrange the design that virtually all the steam entering the ice rompartment would be , . .m.l......

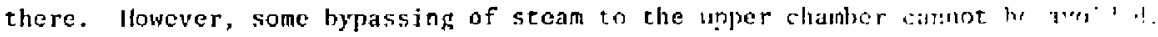

By 'doping'the ice with suitable chemicals (e.g. sodium tetraborate) a large proportion of the iodine can be "fixed" immediately in the liquid phase as the steam condenses. This would mean that a higher leak rate might be acceptable, if the iodine release were the dominant contributor to the overall consequences.

In practice the design pressure for a typical "ice containment" for a Plik is usually about 25 psia (as compared with about 70 psia for a (ypical "dry" containment). This reduction has been achieved in conjunction with a substantial decrease in the volume enclosed by the building,

The 'ice condenser' type of containment can be used in conjuaction with either a single shell or double shell arrangenent.

Eight land-based comercial PWRs with "ice-containment" have been ordered in the U.S., and at least 4 overseas ( 2 in Finland, and 2 in lapan): only one of these, the Donald C. Cook plant in Bridgman, Michigan, is aperational in the U.S. Numerous difficulties leading to expensibe delays have been encountered un the lead plant (Ref. 8)hut it is not yet elcar whether these are "first of a kind" problems, or are of a more goneric jature. Similar probiems appear to have be en encountered wih the 2 reactors which are operational in Finland and Japan.

in cansidering the optimization aspects of the 'ice containment' system it has to be remembered that the laber containnent pressure would lead to some decrease in the rate of re-flooding in the event of a large LOCA. In order to maintain the same safety margin this might 
entail a reduction in peak rating or additional plant costs largo enough to have a significant effect on the overall cost of the plant.

It should be noted that ar advantage of the "ice-containment" and other pressure suppression systens is that since the ratio of the design pressure to atmospheric pressure is well below the critical value, the reduction in leak rate obtained by a given drap in conrainment pressure is greater than in conventional "Jry" containment, particularly in the case of orifice flow. Thus for a given investment in spray system capacity, a greater reauction in leak rate can be achieved.

\section{(4.1.7) External expansion vesse1 concept}

In order to ensure that the leakage of activity from an unlined containment structure is small, it is desirable to reduce the pressure below atmosphericas quickly as possible. As discussed in Section A.t,6, one way of achieving this is by spray or dousing systems. However, for a site on which several reactors are located, it has been shown by Canadian designers have preferred to supplement the dousing systems by a large evacuated "expansion vessel", into which any of the containment structures on the site can discharge their contents, if the pressure rises above some very low pre-selected level. By an appropriate choice of valumes and working pressure for each of the reactor containment buildings and for the central expansion building, together with a substantial dousing capacity, it is possible to reduce the pressure within the system, after LOCA in one reactor, to sub-atmospheric pressure in less than 1 minute.

As discussed in the next Section 5 , this concept appears to offer a significant reduction in cost for a site with three or nore reactors, as compared with the conventional, lined, "dry" containment. The system engineered for the Pickering Nuclear Power Station (Toronto, Canada) is therefore described briefly here: The design of containment system for 
this plant is based on the principle that following a hypotheticai major failure of any of the high energy systems in the reactor halding, accompanied by failure of the reactor protective syster, there shall be no significant escape of harmful offluent to the atmosphere. Hithin less than thirty scconds after any accident resulting in overpressure in a reactor building, the discharge from the failure shall be retained within the containment at sub-atmospheric pressure. (Ref. i)

A charactoristic feature of the systen is the use o: a common vacuur. building which has a clear volume of $2.9 \times 10^{6} \mathrm{ft}^{3}$ and which is maintained at an absolute pressure of 1 psia (51 mu $\mathrm{Hg}$ ) to provide the negative containment. This vacuum building is connected through twelve $6 \mathrm{ft}$. diameter vacuum ducts, and a corresponding set of pressure actuated relief valves, to a pressure relief duct. This duct is in turn connected through $25 \mathrm{ft}$ diameter louvered openings to the "bojler roon" of each reactor building. In the top of the vacuur huiluing an energency water storage tank, containing $350,000 \mathrm{ft}^{3}$ of water, is located. This tank provides the witer for a dousing spray system which operates if the pressure in the vacinm building exceeds ar absolute pressure of $6.2 \mathrm{psi}$.

A major failure in the high energy systems in any of the reactor buildings will cause the pressure in that reactor building to rise. This rise in prossure will be comaunicated direcily to the twelve pressure relief valves located in the pressure relief duct. The valves respond automatically to a rise in pressure of 1 psi, allowing the effluent to be discharged into the vacuun building. The valve openings are sufficiently large that the pressure in the reactor building affected will be brought rapidly down to the range 0 to -0.5 psig. The outward opening louvers in ather reactor buildings prevent them from being 
affected by back pressure from the pressure relief duct. The vacuum building and the pressure relief system are designed collectively to contain ali the energy which could be released inside a reactor building following any postulated accident to the reactor or its heat transfer system. The containment system has a heat energy absorption capability in excess of two and a half times the amount which is stored in the primary and secondary system.

Because of the very rapid Ieduction in pressure to less thar atmos. phere, the uncontrolled leakage from the system should be nc:aligibie. However, the design in-leakage could require an extraction rate equivalent to ahout 5 nercent of the total volume per day. With 93 percent efficient filtration system for iodines, this would be equivelent to leak rate of less than .05 percent per day of the air-borne inventor: of these isotopes, but 5 percent per day of the rare gases inventory. Presumably this would be reduced in practice by operating with a smaller negative pressure differential.

44.1.83 Application of the "post-accident" filtration system" (PAFS) to LWR containment systems

The primary function of the PAFS is to improve the effectiveness of the containment under LOCA condition by providing an external filter through which the air/steam mixture in the containment can be vented to the atmosphere if venting were necessary to prevent the containment from rupturing due to overpressurization. The secondary function of the system is to create a sub-atmospheric pressure within the containment even in situations where the leak rate has incteased greatly. In order to meet these basic requirements, the PAFS is designed with separate filtering components and mechanical devices for rembving the volatilized fission product particulates and the iodine gases. The selection of 
filter components is based on current technology and compatibility

with the post-iaccident environmert.

The basic arrangement of the PAFS (Ref. 10), for bott: Pin's lin's. consists of a 4 foot diameter inlet duct system, which connects the containment volume to a sand filter chamber. An orifice tyically $1 \mathrm{ft}$. in diameter for PHR's and $0.6 \mathrm{ft}$. in diameter for BWR's) is placed at the filter inlet to nvoid any possibic overpressurization of the PAFS. Since the pressure drop across the orifice is substantial, a bypass circuit is used to minimize the fan power requirements when the PAFS is used in its secondary role. The construction of the PAFS is robust enough to withstand the effects of hydrogen burning and large volume flows of moist air.

The design of the post-accident filter for LWR dry containment has only been investigated fas enough to see if there would be any major difficulties in its development and ta estahlish its size. Further development work is required to estabjish a detailed design with. idequate performance.

\$.2 Performance requirements for LltR containments

\subsubsection{Minimum performance required from the containment for a}

$\underline{1,100 \mathrm{MH}(e) \mathrm{LWR}}$

It follows from the discussion in Sections 2 and 3 above that the possible range of performance requirements is extremely wide, if the limiting accident to be considered is a "well conditioned" large Lnca.

In order to provide a lower bound to the performan:e required, it is useful to consider the doses delivered at typical EAB and LPZ distances, using "best estimate" values throughout, for a large LoCA in which all rods are assumed to burst but no containment is provided.

In this case it is necessary to consider the contribution from the shart lived gaseous and volatile isotopes. Since, as shown in Table 4.1 below, these make a substantial contribution, particularly to the whole 
body dose, if the release occurs within a few hours of shutting down the reactor.

For the source terms the most recent ORNL data has been used for the longer lived isotopes; For the short lived isotopes the fractions percent in the fuel-cladding gap have been estimated in Appendix 3.

It is assumed that the $E A B$ and $L P 2$ are $1 \mathrm{Km}$ and $5 \mathrm{Kms}$ from the reactor respectively. With the assumptions outlined above, the estimated values for the whole body dose and thyroid dose are found to $t$ : e the values in Table 4.1. No correction has been made for the beneficial effects of radio-active buoyancy.

Table 4.1 Minimum dose at EAB (2 hr exposure) and at LP 2

from an uncontained large LOCA in an I] is Mi(e)

PWf (all rods assumed to fail)

\begin{tabular}{|c|c|c|c|}
\hline organ effects & $\begin{array}{c}\text { Source of radiation } \\
\text { dose }\end{array}$ & $\frac{\text { Locat }}{\text { EAB }^{6}}=$ & $\begin{array}{l}d \text { dose (rem) } \\
\mathrm{LPZ}\end{array}$ \\
\hline \multirow[t]{2}{*}{ whoie body } & Rare gases onty & 100 (rem) & 9 (rem) \\
\hline & Rare gases + volatiles & 110 & 10 \\
\hline Thyroid & Inhaled iodine only & 5700 & 530 \\
\hline
\end{tabular}

Notes $=$ (a) FAR is at $1 \mathrm{Km}$ from reactor.

(b) LI2 is at $5 \mathrm{~km}$ from reactor.

It will be seen fron Table 4.1 that, iven this set of assumptions, the requirements of $10 \mathrm{CFR} 100$ could not be met without a containment 
which provided a retention factor of at least 20 for the ind nes. However, the values in Table 4,1 are based on the assumption that all the rods burst. Clearly, if it could be shown that less than 5 percent would fail, the requirements of $10 \mathrm{CFR} 100$ could just be met without a containment. Nevertheless, in view of the urcertainties i.l the estimated gap releascs and in the predictions for the number of rods failing in a LOCA, this could not be regarded as a realistic basis for design.

After a loca the volatile isotopes would present a major subce of hazard. unless they cin be preferentially retained. Consequenty the aloos innediate removal of iodine and cesium isotopes from the containment atmosphere, which is possible with pressure suppression systems (including the "lce condenser") and the rapid jousing system used in the CAveU rowerors, could be a major factor in reducing the degree of leak tightness which is required. In the next Section the minimum requirements for leak tightness are estimatcd for a containment system in which the rolatiles are removed fram the containment atmosphare so rapidly that they lan be ignored.

4.2.2 thole body dose due to rare gases as an indication of the naximun acceptable leak rate

The only means of reducing the whole hody does due to tha rare gases is to retain them in the contaisment, while radioactive dec.y proceeds. Thus it is useful to establish the relationship between integrated leakage of the raTs gases and wole rody bloes at the EAB and at the LFZ. This relationship can then be used to escablish the maximum leak rate which could be accepted to meet certain types of criteria (due account being taken of the variation in leak rate with time which is to be expected), if the wind continues to blow in the same direction. 
Using the 'best estimate' assumption concerning atmospheric dispersion and the dose/concentration relationship, the integrated jeakages of Xe-133 alone which would be required to deliver a dose of 25 rem whole body at the EAB and LPZ aTe as shown in Table 4,2,

Table 4.2 Integrated leakage of xel33 required to del iver 25 rem. whole

Body at the EAB (1 KII from reactor) and the LP2

(5 $\mathrm{kms}$ from reactor) (Based on the assumptions of

\begin{tabular}{|c|c|}
\hline Location & $\begin{array}{l}\text { Integrated leakage of rare gases to del iver dose of } \\
25 \text { rem whole body }\end{array}$ \\
\hline EAB (1 $\mathrm{km})$ & $\begin{array}{l}1 \times 10^{6} \mathrm{Ci} \text { or } 0.5 \text { parcent of total inventory from } \\
\text { fuel } \\
1 \times 10^{7} \mathrm{Ci} \text { or } 5 \text { percent of total inventory from fue } 1\end{array}$ \\
\hline
\end{tabular}

We consider initially the situation at the LPZ, as we are concerned primarily with the long tem dose. It follows from intole 4.2 that, on the basis of the assumptions prescribed in feg. Guide 1.3 and 1.4 , it would be recessary to limit the release of Xe-133 to less than 5 percent of the total inventory. As the hayf life of $x e-133$ is about $S$ days, the original inventory would be reduced by a factor of 20 in 20 days. Thus the maximum: acceptable average leak rate over the first 20 days would be in the region of 0.25 0.3 percent per day. In practice the contribution to the whole body dose from the other, gaseous and volatile isotopes, most of which have shorter half lives than $X e-133$, mif ${ }^{*}$ not be negligible, so an average leak rate of less than 0.2 percent per day would be desirable. Depending mainly upon the rate of which the iodines cauld be removed from the contairment atmosphere by the spray system, the requirement not to exceed 25 rels whole hody dose at the EAB, in the first 2 hours after the accident, might be mare limiting. 
With less severe assumptions than those called for in Reg. Cuide 1.3 and 1.4 , it is clear that release from the containment of a larger fraction of $x e-133$ would be possible. For example, the conservatism in the Reg, ruide assumptions conceming factors other than the source teris (See Tabie 2.A) would allow the fractional release of Xe-133 to be increased to 30 percent of the amount relcased into the containment, without exceeding the 25 rem whole body dose limit at the LPZ. This kould allow the average leak rate for the first 20 days to be increased to about one percent per day. In practice, as the pernissible average leak rate increases, the relative importance of the other gaseous and volatile isotopes also increases. Detailed calculations show that the average leak rate would have to be limited to about 0.5 percent per day for typical rates of renoval of the volatile fission praducts.

\subsection{Pesformance characteristics of some possible containment systems} EOT PHRs

In the single shel] containment systems described in this Section, it should be possible to attain leak rates of less than 0.2 percent per day, although in the case of the pressure suppression types, attaimment of such low leak rates would be dependent partly on the succes ifil operation of the pressure suppression system. In the case of "double co.t-inments", the parameter of interest is not the observed leak rate from the outer containment, or the exhaust stack discharge, but the "effective leak sate" from the inner vessel to the atrosphere. This can be defined as the ratio (quantity of specific material escaping per unit titse) to (total quantity of specific material in system at that time). However, the overall sate of release of filterable activity to the atmosphere would be dependent on the capacjty and efficiency of the recirculation filter in the annular space and on the 
efficiency of the exhaust filter. Consequently it has not been possible to quote specific values for "effective leak rates". In both "single" and "double" trpe containments the average Ieak rate over a period will be dependent on the capacity and efficiency of the containment cooling, filtration and spray systems. 


\section{References of Section 4}

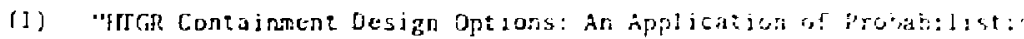

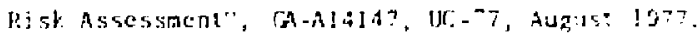

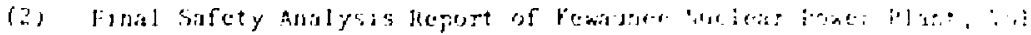
2. Sinuary, $1 \leq 71$.

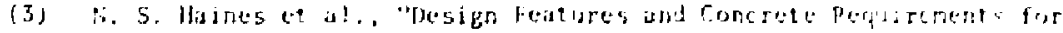

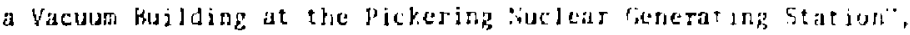
PAPER Si" 3.t-b2, Conf on concrete for bidedear Reactoris

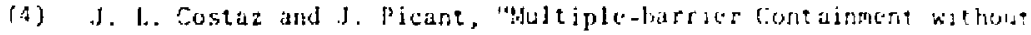
stecl Jiner", Conference on lexperience in the lesign, Constructant and Operition of Prestressed Concreze Pressure Vesseis and Contajuments for Siuclear Reactors, September, 1975.

(3) Final Safety Analysis Report of Kewanec Iuclear fowes flant, Vol. 4, January, 1971.

(6) K. C. Siler and R. S. Marda, "Containment for Snall Pressurized Water Reactors", A'S Trans. 27, Movenber, 1977.

(7) "CAkDll 600 "Hite) Standard Design", Nuclear Engineering International, 19, June, 1974.

(8) Final Safety Analysis Report of Donald $c$. Cook, Suclear Powed PIant, Jinuary, 1972.

(9) C. L. Moon, "Pickering Generating Station", Nuclear Engineering Internationd1, I5, p. 501, Junc, 1970.

(10) B. Gossett, L. Cave, C. K. Chan, D. Okrent, and I. Catton, "PostAccident Filtration as a Acans of Improving Containfent fiffectiveness", Proccedings of Topical lleeting on Thermal Reactor Safery. August, 1977. 
5. Optimization of Containment Design for Class 3 through 8 Aceidents (Ph:R)

\subsection{Factors Affecting the Optinization}

Three different aspects bave to be considered

(a) Performance requirements

(b) Ralative costs of different design features

(c) Constroints joposed by other requirenents fo.g. seismic resistance required from the stractures

fach of these aspects is discussed in the folloxing sections so far as they relate to the optimization process for a phis. The corresponding problems for a Bwh are discussed in Section".

\subsection{Performance Requirements}

As discussed in Sections 2 and 3 , it is difficult to decide what vinimum performance wald be required from the containment of a PliR to be licensed in the U.S. in several years time: if NRC retain requirewents for the source terns sinilar to those currently set out in Reg. Guide 1.4 (Ref, 1 ), there would be little opportunity for relaxation of the present performance requiremonts; similarly, a dility sceking a "ko significant hasm" plant would not wish to relax the present requidements, unless it believed that very few fucl rods lombl tait in is LOCA. Accordingly, the possibilities for re-optimization have been examined in three ways.

(i) By considering how the existing requirements imposed by Reg. Guide $1.4 \mathrm{might}$ be net by the use of existing concepts alpolical in different ways, and the extent to which it mighe be possible,by further work and analysis, to demonstrata th.t lower lcak rates could be achieved than 
have been claimed in the past.

(ii) By examining the cost of arrangements which would provide linited or moderate degrees of retention.

(iii) By examining the cost of arrangements which could provide higher degrees of retention, or the same degree with higher reliability, than is necessary to meet the requirements of Reg. Guide 1.4 in order to meet a possible demand for ut "ro significant ham" reactor design. 5.3 Cost of the basic elements of containment systems

The only comprehensive sources of information of reasonably up to date LhR costs which are readily accessible is provided by Refs. 2 and 3. These are based on 1976 data and have the disadvantage that for scme parts of the plants, the infomation is not broken down into sufficiently fine detail. The more extensive data on containnent cost compiled by ORNL in 1970 is based on 1963 cost data and much smaller reactors, so that these data are now of limited value. A more up to date compilation has recently been completed by DOE but the finil regrert is not yet arailable (Ref. 4). Some additional inforsation on specific points has bees obtained from utilities and architect engineers but it is difficult to be sure that the prices quoted relate to the same tire. frame as that on which Ref. 2 and 3 are based.

The basic data on containment prices which have been extracted from Ref. 2 and 3 are shawn in Table 5.1. It will be seen that there is broad similarity between the individual itens of data for PSR's and BWP's.

By taking account of the differences in dimensions and design pressures of the two containment systems to which these data relite, it has been possible to confirm that the cost relationships are 
sufficiently linear to estimate the cost of possible arranpements that appear to be of promise from the point of view of cost cr performance.

Table 5.1 Summary of Containment Structure Costs (1976 noliarsi from ER IA Meport (Ref. 2') for PliR, stee] lined, single P/T concrete thell

\begin{tabular}{|c|c|}
\hline Component of Structure & $\begin{array}{l}\text { Cost } \\
\text { \$n (millionl) }\end{array}$ \\
\hline Substructure concrete $\& \mathrm{R} / \mathrm{F}^{* *}$ & $2.3 \mathrm{~m}$ \\
\hline Interior cincrete and $R / F^{* *}$ & $8.5 \pi$ \\
\hline $\begin{array}{l}\text { Superstruliture }{ }^{\text {concrete and } R / F} \\
\text { (Shel } \mathrm{F} \text { Dome) }\end{array}$ & $10.9 \mathrm{~m}$ \\
\hline $\begin{array}{l}\text { liner (Including st ifforransl } \\
\text { penetrations] }\end{array}$ & $10.5 \mathrm{~m}$ \\
\hline $\begin{array}{l}\text { Other items (e.g. structural steel } \\
\text { \& painting) }\end{array}$ & $1.0 \mathrm{~m}$ \\
\hline Total & $5.21 \pi$ \\
\hline
\end{tabular}

The total cost of the structure is abou: b percent of the caitial cost of the plant.

Notes

*Estimated prices exclude interest during construction and escalat:"in since 1976. ! ;ineering costs are not included in the above figures but can be accounted for by increasing them by 30 percent.

" Costs include labor, formwork, cadwelds and minor items such as embedded steel fittings.

Othes data from the ERDA report.

From the ERDA report it can be deduced that:

(i) A "standard" figure of $\$ 35$ per c. yard far concrece (as placed) has been used.

(ii) For steel reinforcenent (as placed) the cost varies betweer. 
$\$ 300$ and $\$ 1200$ per ton.

(jii) "Reinforcenent ratio" (tons of steel/c yd cancrete, is atrout 0,2 for the substructure and interior and ahout 0.33 for the shell. For "tornad, and acismic proof" bujldings, jt appears to vasy from ahoul t, 1 to r..2.

To obtain some appreciation of the absolute lewe? of costansest was. it should be notod that the corresponding total direct tapitat rose for the plant is estimated to be $\$ 421$ or $\$ 370$ per $\mathrm{kw}$.

Sone addigonal cost dalis bave al so been shitainod from seluthern halifortia i.lison (Ref. 5). These data are based on the aciual costs or tibe enatallments for Sin Unofre reactors 2 and 3 and reflect the high seistaic accelerations for which the plant is designed. lowever, it is porsirite to deduce from these dat a that the cost of the penetrations for the "levereace besign" of Ref. I would be about $\$ 1.5 \mathrm{~m}$, when expressed in a conparable manner.

Some data relating to the cost of the support systems for the contajnment can also be derived from Refs. 1 and 2 . For pir thesc are show in Table 5.2. Table 5.2 Sumnary of Contajnment Support Systcir Costs (1976 dollars) for PWR, from ERDA Report (Ref. 2)

\begin{tabular}{|c|c|c|}
\hline $5 y \mathrm{stem}$ & & Cast smilitionj: \\
\hline Pre-entry purge system & & 0.17 \\
\hline Refuelling purge system & & 0.35 \\
\hline Containment recirculating filter systom & & 0,24 \\
\hline Recirculating cuoling system & & $1.4 ?$ \\
\hline Containtment spray system $(2 \times 3000 \mathrm{GPM})$ & & 4.18 \\
\hline & TOTAL - & 5.41 \\
\hline
\end{tabular}

Lote: The above costs do not include essential additional items such as whling, switehgear and emergency power sources. These would add about 10 fercent to the total cost. Thus the total cost of the containment, including supporting systems and services, is about (as defined in Ref. 2) $\$ 40$ million, or 10 perzent of the direct capital cost. 


\section{(5.4) Constraints other than leak tightness imposed on the optimization of cuntainment systems}

\section{(5.4.1) Constraints an structural design}

As indicated in Sec. 4.1.1, it would be difficult to avoid a situation in which some form of shiclding structure around the reactor

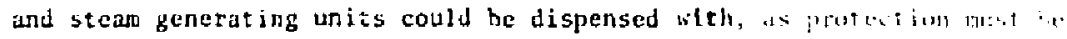

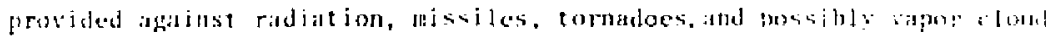

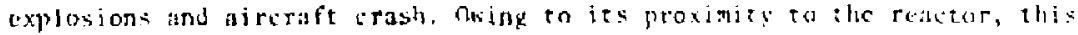
st ructure would also need to have seismic resistance comparale to that af the reactor itself. The effects of theie constraint on cost art disished in more detail in Section 5.5 .

(5.4.2) Effects in service isspection, maintenance and repair

Although the discussion in the next Section suggests that a reduction in containment size could lead to a reduction in cost, it is necessary to ensure that there is adequate space to carry out in-service inspection, maintenance and repair. In particular the increasing concern about the doses received by maintenance workers, emphasizes the need to leave sufficient space to erect temporary shielding, during some maintenance operations.

\section{$(5,4,3)$ Effects on construction program}

In addition to the operational reasons which militate against size reduction there is also likely to be a strong inter-relation between space available within the containment and plant construction $t$ ine. Mwing to the high cost of delays, in tems of interest charges and differential generation costs as compared with fossil plant, savings on capital cost that might appear significant could be offset by these factors. 


\subsection{Possible means of reducing containment costs}

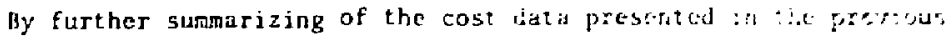
Section, the main elements of the cost of a "dry" contianment fu:

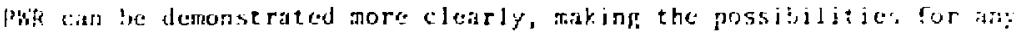
seanificant reduction in cost readily apparent.

From Table 5.$]$ it will be seen that the wain costs, apart from the engincercol saluty systems of a "dry" containment from a like are, is (fiect:

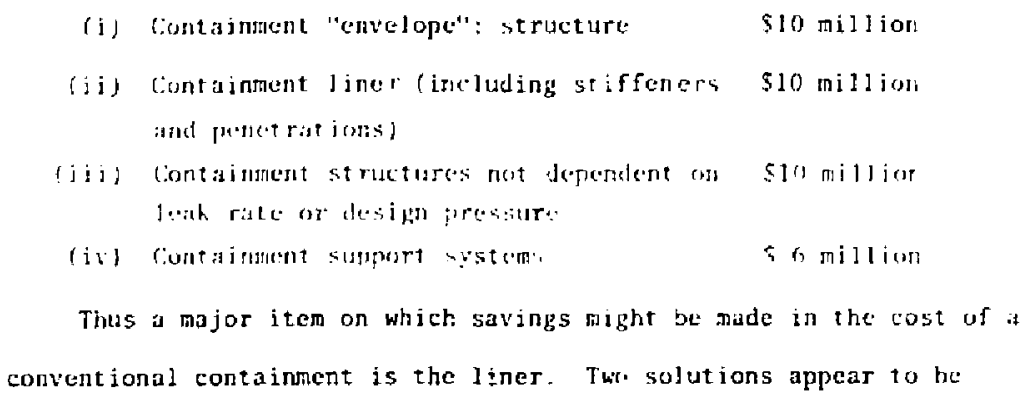

Thus a major item on which savings might be made in the cost of if conventional containment is the liner. Thr solutions appear to he possible:

(a) Dispense with the steel liner, possibly using sore clastonetic cont je:p in its place.

(b) keplacement of the single shell structure by a double shell. both unlined, with pump-back from the inter-space into the primary vessel, or with a filtered extract facility.

It is loulth ful whether a single, unlined, shell would be a practicable design solution, as the leak rate would be difficult to predict, awing to the effects of quite small errors in construction. Rectification (e.g. by pressure grouting) would be feasible but could lead to expensive delays in construction. However, if it were feasihle 
to design on the basis that rejease of virtually all the rare gases could be permitzed, providing that the high proportion of the volatiles wis retained, or that the pressure could be reduced to subatmospheric within a few minutes, then an unlined single shell might be an acceptable sis!ution.

The wxtent of the savings in cost which might be achieved by dispensing with the liner are estimated in Sec, 6, below.

Alout 60 percent of the cost of the containment "envelope" structure (i.e. the cylindrical shejl and dome), for g given diameter is proportionai to the design pressure, as this determines the amount of reinforcing steel required (See Appendix 8); the remaining 40 percent is largely altributable to the mass concrete and the formwork, which will not vary grcatly in cost with design pressure.

Thus in a design, such as an "Ice Containgent" in which the design pressure could be reduced by, say, a factor of 4 , there could be a significant reduction in the civil costs. However, these could be offset to some extent, hy additional plant costs. A quantitative estimate of the savings is given in Section 6 below. The methods for reducing design pressure which have been used in the CAIDU PHhs are also of interest in this respect.

In case of an unlined, double-shell design, the design-pressure for the inner shell would have to be the same as for a single-shell design but the strength of the outer shell would be deternined by other site rejated factors, such as: tornado and seismic resistance.

Resistance to missile impact and aircraft crash Resistance to effects of vapour cle dd erplosions 


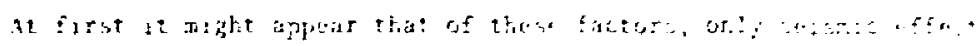

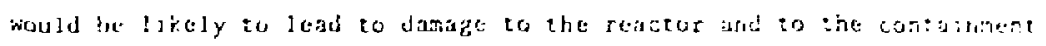

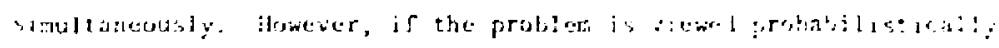

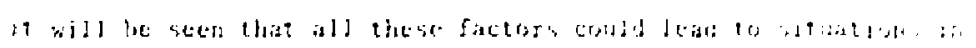

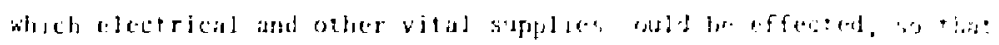

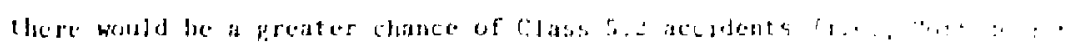

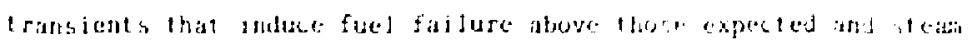

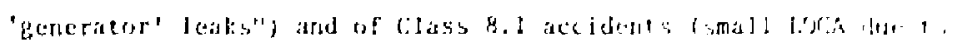

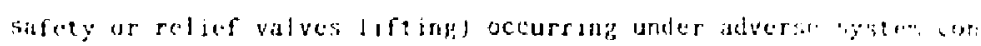

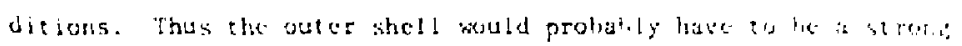

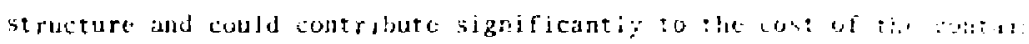

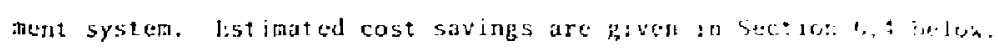

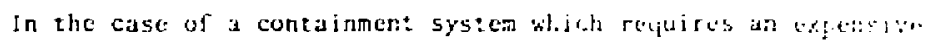

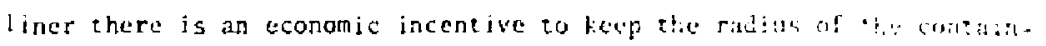
mont structure small: it is shown in Appendix 8 that for a gitill libiast of encrgy into the containaces, the cost of the stecl regujred for the pressure resistance purpose is virtually independent of rafius, hut the cost of the Iiner is approximately proportional to (radius)?

From the break-dokn of costs in Table 5.1 it can be shown thit il ten percent increase in radius of a steel lined containment vessel would ald about 0 percest to the cost of the structure. Nevertheless, cunsideration of access for inspection and repair necessitate sone minimum internal radius.

It is also shown in Appendix 8 that, if a stoel ressel is twployed for the pressure retaining role, there is likely to be an economic advantage in using a spherical vessel in preference to a cylindrical one and, in this case, the potentially cheaper design would provide 
Fore w. An impert * factor here is that the thickness of the sliell should he les. :han 1.5 in. so that stress-relief after fabrication in the fielel is not mandatory.

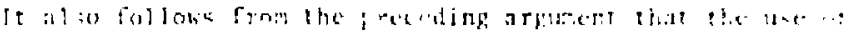

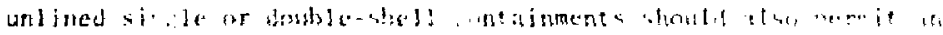

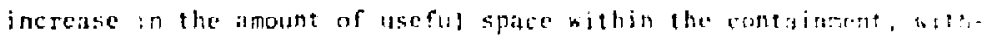

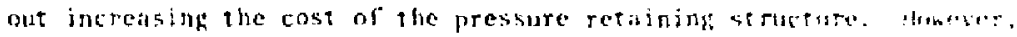
the increase in the dimensions of the ouser shell of at thethe wh tainment cauld add significantly to its cost, as the ?roport jon ar reinforcement $t u$ concrete would remain approximately constast. 


\section{References of Section 5}

(1) U.S. NRC Regulatory Guide 1.4, "Assumptians lised for Evaluat ing the potential Radiological Consequences of a loss of coolint Accident for pressurized Hater leactors," June, 1924 (ket: 0 -)

(2) "Capital Cest: Pressurized Water feactor plant," Silmti-1 211. $2477-\therefore$, lune, $[977$.

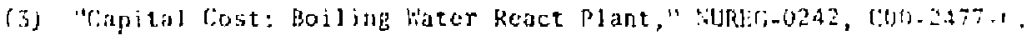
Junc, 1977.

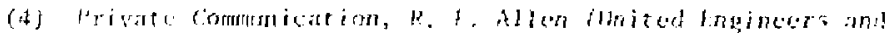

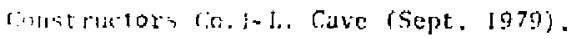

(5) Private communication, F. Cramer (Southern California foliem 6., ) L. rave (hug. 1979). 
5. Estimated costs cf some possible containment arrangements for PhR

relative to the standard 'dry" containment systum of Re'. I

6. Introdustion

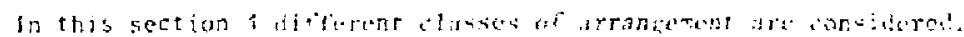

Thist ate as follows:

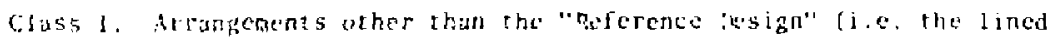
reinforced ebnerete shell of Ref, 11 alseady being used in If.S, reactors which should lead to reduced costs.

[ajs.5 2. Changes to existing arrangements, which could leari to a hjgher staldaic of perfornance that is required by Reg. Guide 1.4 (tef. $2 j$.

:lass 5 . Arrangenents currently in use in foreign reactors, but not in use in the U.S., which could lead to a significant reduction in cost while complying with the requirements of Reg. Guide 1.4.

Class 4. Arrangements, not currently in use in any commeristal reactors, which would lead to a substantial reduction in cost but would not necessarily meet the requirements of Reg. Guide 1.4.

ixamples of each of these classes are given below; the e. injatcd cost changes are showr as a percentage of the total containment cost (as est imated in Ref. 1), which is itself estimated to be about ien percent of the diret capital cost of the nuclear station.

(6.2) Eelative cost of licensed alternatives to the reference design

(6.2.1) Containment systens used in PlWR's now in operation, or under. construction in the U.S.

The following arrangzients are in use in plants licensed since 1968. (-.) "Dry" containments 
(i) Single mild steel (MS)-I ined,reinforced (RF) concrete shell (i.e. the "Reference Design'),

(ii) Single MS-1 ined,prestressed (PS) or crete shell.

(iji) Free-standing, stcel cylindrical vesse!, with surrounding sealcd or unseated shiclding seructure, or "silo".

(iv) Free stonding steel cylindrical vestel in a closed, unlined, moderate !eak-rate silo.

(v) Free standing, stecl, spheratal vessel with closed, unlined, moderate leak-rate silo.

(b) Ice condenser containment

(i) Free-standing steel cylindrical vessel, with clased, unlined, moderate leak-rate silo.

(ii) Single, MS-lined, RF concrete shell.

(6.2.2) Relative costs of the various "dry" containment arrangements

TVA have costs of single she!l, lined designs using both prestressed and reinforeed concrete and have coneluded that there is no significant difference in cost (Ref. 3).

TVA have also found that a plant with a low leak rate spherical steel vessel design, enclosed in an unlined concrete silo, is no note expensive than one with the Reference Design type of containment (Ref. 5) which suggests that the two types of containment are similar in cost. This conclusion was also reached by Duke Power Conpany, from their analysis of the extensive experience gained in West Gernany with this type of design (Ref. 4). Thus it appears that the free-standing spherical steel vessel has the advantage that the increased contro! over leakage which is ubtained by the use of the dual containment concept is secured without additional cost, wher as to provide the additional silo structure 
in the Reference Design would increase its cost simificantly viz:

Allowing a 4 feet annular space between inner and outer vessel would lead to an inger diameter for the silo of 148 feet, compared with 140 feet for the Reference design.

Scaling the cost of formwork and concrete as (radius) ${ }^{2}$, but reducing the proportion of reinforcement to concrete from 0.3 .3 to 0.2 (as in the silo for the Reference Design BWR) leads to a cos of about $\$ 9$ million for the silo, with the assumptions of Ref. 1 . This increment of $\$ 9$ million is about 25 percent of the cost of the Reference nesign "building structure" (A/C 1tem No. 212.1 of Ref. 1). Consequently, if there were a demand for higher performance, the use of a spherical steel vessel, with enclosing silo, should provide a cont inment system about 20 percent less expensive than the Reference nesign $p$. is an enclosing silo.

Although free standing cylindrical steel designs were used for the second generation of PWR's, these are not attractive for the large plants of the present generation, as the thickness of steel for the cylindrical portion is tow al to avoid the need for stress relief in the field, after fabrication, unless the radius is made excessively large.

\section{(6.2.3) Relative costs of "ice condenser" containment}

It is understood that the initial incentive for the development of the "ice condenser" was to reduce cost. From the point of view of the containment structure itself, the saving should be considerable, viz:

The radius of the cylindrical portion of the pressure retaining structure can be reduced to $57.5 \mathrm{ft}$. for a 1,100 $\mathrm{MW}(\mathrm{e}$ ) reactor (Ref. 5) at a design pressure of 28 psia. At this design pressure, cylindrical steel vessels, with separate silos, and single shell MS lined, concrete vessels are equally feasible. 
Using the data of lief. 1 , jt is found that the reduction in the cost of the containment super-structure (including MS liger or free stancin: steel vessel) as compared with the Reference Design, should be abuut $\$ 6$ million, or 18 percent of the total cost of the "building structure" (A/C Item No. 212.1) of the Reference Design. It bas not yet been possib]e to obtain data on the additional cost of the "ice condenser" itself but as the racks and baskets for the ice are "factory items" they should not add substuntially to the cost. Similarly, the chiller units required to maintain the jce are a standard industrial product. Overall it is likely that the additional costs would be between $\$ 1$ million and $\$ 2$ million. The conservative assumption has been made that the cost of the contuinment support systems would not be reduced; in practice the capacity and cost of the recirculating cooling system and the containment spray system could presumably be reduced.

Thas the net saving is probably about 15 percent of the total cost of the Reference Design. However, if the use of a plastic Iiner, in conjunction with a pre-stressed concrete shell, could gain acceptance in the US, the vet saring could be increased to about 25 percent. In order to nale use of a plastic liner, mears for preventing the long term sharp rise in pressure (See Ref. 5) would probably be necessary. The rise occurs when the last of the ice melts. It should be possible to achieve this by an increase in the concainment spray system capacity. That is, the use of the ice condenser pressure suppression systom could lead to savings similar to those obtainable with the Canadian high dousing rate pressure suppression system. (See Sec. 6.4.3, below) 


\section{(6.3) Minor modifications to licensed designs which could 1 ead to a}

higher standard of performance and/or lower cost

[6.3.1] Double she11 systems with improved control over annular leakage

In principle the double shell systems currently offered could give an improved perfomance over the single shejl designs, which are boing offered at the present time, since at relatively little additional cost the capacily of the recireulation and exhaust systems for the annual space between the shells could be increased substantially e.g., increasing the efficiency of the exhaust system filter by a factor of 3 should reduce the net leakage by a comparable factor, but it should not increase the total cost of the containment system by more than $\$ 0.5$ million (i.e., about 1 percent).

(6.3.2) Double shel1 systen with 1 ined inner and outer shel!s

By the use of an outer shell with a relatively low leak rate (see below) the in-leakage couId be reduced to a Ievel at which a "pump-baci" system, instead of an exhaust system, could be used to control the activity buildup in the inter-space for the first 48 hours, at least.

In principle the use of a pre-stressed outer shell with an elastomeric liner should be sufficient to redtce the in-leakage to Jess than 0.5 percent of the annular volume per day (See Section 4.1.5), whick should make pump-back feasible for at least 48 hours. Alternatively, in view of the doubts apparently entertained in the U.S. about the use of plastic liners, a mild-steel liner could be considered for the silo, as well as for the pressure retaining shell.

The additional cost of the elastomeric liner, extrapolated from Canadian experience, should be about $\$ 0.5$ million $\{$ i.e., about 1.5 percent of the "building structure" cost for the Reference Design] whereas 
the mild steel liner would add about 25 percent to the cost of the "building structure". In view of this Iarge difference in cost, further consideration of the effectiveness of a plastic liner in the less severe environnest provided by the annular space would be worthwile, if there were an interest in "pump-back" systems.

\section{(6.3.3) Partial dual containment systems}

A method for obtaining most of the advantage of a dual containment system at relatively little cost has been suggested by Stone and Webster Engineering Corporation (Kef. 6). The proposal is based on the concept that the greater part of leakage from a single shell containment structure is likely to uccur in the vicinity of the penetrations. As these can be lacated relativeiy near the ground level, and concentrated azimuthally, it is possible to provide dual containment in these areas at lower cost. Alematively, on sites where higher performance is particularly important (e.g. short distances to EAB OT LPZ) the same basic design can be adapted readily to full dual containment.

By utilizing the reactor buildings surrounding the lower part of the primary containment shell, which have to meet the same strength requirements as a containment silo, as the basis of the partial dual containment, the additional cost of reducing the leak rate to a sufficiently low level and providing the necessary filtered recirculation and exhaust systems would be unlikely to exceed $\$ 1$ million. Thus most of the benefits of a double shell system should be available for about 10 percent of the cost of the sealed silo required for a dual system, i.e., the higher performance could probably be attained at a cost of less than 3 percent of the containment "building structure" of Ref. 1 instead of 25 percent. However, this 
approach introduces a further element of commercial risk since, if a leak should occur in the "single shell" part, this might be difficult to locate, leading to a delay in reaching comercial operation.

\section{(6.3.4) Relaxation of leak rate requirements for mild steel 1 iners}

A further alternative approach, which could iedd to a significant reduction in the cost of double shell systems which embody a mild steel lined inner she11, is to accept a higher leak from the inner shell and to place greater reliance on the filtered recirculation and exhaust system provided to control activity in the annular space, as in the case of the Kewaunee and Prairie Island plants (See Section 4.1.5). For example, in the case of Kewaunee it was shown that the requirements of 10 CFR 100 could be met if the leak rate of the primary shell were as high as 2.5 percent per day at design pressure. At this level of leak tightness it should be possible to dispense with the "leak chasing" channels provided for each weld of a mild steel liner. The saving which might be made by this change is estimated to be about 15 percent of the cost of the liner, or about 4 percent of the cost of the "building structure" defined A/C No. 212.1 of Ref. 1.

(6.4) Some foreign containment systems with potential for cost reduction (6.4.1) Double containment using unlined inner and outer she11s

As shown below the modification introduced by the French uti]ity (Electricite de France, EDF) for their 1,300 $\mathrm{MW}(\mathrm{e}) \mathrm{PWR}$, embodying an inner, unlined, prestressed concrete shelI and a reinforced concrete outer shell, also unlined, seems unlikely to lead to a saving in cost, if used in the U.S., as compared with the "Reference Design". 
For an 1,100 BW(e) PWR with dry containment the major changes in the cost would be:

a) Elimination of liner of inner shell, saving $57.5 \mathrm{million}$

b) Introduttion of outer shell, or silo, adaling so million (See Section 6.2.2)

There would also be some increase in cost due to:

(i) Increased cost of penetrations, as "guard tubes" would be required in the anlular space.

(ii) Increased cost of foundations, due to greater area and substantial increase in loading.

(iji) lncrease in plant costs due to increased length of pipe sork and cabling.

t Sotc: Mlowance made for increase in cost of formkork, in absence of steel Iiner.

Thus in uS conditions it is likely that there would be an jncrase in cost of at least 5 percent, compared with the single shell, concrete clad Peference Design.

In practice EDF too have found that there is virtually no saving in theif conditions, and that decreased flexibility of the construction program, as compared with that for the single, lined shell system makes this approach unattractive (Ref. 7). However, a possible modification of this approach, which might be wtilized for U.S. sites where a single shell system might not meet JO CFR 100, can be visualized. This is discussed in Section 6.5 below.

(6.4.2) Use of low pressure systems ircorporating a vacuum relief vessel

If the Canadian systen described in the Section 4 above were applied in U.S. conditions to an 1,100 MW(e) PKR, the major changes in cost would be: 
(a) Removal of mild steel liner (less penetrations)

from reactor containment shell

saving $\$ 7.5$ milion (net)

(b) Reduction in reirforcement for reactor

containment shell from 0.33 tons per cubic

yard to 0.2 tons per cubic yard of concrete, saving $\$ 2.8$ million $\begin{aligned} & \text { (c) Addition of vacuum relief vessel, cost } \\ & \text { shared between several reactors }\end{aligned},\left\{\begin{array}{l}\text { additional cost, see } \\ \text { below. }\end{array}\right.$

(d) Addition of isterconnecting ducts,
duct isolating valves and control system, $\left\{\begin{array}{l}\text { additional cost, see } \\ \text { below. }\end{array}\right.$

The cost of the additionai items has been estimated as follows:

The vacuum buifding for a CANDU $500 \mathrm{NW}(e)$ PHWR has a free internal volume of $2.9 \times 10^{6} \mathrm{ft}^{3}$. The volume of each reactor containment shell is $1.8 x$ $10^{6} \mathrm{ft}^{3}$. These volumes are to cope with a large LOCA accompanied by loss of all the secondary coolant from one reactor. It is assumed that the reactor containment shells would be the same size as in the Reference design and that in the U.S. it would not be necessary to cope with the water from nore than one secondary loop, in addition to the primary coolart. As a first approximation a vacuum building with same free volume as the Pickering plant should be sufficient (i.e. $2.9 \times 10^{6} \mathrm{ft}^{3}$ ).

The cost of the vacuum building has been estimated as it it were an unitined silo building, except that allowance has been made for the stiffening effect of the internal reinforced concrete grid structure used in the Canadian design. It has been assumed that the total amount of reinforcement would be the same as in a U.S. containment silo of the same volume. These costs are est imated to be:

$\begin{array}{ll} & \pi=\text { million } \\ \text { vacuum building, substructure } & \$ 2.5 \mathrm{~m} \\ \text { " } & \$ 7.1 \mathrm{~m}\end{array}$




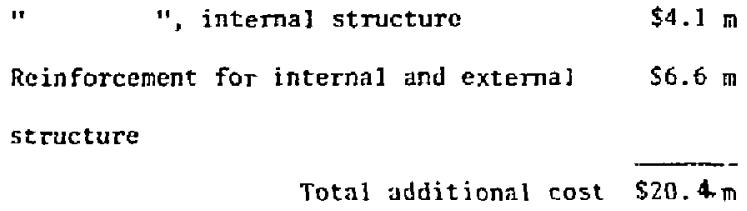

The inter-connecting ducts would require about 100 tons of steel per reactor: the cost of these tegether with the valves and the other items would be un]ikely to exceed $\$ 1 \mathrm{~m}, 1 . e$, it would be barely signjficast in comparison with the cost of the vacuum building.

Thus the additional cost to be set against the saving of slo million per reactor would be about $\$ 21$ million overall. Thus the: $:$ would be al saving only for stations with 3 or more reactors.

Overall, therefore, this Canadian system should provide a potentiai saving of about 11 percent of the total cost of the containment sysems of the Reference Design, for a 4-reactor station.

\section{$(6.4,5)$ Use of rapid dousing systems for pressurc suppression}

The Canadian concept, for single reactor stations, of extremely rapid condensation of steam released in a LOCA, permits the use of a plastic lined, low pressure containment building.

If the concept were applied to a U.S. 1,100 MW(e) PWR, the cost savings would be as follows:

$$
\text { m = million }
$$

Temoval of mild steel liner (less penetrations) Saving of $\$ 7.5 \mathrm{~m}$ (net)

Reduction in reinforcement from 0.33 tons/cu.yd of concrete to 0.2 tons/cu. $y d$. Saving of $52.8 \mathrm{~m}$ The additional cost of the plastic liner is estimated to be 0.5 million (See Sec, 6.3.2). The dousing system, per se, would probably cost no more than the conventional spray systen of a typical U.S. PWR, but 
carrying the weight of water at the top of the reactor building might slightly increise the cost of the structure. Overall it appears likely that a saving of about $\$ 10$ million per reactor $\{i, e$. , about 25 percent. of the total cost of the containment system of the "Reference Design") might he achieved.

(6.5) Estimated : its of some simple containment systems (6.5.I) Shielding structure with no retention or dousing capability

The structure visualized would be used simply to protect the reactor from external hazards such as tornadoes, aircraft and missiles from turbine break-up. To be fully effective as a shield, the building would have to be closed but to avoid having to design for high transient pressures in the event of a large LOCA it would a] so have to be vented. The cost can therefore be estimated in the same way as that of the "silo" described in Sec. 6.2.2, above, except that it need be no larget than the shell of the "Reference Design". Thus the cost of the shielding structure alone would be about $\$ 8 \mathrm{million}$, which would represent a saving of about $\$ 14$ million, or 35 percent of the total cost of the Reference Design containment system; there would be a further saving of about \$4 million on the support services which, in this hypothetical case, could also be regarded as superfluoic. Thus the upper limit to the possible raving is about $\$ 18$ million, or approximately 50 percent of the total cost of the Reference Design containment system.

(6.5.2) Vented containment (unfiltered)

The only substantial saving achieved by the use of the vented containment concept would be the reduction in cost of reinforcement and, if a lower performance were acceptable, the cost of a low leak rate mild 
steel liner (less the penetrations) as this could conceivably he replaced by a mild steel liner with a high leak rate, or by a plastic liner. It follows from carlier examples that the savings would be as follows:

$$
m=\text { million }
$$

with low leak rate steel liner $\$ 2.8$ m or $7{ }^{\circ}$ af Reference nesign Cost with high leak rate steal liner $\$ 4.6 \mathrm{~m}$ or $11 \%$ of Reference Design Cost with plastic liner $\quad \$ 10 \mathrm{~m}$ or $25^{\circ}$ of Reference Design Cost The cost of scme form of re-sealing vent yould have to be set against these savings; however this would be unlikely to increase tile cost by more than one percent of the total system cost.

\section{(6.5.3) Pressuts suppression systems}

As disulssed in Section 6.4.3, the maximun use of the pressure suppression concept, as in Canadian reactors, could lead to a reduction of up to 25 percent in the total cost of the containment system. In principie, there is no reason why a comparable saving should not be obtained with other pressure suppression systems, such as the "ice condenser" or a water pool in the base of the containment building. In both of these c:ses, the proportion of iodine in the containment atmosphere would be reduced to the order of 1 percent alnost inmediately and the low maximum overpressure could be brought down nuarly to atmospheric within a few minutes by a supplementary dousing system. In these circunstances, the combination of a pre-stressed concrete shell and a plasfic liner should limit the leakage rate to the order of 0.1 percent per day within a few minutes.

Taking the "ice condenser" of Sectiun 6.2.3 as an exampie, the saving, as compared with the total cost of the Reference Design containrent system could probably be increased from 15 percent to abnut 25 percent. 


\section{(6.5.4) Further exploitation of double shell concept, at low cost}

As noted in Sec. 6.3.1, the French experience has been that the use of the unlined double sheli containments concept does nut lead to any worthwhile saving. However, if pre-stressed concrete structures were used for hoth the inner and outer shells and both wert provided with plastic liners, it is likely that the leakgges into the annular space would be sufficiently low to permit the system to be operated in a "pump back" made for 2 or 3 days, at least, so that the discharge of rare gases to the atmosphere could be reduced. Thus at a cost about 7 pereent higher than that of the Reference Uesign, it should be possibje to abtain a marked improvement in performance, which would be useful if a utility wished to build a "no significant harm" reactor. If the pressure suppression concept were also employed the overall cost should be wirtually the same as that of t'e Reference Design. The use of the pressure suppression concept would also facilitate the use of plastic lining, as the temperatures within the containment would be substartially lower. 6.6 Spray cooling capacity as a factor in containment optimization

It is claimed for the CANDU single-reactor plants that the rapid dousing system provided is sufficient to arrest the rise ir. pressure witl:in the containment following a large LOCA ind to lirait the peak pressure to a few psi. It has not yet been possible to find a detailed analysis of the system in the published literuature but it appears that an initial flow rate of order $10^{5}$ gal, per min. is emplayed for 500 m (a) PIllis. Using this flow rate it is possible to determine whether the adoption of this concept in the Reference Design would be advantageous. In the Canadian designs, a high initial rate of cooling is achieved by the discharge of water from storage tanks located high up in the building, 
whereas it the US designs a pumped spray system has been preferred. This it is necessary to establish the cost of increasing substantially the capacity of the containment cooling system in the (IS system.

From Ref. I it has been found that 90 percent of the cost of the US containment spray system is attributable to pipemork and valves and 10 percent to the pumping equipment (i.e, about $\$ 0.5$ million). Given sufficient had from the pumps, it should he possible to increase substantially the rate of delivery from the existing pipework, thus a 10 -fold increase in flow rate would probably cost about $\$ 5$ milion.

The flow rate of the system costed in Ref. I is 6000 gaI. per min., thus in order to use the rapid dousing concept this would have to be increased by an order of magnitude; with a pumped system thjs would lead to a cost increase of about $\$ 5$ million. If the only gain were a reduction in design pressure of the containment structure, the change would not be worth while, 3s the maximum saving would be less than $\$ 3$ million, which could be achieved by a reduction in the quantity of reinforcement. However, if the Canadian practice of using a plastic liner were adupted, there could be an overall saving. However, this would be unlikely to exceed 10 percent of the total cost of the Reference Design.

0.7 Effect of the "Post-accident F11tration" concept on containment costs

In the usual scenatios for accident class 3 through 8 it is not visualize $d$ that containment pressures would rise beyond the design pressure level, singe it assumed that the various engineered safety systens will funcrion as designed.

Consequent $1 y$, with a remit to design for accidents no more severe than a well-conditioned large LOCA, the designer rould have no need to consider the provision of a post-accident filtration system (PAFS) such as that discussed in Ref. 8 , in the containnent. 
It should be noted that a PAF5 such as that described in Ref. 8 would not have sufficient capacity to reduce the initial maximum pressure within the containment to any significant extent and thus could not be used to reduce the design pressure and thereby reduce the cost of the containment structure.

\section{(6.8) Surninary}

The cost savings of some possible containment arrangements, expresset as a percentage of the total cost of the "Reference Design" containgent system for PWRs (Ref. 1), are summarized in Table 6.1 for single and double containments. 


\section{References of Section 6}

(1) "Capital Cost: Pressurized Water Reactor Plant," NURJ:G-0241, (:OO. 2477-5, June, 1977 .

(2) U.S. IRC Regulatory Gujde 1.4, "Assumptions used for Fvaluat 20 g the Potential Radiological Consequences of a l.OCA for PlR's," June, 1974 (Revised 2).

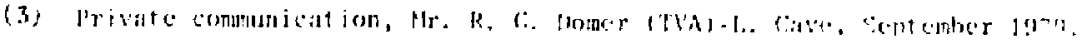

(4) Godfrey, A. D., Schabert, 11, P, and Loef, H, A, "The Spherical Contajment System for 1300 :AW(e) PWR's," Proc. of the Amer. I'awer Conference, Vol. 37,1975 .

(5) Final Safety Analyais Report of Watts Par Nuclear Plant, 1976.

(6) Kent, G. F. and hille, D. J., "Design and licensing of a Flexible Containment Approach," ANS transaction, Yol. 27, 1977.

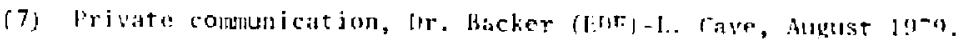

(8) B. Cosset, L. Cave, C. K. Chan, D. Okrent, and I. Catton, "PostAccident Filtration as a licans of Improving Contajnment liffectiveness," Proceedings of Topical Meeting on Thermal Reactor Safety, Silu lill liv. laiko, August, 1977 . 
Table 6.1 Possible Cost savings for PWR Containments,

expressed as a percentage of total cost of

Reference Design Containment (Ref. 2)

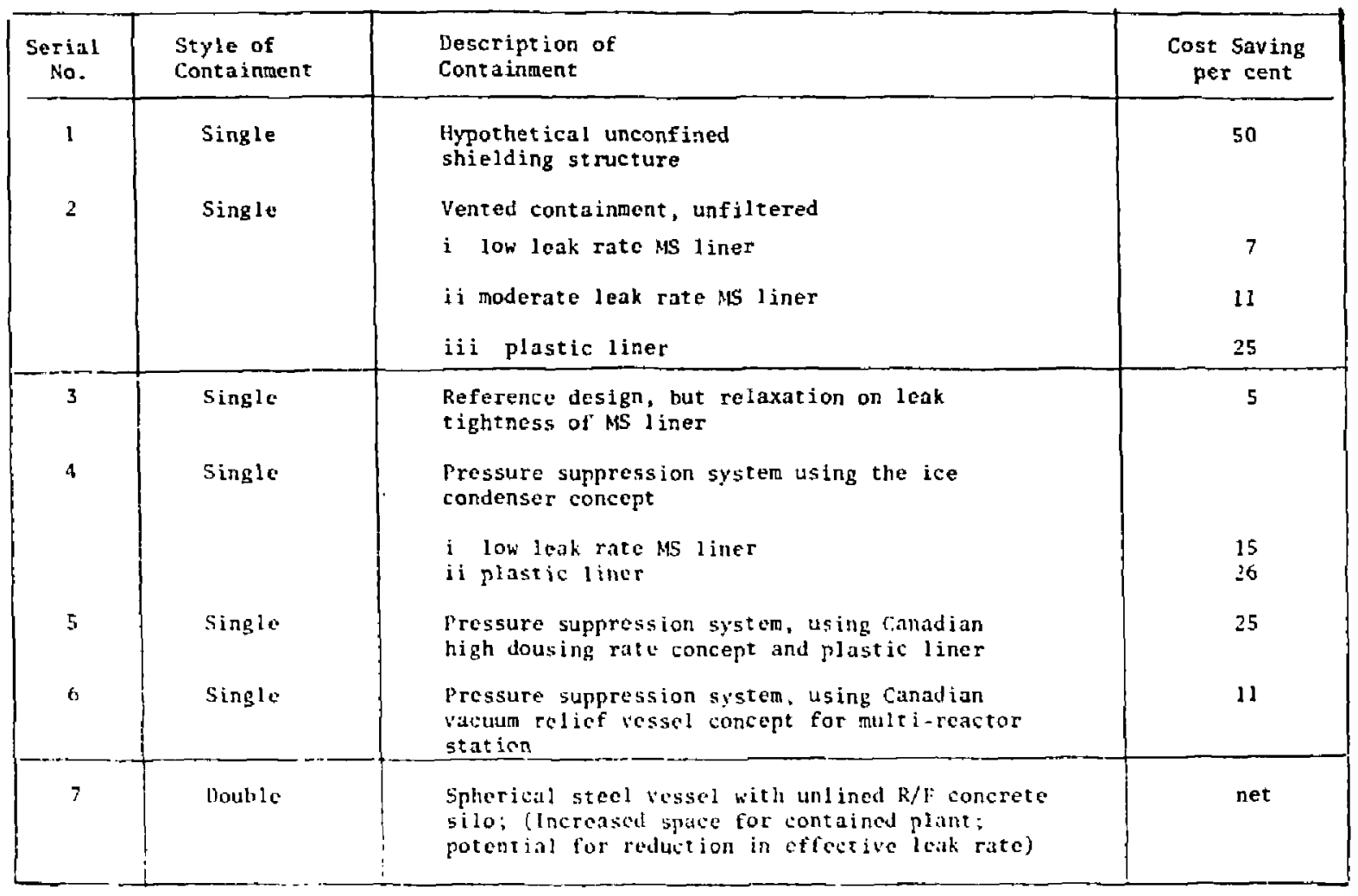


Tablo 6.1 (bont jnued)

\begin{tabular}{|c|c|c|c|}
\hline $\begin{array}{l}\text { Serial } \\
\text { No. }\end{array}$ & $\begin{array}{l}\text { Style of } \\
\text { Containment }\end{array}$ & $\begin{array}{l}\text { lhescription of } \\
\text { contajument }\end{array}$ & $\begin{array}{l}\text { Cost Saving } \\
\text { per cent }\end{array}$ \\
\hline 8 & $\begin{array}{l}\text { Double } \\
\text { Doubla }\end{array}$ & $\begin{array}{l}\text { As Serial vo. } 7 \text {, with plastic lined } \mathrm{M} / \mathrm{S} \text { concrete } \\
\text { bessel } \\
\text { Jnlined inner and outer concrete shells } \\
(\mathrm{P} / \mathrm{S} \text { and } \mathrm{R} / \mathrm{F})\end{array}$ & $\begin{array}{l}1 \text { to } 2 \\
\text { No saving in } \\
\text { U. S. conditions } \\
\text { (Increase of } \\
5 \text { per cent) }\end{array}$ \\
\hline 10 & Double & $\begin{array}{l}\text { Slast ic linet innet and outer } P / S \text { concrete } \\
\text { shells (Potential for use of pump-back } \\
\text { concept) }\end{array}$ & $\begin{array}{l}\text { (Increase of } \\
7 \text { per cent) }\end{array}$ \\
\hline 11 & Double & $\begin{array}{l}\text { Roference Design (Inner vessel, MS lined } R / F \\
\text { concrete) with unlined silo vessel } \\
\text { (Potential for reduction in effective leak rate) }\end{array}$ & $\begin{array}{l}\text { Increase of } \\
20 \text { per cent }\end{array}$ \\
\hline 12 & Partial & $\begin{array}{l}\text { Reactor building adopted to role of half-height } \\
\text { outer huilding } \\
\text { (Potential for reduction in effective leak rate) }\end{array}$ & $\begin{array}{l}\text { Inerease of } \\
3 \text { per cent }\end{array}$ \\
\hline 15 & Single & $\begin{array}{l}\text { Pressure suppression, using Canadian bigh dousing } \\
\text { rate concept with U.S. type pumped witer supply. } \\
\text { (i) with MS liner } \\
\text { (ii) with plastic liner }\end{array}$ & $\begin{array}{l}\text { Increase of } \\
\text { about } 5 \text { per } \\
\text { cent } \\
\text { Saving of about } \\
10 \text { per cent }\end{array}$ \\
\hline
\end{tabular}




\section{(7). Estimated costs of BWR containment}

The ERDA/NRC analysis of BWR capital costs (Ref. 1) shows that the tatal cost of the Mark III BWR/6 containment system is about 20 percent higher than that for a PWR "dry" containment of the same power output. These are no comparable cost data for the earlier types of BlWR containment (Mark I and Mark II), but from the jetailed discussion in Ref. 2 seems most unjikely that the vendnr would recommend the further use of the earlier designs.

Examinations of the cost make-up for the Mark III containment shows that a substantial proportion is attributable :0 the various items required for the interior concrete viz:

\begin{tabular}{lc} 
Stainless stecl plate & $\$ 1.2 \mathrm{~m}$ \\
Carbon steel plate & $\$ 1.0 \mathrm{~m}$ \\
(Sacrificial shield) & \\
Drywell/Weirwell liners & $\$ 5.2 \mathrm{~m}$ \\
\hline
\end{tabular}

Total $7.4 m$, or $20 \%$ of the total cost of the "building structure"

There is no mention of a need for these items in Ref. 2. Conceivably much less expensive plastic coatings could be developed for one or more of these liners. However, there has been no discussion in the nublished literature of this nossibility.

In the Mark IJI containment of the BWR, the jnner shell is in the form of a steel cylinder. This, in tum, is enclosed in an uslined reinforced concrete silo. The reasonsfor the choice of this arrangement are not clear, and appears to lead to an increase of about 7 percent in the cost of the complete containment system, as compared with the single, MS-lined concrete shell used for the Reference nesign of PWR. 
In view of the relatively low design pressure $(15 \mathrm{psig})$ and the early removal of a high proportion of the volatiles by the suppression peos, it might be possible to achieve an adequate performance witil a singis pro. stressed concrete shell, with a plastic liner, and an increase in the capacity of the containment spray system. It is estimated that the overall saving would be about 15 percent of the totel cost of the contajument system. Similarly, if it were necessary to employ the double containment concept, in order to improve the perfomance, the Reference besign would be about 15 percent more costly than an arrangenent based on two separate plastic-lined, pre-stressed concrete shells. 
References of Section?

(1) "Capital cost: Bailing hater Reacror plant," NUREG-0242, C00-2477-6, June, 1977.

(2) L. C. Koke, G, M. Roy and R. E. Brandon, "Optimizing the design of BWR Power Plants," Proceeding American Power Conference, 1972. 


\section{Discussion of Results}

The main points which emerge from this study are discussed in this Section. 8.1 Digree of conservatism in Reg. Guides 1.3 ind 1.4

If, as appeared to be the general belief prior to the Till-2 accident. the most severe accident for which the containment need be designed was a we1l-conditioned large LOCA, then feg. Guides 1.3 and 1.4 could be considered to be over-conservative. Since the TMI-2 accident this premise can no longer be sustajned, and can now be seen that less severe initiating events can lead to accidents in which the sourer terms are much iarger that had previously been expected.

Moreover, even before the TMI-2 accident, there was a growing appreciation by the electrical gemerating industry in the U.S. and in other countries that, in the face of mounting public resistance to nuclear power, it could be advantageous to be able to ciain that accidents to their reactors hould not cause any interruption of the public's actiytics. To justify this clain for accidents up to, and including, Class 8 would have required a standard of contaimment comparable with that needed to meet the requirements of Reg. Guides 1.3 and 1.4.

\subsection{Scope for re-optinization of containment systems in the U.S.}

A simple cost-benefit approach, based on the "expectation of loss" princinle, suggests that there should be no need of containments for LiRrs. lowever, it seems so unlikely that this basis for optinization would be acceptable in the U.S. this approach has not been pursued further in this study. In U.S. conkijtions the cost of the containment system for a 1140 MP(e) PHR is about 10 per cent of the total cost of the plant (i.e. about $\$ 70$ million at 1979 prices); however, it should be noted that this figure 
includes the cost of all the reactor support and shielding structures. In the U.S., even if there were no requirement for a containment per se, the need to provide a shielding strueture proof against earthquakes and tornadoes, together with the other support and shielding roles, would Iimit the maximum achievable saving to about 50 per cent of the total cost of the containment system, or about 5 per cent of the total plant cost. Thus, an upper limit to the achievable saving is about $\$ 35$ million, in 1979 prices. 8.3 Most promising means for reducing containmont costs in PhiRs

It seems unlikely that overall leak rates of more than 0.1 per cent per day, by volume, will be acceptable. The most promising methods for securing a substantial reduction in cost without sacrificing performance depend on decreasing the design pressure of the primary containment structure and obviating the reed for a leak-tight steel liner which does not contribute to the strength of the structure.

The possible configurations which would meet these objectives falls into three classes:

Class 1. Use of a steel vessel as the pressure retaining envelope.

Class II. Use of pressure suppression systems to lower the design pressure and to reduce the post-accident working pressure rapidly to such low levels that low leak rates can be achieved without the use of stcel liners or

Class IIi. Use of the double containment concept to reduce the overall leak-rate in systems embodying the features of Class $I$ and/or Class 1I.

Unfiltered venting of the containment, to reduce the peak pressure, is a possible alternative to pressure suppression in Class II but offers so little additional advantage in cost that it is an unattractive solution. 
The alternative objective, that of achieving a higher standard of performance without a significant increase in cost, is more likrly ta ise achieved at joinimum cost by further exploitation of the double containter concept, with the aim of using it in the "pump-back" mode rather than in the "extract" mode.

\subsection{Sunmary of results of optimization study for PkR containnent}

The rost promising individual schemes for reduction in cost of contisinent, without a reduction in performance, are:

Class 1. IJsc of stcel vessel as the pressure retaining envelope. In practice this upproach is mainly of walue as a basis for a double she1l containment system at minimum cost (see belok), rather than for saving cost in situations where a single shel] system can provide adequate performance. However, the use of the spherical steel shell offers some advantages that cannot be expressed in economic terms, in the form of more space for plant items, at no increase in cost.

Class II. Pressure suppression systens. Partial exploitation of the concept, as in the Westinghouse ice containnent design, leads to a saving of about 15 per cent of the Ref. 1 system cost whilst retaining the conventional MS Iiner. However, about 40 per cent of this saving is attributable to the redurtion in containment vessel dimensions, which introduces economically unquantifiable disadvantages. Full exploitation of the concept, as in the Canadian high dousing rate design, should permit the use of a plastic liner, in conjunction with a pre-stressed concrete shell, giving a saving of about 25 per cent of the Ref. I system cost. 
Thus the same percentage saving would be achieved as that estimated for the Canadian systen, although in the latter case the disadvantages of reduced space are avoided, as it has been asstmed that the dinensions of the containment vessel would be the same as in Ref. 1 . It should be noted that at the present time it is not entirely clear whether the difficulties encountered with the limited number of ice containments in operating reactors are of a gereric nature or are readily remediable design errors. 1t should be noted that a verted containment system (unfiltered), which can be regarded as a more primitive form of pressure suppression, is also estimated to give a 25 per cent saving, if a plastic liner is used, without reducing the dimensions of the containment vessel.

of these 3 pressuce suppression systems the Canadian one night prove to be the most acceptahle, as it provides full retention of the initial containment atmosphere but yields the same saving as the ice condenser without having to reduce the space available for plant itens. However, full substantiation of the pressure/time behavior of the system is not readily available in the U.S. $z^{+}$the present time. The use of pumped systems to provide high rate dousing, which would be more in accordance with U.S. practice is estimated to be substantially more expensive than the Canadial gravity fed system and would not be economically viable. One outstanding query to be resolved in relation to the use of pressure suppression systems for PHRs is that of the effect of the reduction in back pressure on the ECCS. However, as the total cost of the Safety Irjection System and Residual Heat Renoval system is only 15 per cent of the total cost of the containment system, a substantial increase in injection capacity or pumping capacity should not have a major effect on costs. 
Class 111. Use of double contaimont concept to improve performance and/ or reliability.

Ir situations where high performance and reliabilit: of performares are required the double contajnent concept should have a substantial advantage over single shell systams.

The use of a spherical steel shell for the inner vessel, in cunjunction with a plastic lined pre-stressed concrete outer shall, should provide this advantage at an insignificant increase in cost, as compared with the puf. 1 design. Similarly, the use of two plustir lined pre-stressed conerete. shells is a possible alternative, but would lear! to : significant increase in cost (about 7 per ce:t). Obviously designs based on the use of a stecl lined inner concrete shell and a plastie-lined, outer, prestressed conerete shell would also be sat isfactory, but these are estinated to be some 2 ; per cent more expensive than the Ref. l dosign. It is of interest that, in. fact, in a number of plants this additional cost appears to have been incurred, on the grounds that it would provide an additional margin of safety in meeting the requirements of Reg. Guide 1.4 .

\subsection{Mast promising means for reducing containment costs in Bliks.}

As all BWR containment systems are based on the pressure suppression concept it follows, from the discussion in Sec. 8.3 above, that there is less scope for re-optinization than in the PWR system. Nevertheless it may be possible to achieve a reduction of $15 \mathrm{per}$ cent of the total cost of the containment system (equivalent to 17 per cent of the total cost of the Plik containment system of Ref, 1), by the use of a single, pre-stressed concrete shell, with plastic liner, and increased containment spray capacjty in preference to the double shell arrangement (inner steel shell and outer reinforced concrete silo) of the Ref. 2 design. In situations where a 
higher standard of perfornance and reliability is required a couble containment system based ol the use of two plastic-1ined, pre-stressed concrete shells would cust about the same as ti.e arrangement described in Ref. 2 .

There is also the possibility of a substantial reduction in cost, up to 15 per cent of that of the total system, if alternative means rould be found for protecting the interior concrete structures.

\subsection{Reconnendations for further work}

Although this study has shown that there is scope for changes in existing contaimment desizns which could lend to substantial reductions in cost (up to 25 per cont of total cost of containment system) mast of thesc changes would requje further divelopment work. Belure emoarking on a development program it would be desirable to address two othe: questions. These are:

(a) What effect will the TMI-L accident have on the requircments for containment desigh, e.g., will there be a requirement to design for accidents more severe than Class 8 ?

(b) Is there sufficient incentive for utilities to seek savings of up to 25 per cent of the cost of containment systems (about $\$ 15$ million per reactor, at 1979 prices) to justify the cost of th? development which would be required?

Some useful work could be carried out in telation to both of these questions, viz: evaluation of the suitability of those systems which of fer most promise of a substantial cost reduction as a basis for more accidentresistant designs. Examination of the factors likely to effect utility decisjons on containment requirements in the future, including the attitudes of both regulators and utilities to the use of quantified risks as a basis for design decisions. If it appears worthwile to continue the generic development of containnent systems in order to reduce costs and/or inprove 
their resistance ta severe accident conditions, areas which should be given high prinrity are:

1. Analysis of the relative reliabilities of pressure suppressictiat: presstre-retaining containment systems, in order to confirm that further development of pressure suppression systems will not prove to be ibortive on grounds of inadequate reliability.

2. Analysis of the operating and pre-operational experience with ice-containments in U.S, and elsewhere, in order to establish whether the difficulties encountered to datc are inherent in the concept or are due to specific and remeciable design faults.

3. Analysjs of the pressure-time response in the Canadian high dousing rate pressure suppression system, in order to define a program of test work, if this should be necessary.

4. Review of $U_{+} S$. and other data relating to the leak rates of large pre-stressed concrete sholls and review of the effects of plastic liners as a means of reducing the leak rate of such structures, in post-accident conditions, from

(a) Single shell pressure suppression containuent systems.

(b) Inner and outer shells of double pressure retaining containment systems.

5. Fxamination of possible methods for reducing the cost of protecting interior concrete structures of BhR containments.

In each of these 5 areas the maximum severity of the accident conditions to be designed for would have to be defined at the start of the program. The develofment of the detailed program of work aimed at cost reduction woula also have to take account of the progress of work related to the improvement in resistance to more severe accidents, which it is assumed would be continuing in parallel. Fortunately, one of the more likely additional 
requirements, the provision $u t$ a post-accident filtered venting system, would be unlikely to inter-act strongly with the most promising methods for cost reduction. 


\section{References of Section 8}

(1) "Capital Cost: Pressurized Water Reactor Plant," NUREG-0241, Co0$3477-5$, June 1977 .

(2) I. C.. Koke, fi, M. Roy and R. I. Brandon, "gptimizing the design of BWR fower Planis," Proceeding hmericin Power conference, 192. 


\section{Conclusions}

There is scope for the reduction of containment systens costs of up to 25 per cent in both PWRs and Biks, without sacrificing present performance standards.

Prior to the TMI-2 accident it might have been argued that the present performance standards were unduly severe, so that somewhat greatcr savings might have been achieved. This now appears to be unlikely. Further work will be required to establish whether the impact of the TM1-z aceident will prevent the achievement of any significant cost savings. In this context the effects of the TMI-2 accident on both the regulatory body and the utilities have to be taken into account.

Achievement of reductions of more than 2 or 3 per cent of present PWR containment system costs depend on the use of pressure suppression; it is estimated that existing "ice containment" designs provide a 15 per cent reduction. If plastic liners for pre-stressed concrete containment shells could be developed to a point at which they would be acceptable in the U.S., this cost reduction could be increased to about 25 per cent. A similar reduction should be achievable by the use of the Canadian rapid dousing system of pressure suppression in conjunction with plastic Iined pre-stressed concrete containment shells. The Canadian system has the advantage that the cost reduction could be achieved without reduc:ng the space available within the containment. If plastic liners became acceptable in the U.S., savings of up to 15 per cent of BWR containment system costs should be possible. Further savings by the use of alternative lining materials for interior concrete are also possible. As an alternative to cost reduction whilst retaining present performance standards, there may also be a demand for higher performance without an increase iл cost. 
Double containment systens (using plastic lined, pre-stressed concrete outer shells and either similat inner shells or spherical steel shells) should be capable of meeting this requirement, jncluding control of the rare gases emissions, by utilization of the "pump-back" principle. It is possible to define the main elements of the technological development program. required to justify changes that would lead to the cost reductions described above. However, whether or not the utilities would have a need for such a program is uncertain at the present $t$ ine, owing to the effects of the TMI-2 accident. Severtheless, some specific areas of work to assist in resolving this uncertainty have been identified. Some prelininary work 10 identify the effects of the TMI-2 accident on containment design requirements has also been identified; as an outcome of this work a need for additional fuatures in the containment design (e.g. a post-accident filtercd venting system) may be identified. This preliminary hork should also have as one of its objectives, a clear definition of the coublitions within the containment on which the design of the system should be based. 
Appendix 1. Assumpticns used in Reg. Guide 1.4 for evaluating the potential radiological consequences of a loss of coolant accident for pressurized water reactors.

The assumptions related to the release of radioactive material from the fuel and containment are as follows:

(a) Twenty-five percent of the equilibrium radio-active iodine inventory developed from maximus fuld power operation of the core should be assumed to be immediately available for leakage from the primary reactor containment. Ninety-one percent of this 25 is to be assumed to be in the form of elemental iodine, $5 \%$ of this 258 in the form of particulate iodine, and $4 \%$ of the $25 \%$ in the form of organic iodides.

(b) One-hundred percent of the equilibrium radioactive noble gas inventory developed from the maximun full power operation of the core should be assumed to be imnediately available for leakage from the reactor containment.

(c) The effects of radiological decay during holdup in the containment or other buildings should be taken into account.

(d) The reduction in the amount of radioactive material available for leakage to the environment by containnent sprays, recirculating filtar systems, or other engineered safety features may be taken into account.

(e) The primary containment should be assumed to leak at the leak rate incorporated in the technical specifications for the duration of the accident. The leakage should be assumed to pass directly to the energency exhaust system without mixing in the surrounding reactor building atmosphere and should be assumed to be released as an elevated plume for those facilities with stacks.

Acceptable assumptions for atmospheric diffusion and dose conversion 
are:

(a) The $0-8$ hour ground level release concentration may be reduced by a factor ranging from one to a maximum of three (Ses Fig. A1.1) for additional dispersion produced by the turbulent wake of the reactor building in calculating potential exposures. The volumetric buildine wake correctinn, as defined in section 3-3,5.2 of Meteorology and Atornic Energy 1968, should be used only in the $0-8$ hour period; it is used with shape factor of $1 / 2$ and the minimum cross-sectional area of the reactor building only.

(b) No correction should be made for depletion of the effuent plume of radioactive iodine due to deposition on the ground, or for the radiological decay of iodine in transit.

(c) The breathing rate of persons offsite should be assumed to be those given in ICRP publication 2, Committee II-1959 as follows:

$\begin{array}{cc}\begin{array}{c}\text { Time Period } \\ \text { (Hours) }\end{array} & \begin{array}{c}\text { Brequthing Rates } \\ \left(\mathrm{M}^{3} / \mathrm{sec}\right)\end{array} \\ 0-8 & 3.47 \times 10^{.4} \\ 8-24 & 1.75 \times 10^{-4} \\ 24-720 & 2.32 \times 10^{-4}\end{array}$

(d) The iodine dose conversion factors should be assumed to have the Values given in 1CRP Publications 2, Report of Comittee II, "Permissible Dose for Internal Radiation," 1959. These are as follows: lodine Dose Conversion Factors

Isotope

$1-131$

$1-132$

I -133
Ren-Thyroid/Curie Inhaled

$1.48 \times 10^{6}$

$5.35 \times 10^{4}$

$4.00 \times 10^{5}$ 
Isotoge

$1-134$

$1-135$
Res-Thyroid/Curie Inhaled

$2.50 \times 10^{4}$

$1.25 \times 10^{5}$

(e) External whole body doses should be calculated using "infinite cloud" assumptions i.e., the dimensions of cloud assumed to be large compared to the distance that the gamma rays and beta particles travel. Under these circumstances the rate of energy absorption per unit volume is equal to the rate of energy released per unit volume. For an infinite uniform cloud containing $X$ curies of beta-radioactivity per cubic meter the beta dose in air at the cloud center is:

$$
B_{\infty}^{D_{\infty}^{\prime}}=0.457 \quad \bar{E}_{B} X
$$

The surface body dose rate from beta enitters in the infinite cloud can be approximatei as being one-half this amount (i.e., $\mathrm{g}_{\infty}^{\prime}=0.23$ $\left.\overline{\mathrm{E}}_{B} \mathrm{X}\right)$. For the gamma emitting material the dose rate in air at the cloud center is

$$
B_{\infty} D_{\infty}^{\prime}=0.507 \bar{E}_{\gamma} X
$$

From a semi-infinite cloud, the ganma dose rate in air is

$$
r_{B}^{\prime}=0.25 \vec{E}_{\gamma} x
$$

(f) The following specific assumptions are acceptable with respect to the radioactive cloud dose calculations:

(1) The dose at any distance from the reactor shouId be caIculated based on the maximutn concentration in the plume at that distance, taking into account specific meterological, topographical, and other characteristics which may affect the maximum plume concentration. In the case of beta radiation, the receptor is assumed to be exposed to an infinite 
cloud at the maximum ground level concentration at that distance from the reactar. In the case of gamma radiation, the receptor is assumed to be exposed to only one-half the cloudowing to the presence of the ground. The maximum cloud concentration always should be assumed at ground Ievel.

(2) The appropriate average beta and gamna energies emitted per disintegration, as given in the Table of Isotopes, Sixth Edition, by .). M. Holjander, 1. Perlman should be used.

(g) The atmospheric diffusion model should be as follows:

1. The basic equation for atmospheric diffusion fron a ground level point source is:

$$
x / Q=\frac{1}{\pi \sigma_{y} \sigma_{z} \overline{4}}
$$

whetc

$$
\begin{aligned}
X= & \text { the shart term average centerline value of the ground level } \\
& \text { concentration (curie/meter }{ }^{3} \text { ) } \\
Q= & \text { amount of material release (curie/sec) } \\
\vec{u}= & \text { wind speed (meter/sec) } \\
\sigma_{y}= & \text { the horizontal standard deviation of the plume (meters) } \\
& \text { [See ligure } V-1, \text { Page } 48, \text { Nuclear Safety, June 1961, Vol, } 2, \\
& \text { Numer } 4, \text { "Use of Routine Meteorological observations for } \\
& \text { Estimation Atmospheric Dispersion," F. A. GIfford, Jr.] } \\
\sigma_{2}= & \text { the vertical standard deviation of plume (meters) [See the same } \\
& \text { reference for } \sigma_{y} \text { ] }
\end{aligned}
$$
assumed to meander and spread uniformly over a $22.5^{\circ}$ sector. 
The resultant equation is.

$$
X / Q=\frac{2.032}{\sigma_{z} \vec{u} x}
$$

3. The atmospheric diffusion model for an elevated release, as a function of the distance from the reactor, is based on the information in the table below.

Time Following

$0-8$ hours

$9-24$ hours

1-4 hours

4-30 days

\section{Atmospheric Conditions}

Pasquill Type F, Wind Speed 1 meter/sec, uniform direction

Pasquill Type F, Windspeed 1 meter/sec., variable direction within a 22.5 sector.

a) 40\% Pasquill Type D, Windspeed 3 meter/sec.

b) 60\% Pasquil1 Type F, Windspeed $2 \mathrm{~m} / \mathrm{sec}$.

c) Wind direction variable within a 22.5 sector.

a) 33.3\% Pasquill Type C, Windspeed $3 \mathrm{n} / \mathrm{sec}$.

b) 33. 35 Pasquill Type D, Windspeed $3 \mathrm{~m} / \mathrm{sec}$.

c) 33.3\% Pasquill Type F, Windspeed 2 to/sec.

d) Wind direction 33.3 frequently in a 22.5 sector.

4. Figures Al.2(A) and Al.2(B) give the ground level release atmospheric diffusion factors based on the parameters given in $\mathrm{g} .3$. 


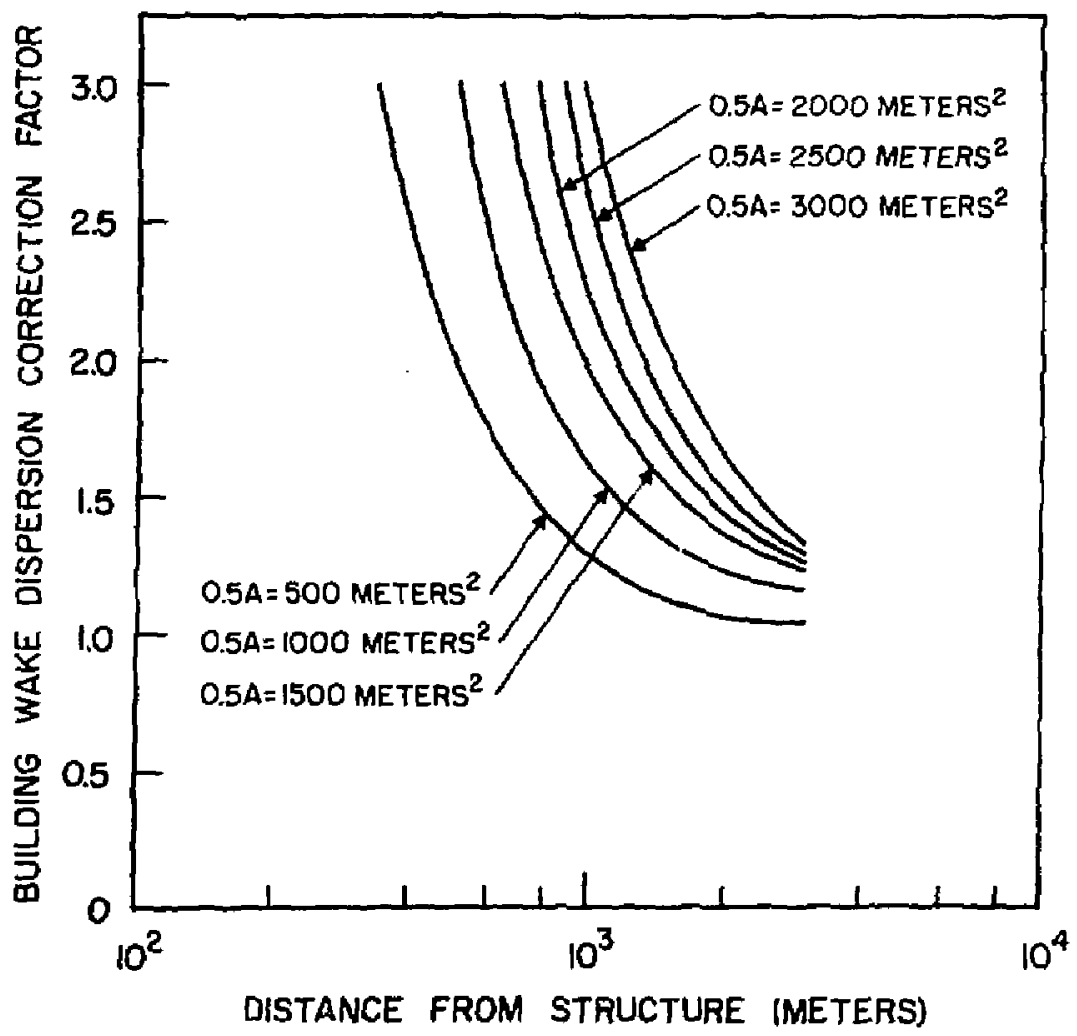

Fig. Al.l Building Wake ltispersion Correction Factors 


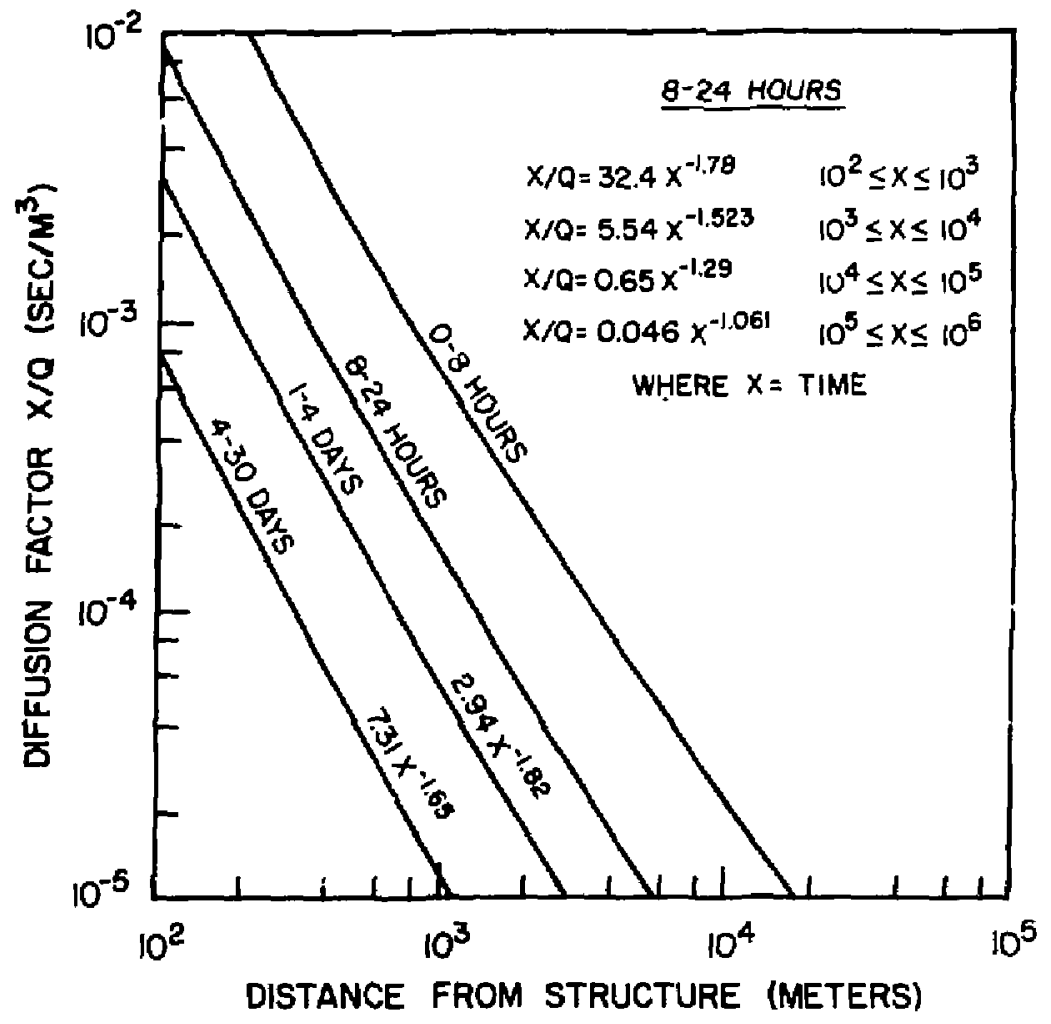

Fig. Al.2(N) Ground level Relcase Atmospleric Diffusion Factors for Various times Following Accidents 


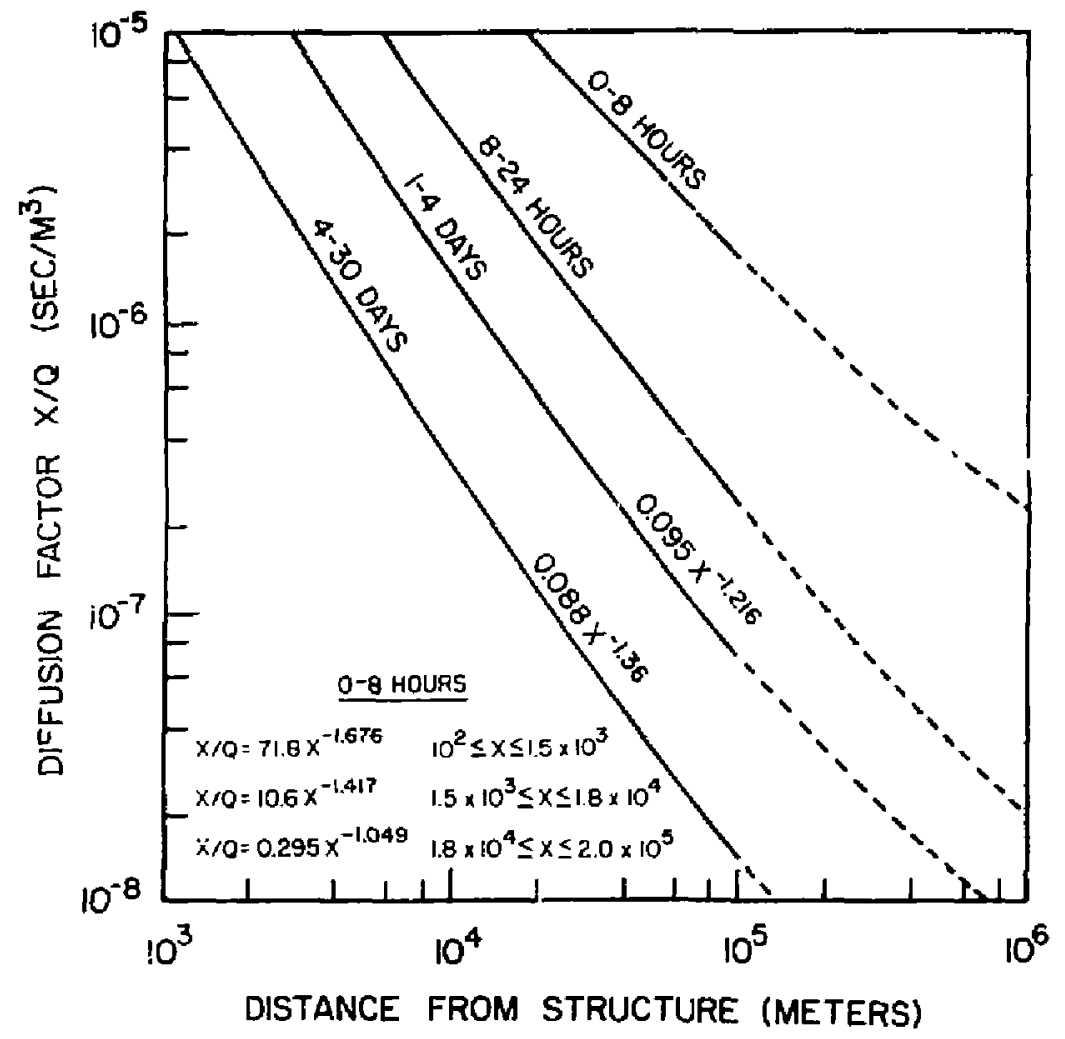

Fip. AJ.2[B] Cirotund level Release Atenospheric laiffusion

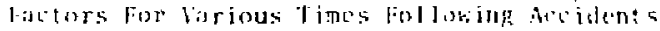


Appendix 2 Accident Assumptions Used in Discussion of Accidents in

Environmental Reports (Reg. Guide 4.2)

Accident 2.0 SMALL RELEASE OUTSIDE CONTAINMENT

These releases shall include such thing: as releases through steamline relief valves and simall spills and leaks of radioactive materials outside containment. These releases shall be included and evaluated under routine releases in accordance with proposed Apperdix I. Accident 3.0 RAONASTE SYSTEM FAIl,URE

3.1 Equipment leakage or malfunction (includes operator error)

(a) Radioactive gases and liquids: $25^{\circ}$ of average inventory in the largest storage tank shall be assured to be released.

(b) Heterojogy assumptions: $x / Q$ values are to be $1 / 10$ of those given in NRC Safety Guide No. 3 or 4.

(c) ronsequences should be calculated by weighting the effects in different directions by the frequency the wind blows in each direction.

3.2 Release of waste gas storage tank cortents (includes failure of release valve and rupture disks)

(a) $100 \%$ of the average tank inventory shall be as.umed to be released.

(b) Meteorology assumptions: $X / Q$ values shal 1 be $1 / 10$ of thase given in Safety Guide No. 3 or 4.

(c) Consequences should be calculated by weighting the effects in different directions by the frequency 
the wind blows in each direction.

3,3 Release of 1 iquid waste storage tank contents

(a) Radioactive liquids: $100^{\circ}$ of the average storage tank inventory shall be assumed to be spilled on the floor of the building.

(b) Building structure shall be assuned to cenain intiact.

(c) Meteorology assumptions: $x / Q$ va]ues shall be $1 / 10$ of those given in NRC Safery Guide No. $\overrightarrow{3}$ or 1.

(d) Consequences should be calculated by heighting the efrects in different directions jy the irequency the wind blows in sach direction.

Accident 4.0 FISSION PRODUCTS TO PRIMARY SYSTEM (BiR)

4.1 Fuel cladaing defects

Release from these events shall be included and evaluated under routine releases in accordance with proposed Appendix 1 .

4.2 off-design transients that induce fucl failures above those expected (such as flow blockage and flux maldistribations).

(a) $0.02 \%$ of the core inventory of noble gases and $0.02{ }^{\circ}$ of the core inventory of halogens shall be assumed to be relsased into the reactor coolant.

(b) One percent of the halogens in the reactor coolant shall bt assumed to be released into the steanline.

(c) The mechanical vacuum pump shall be assuned to be 
automatically isolated by a high radiation

signal of the steamline.

(d) Radiosctivity shall be assumed to carry over to the condenser where $10 \%$ of the halogens shall be assumed to be available for leakage from the condenser to the environment at $0.5 \%$ day for the course of the accident ( 24 hours).

(e) Meteorology assumptions $x / Q$ valtues shall be $1 / 10$ of those given in NRC Safety Guide No. 3 dated November 2, 1970.

(f) Consequences should be calculated by weighting the effects in different directions by the frequency the wind blows in each direction.

Accident S.0 FISSION PRODUCTS TO PRIMARY AND SECONDARY SYSTENS (PRESSURIZED WATER REACTOR)

5.1 Fuel cladding defects and steam generator leak release from these events shall be included and evaluated under routine releases in accordance with proposed Appendix 1.

5.2 Off-design transients that induce fuel failure above those expected and steam generator leak (such as flow blackage and flux maldistributions).

(a) $0.02 \%$ of the core inventory of noble gases and $0.02 \%$ of the core inventory of halogens shall he assured to be relcased into the rcactor coolant.

(b) Average inventory in the primary system prior to the transient shall be based on operation with $0.5 \%$ failed fuel. 
fe Secondary systen equilihriat radiuactiti: prior to the transiene shal be based on a $20 \mathrm{gall}$ day stcain generator leak and a 10 gpm blowdonn rate.

(d) All noble bases and 1). d" of the hilogens an the

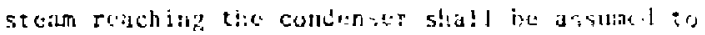
be releaged by the comenser air ejector.

(e) Hetcrology assumptions $/ 2$ yalues should be $1 / 10$ of those given in sile Safety luide io. .t.

(f) Consequences should be calculated by weishting the offeces in Jifferent directions hy the Ercencency the wind blows in each direction.

5.3 Stean generatos tube rupture

(a) $15^{\circ}$ of the average inventory of nobic gases and halogens in the primary coolant shall be assumed to be reicased joto the secondary coolant.

The average primary coolant activity shall be hased on $0.5 \%$ failed fuel.

(b) Equilibrium radioactivity prior to rupture shad be based on a 20 gullon jer day stean generator leak and a jo gpa slondoun rite.

(c) All noble gases and 0.13 of the hajogens in the stean reaching the condenser shall be assumed to be released by the condenser ajr gjector.

(d) Metcrology ussumptions: i/l walues shald be 1/10 of those given in XRC Safety Guide No. 4.

(c) Consequences should be calculated by weighing the effects in different directions by the 
frequency the wind blows in each direction.

Accident 6.0 Refueling Accidents

6.1 Fuel bundle drop

(a) The gap activity (noble gases and halogers) in one rok of fuel pins shall be assumed to be released into the water. (Gap activity 19 of total activity in a pin.)

(b) One week decay time before the accident occurs shall be assumed.

(c) Iodine decontamigation factor in water shall be 500 .

(d) Charcoal filter efficiency for iodines shall be $99 \%$.

(c) A realistic faction of the containment volume shall be assumed to leak a the atmosphere prior to isolating the containment.

(f) Metcorology assumptions $x / Q$ values shall be $1 / 10$ of those given in NRC Safety Guide No. 3 or 4.

(g) Consequences should be calculated by weighing the cffects in different directions by the frequency the wind blows in each direction.

6.2 Heavy obinct drop onto fuel in core

(a) The gap activity (noble gases and halogens) in one average fuel assembly shall be assumed to be released into the water. (Gap activity shall be $1 \%$ of total activity in a pin.)

(b) 100 hours of decay time before object is dropped shall be assumed. 
(c) lodine decontamination factor in water shald be 500 .

(d) Charcoal filter efficjency for iodines shall be $99 \%$.

(c) A realistic fraction of the containment volume sha!! he assumed to leat to the atmosphere prior to isolating the containmen:

(f) Me*corolopical assumptions: i/l values shall be $1 / 1$ th $^{2}$

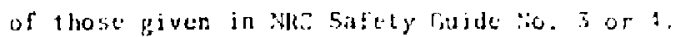

(g) Consequences should be calculated by weighting the erfects in different directions by the frequency the will blows in each direction.

Ace ident 7.0 Spent Fuel Handling Acciden:

7.1 Fued asseratly drop in fuel storage pook.

(a) The gap activity (noble grises and halogens) in onu row of pins shall be assumed 10 be rejeased into th. water. (Gap activity shall be 1 to of tal activity in a pin.)

(b) One week decay tine before accident occurs shall be assumed.

(c) Jodine decontamination factor in water shall be 500 .

(d) Charcoal filter efficiency for iodines shall be 99 a.

(c) Sieteorology assumptions: $\chi / Q$ values shall be $1 / 10$ of those given in NhC Safety Guide No. 3 or 4.

(f) Consequences shall be calculated hy wighting the effects in different directions by the frequency the wind blows in each direction. 
7.2 Heavy object drop onto fuel rack

(a) The gap activity (noble gases and halogens) in one average fuel assembly shall be assuned to be released into the water. (Gap) activicy is 1 n. of total activity in a pin.)

(b) 30 days decay time before the uecident otcurs shall be assumed.

(c) Iodine decontamination factor in water shall be 500 .

(d) Charcoal filter efficiency for iodines shall be $99 \%$.

(e) Hetcorology assumptions: $/ / Q$ values shall be $1 / 10$ of those given in NRC Safoty Guide No. 3 or 4.

(f) Consequences should be calculated by weighting the effects in different directions by the frequency the wind blows in each direction.

\subsection{Fuel cask drop}

(a) Nobje gas gap activity from one fully loaded fuel cask (120-day cooling) shall be assumed to be released. (Gap activity shall be $1 \%$ of total activity in the pins.)

(b) Meteorology assumptions $-x / Q$ values shall be $1 / 10$ of those given in NRC Safety Guide No. 3 or 4. 
(c) Consequeness should he calculated by keighting the effuets in different directions by the frequency the wint blows in rach direction. 
Appendix 3. Fission product gas release from thermal reactor fuel

Appendix 3.1 Introduction

The principal objective of defining the source term is to determine the quantity of radiologically significant fission products released from defected l, liR fuel rods under accident conditions. One of the fission product release terms for a reactor loss of coolant accident (LOCA) is the rapid escape of gaseous activity that occurs when fucl claddings first rupture. The rapid depressurization of the ruptured rods sweeps out the fission products that have accumulated in the gas gap and the gas plenum during the nomal operating period of the fuel rods. This release term is frequently referred to as the gap release component. Analytical techniques have been developed by different laboratories for estimating the magnitude of release. These techniques, which depend upon different mathematical models or different interpretations of experimental release duta in making gap release data, have been developed independently by different labosatories as discussed below each section.

Below about $1,900^{\circ} \mathrm{K}$, the main gas release mechanism in $\mathrm{UO}_{2}$ is a fission gas atom diffusion-like process. However, this process which is zemperature dependent does not make a significant contribution at temperatures less than $1300^{\circ} \mathrm{K}$. Below that temperature there are two other processes which are of some significance in the surface layer of the fuel and which are temperature independent. These are described as "recoil" and "knock-out" mechanisms and are dependent on the kinetic energy of the fragments formed by fission. However, because of the only Iimited range of these effects (about $10 \mathrm{Hm}$ ) their contribution to the tatal fission product release from LWR fuel is neglible. Above about 


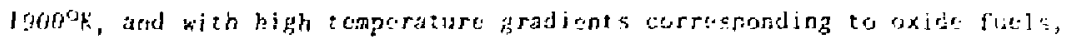
several other release mechanisms, which tend to faver still-hipher

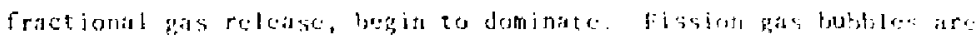

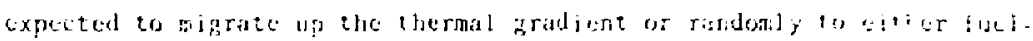

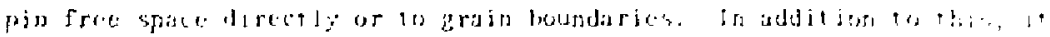

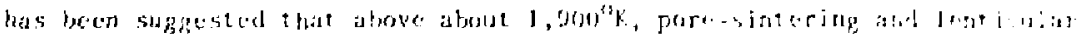

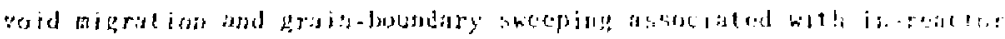

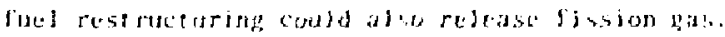

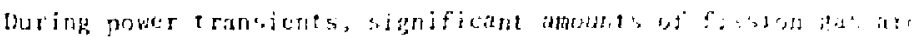

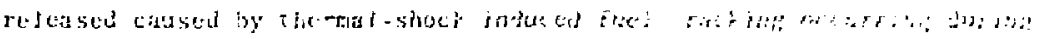

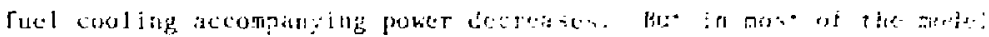

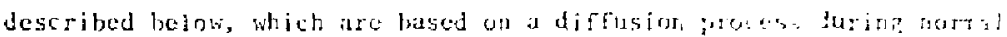

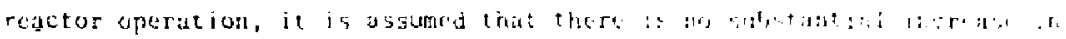
fuel temperature furing accidents.

The various models for the diffusion precess and at fold batary cmpiricil model are deseribed in the fo] jowing itctions. 
Appendix 3.2. BCL's model (Battelle's Columbus laboratories) ${ }^{(1)}$

In this model, it is assumed that the fission products migrate through the fuel by a diffusion process during reactor operation, and are released to the rod gap and plerum spaces by escape from external surfaces, surface-connected cracks, or surface-connected porosity. The equivisent sphere madel origially proposed by Booth ${ }^{(2)}$ and discussed by lustman (3) constitutes the basis for calculating release from the sintered $\mathrm{VO}_{2}$ characteristic of water reactor fuels. The sintered fuel, although near theoretical density, contains some interconnected porosity which effectively increases the surface area for release of fissiun gases. Ir. the equivalent sphere approach, the fuel body is considered to be composed of spherical particles of uniform size whosc surface to volume ratio is equivalent to the actual surface area to fuel volume ratio of sintered material. Solutions for the appropriate diffusion equations for a sphere in which production and decay of the diffusion product are taken into account have been obtained by Beck ${ }^{(4)}$ and these are used directly in the REGAP computer code developed at Battelle-Columbus.

The differential equation which describes the diffusion gas from a sphere is

$$
\frac{\partial C}{\partial t}=\frac{D}{r} \frac{\partial^{2}(x C)}{\partial r^{2}}+B-\lambda C
$$

With boundary conditions: $c(0, t)=$ finite

$$
c(a, t)=0
$$

initial condition: $C(r, 0)=0$

where

$$
\begin{aligned}
& c=\text { concentration } i \pi \text { the sphere, atoms per } \mathrm{cm}^{3} . \\
& D=\text { diffusion coefficient. } \mathrm{cm}^{2} \text { per sec. }
\end{aligned}
$$




$$
\begin{aligned}
& B=\text { production rate, atoms } / \mathrm{sec} / \mathrm{cm}^{3} . \\
& Y=\text { decay constant, } \sec ^{-1} . \\
& t=\text { time, sec. } \\
& r=\text { radial coordinate in the spherc. } \mathrm{cm} . \\
& a=\text { equivalent }- \text { spherc rndius, cri. }
\end{aligned}
$$

The rate of release $(R)$ is found from the concentration gradient at the out "r surfice and for a unit volume of the solid is given by

$$
\mathbb{k}=\frac{3 D}{a}\left(\frac{\partial C}{\partial r} \mathbf{r}=a\right.
$$

The accumulation of a fission product external to the solid can be cisiculated by considering the rate at which it is released and the rate at wich it decays:

$$
\frac{d N}{d t}=R-\lambda N
$$

where $x$ is the accumulation of undecayed relcase atoms from a unit volume of sphere (atoms per $\mathrm{cm}^{3}$ ). Beck ${ }^{(4)}$ restated the probiem in terms of dimonsionless variables and obtained the following solution:

$$
\begin{aligned}
& r=3 \cdot \frac{1}{\sqrt{u}} \operatorname{coth} \sqrt{u}-\frac{1}{u} ; i-\exp (-u) j \\
& -\frac{6 u \exp \left(u z_{j} ;\right.}{n^{2}} \sum_{n=1}^{\infty} \frac{1-\exp \left(-n^{2} \pi^{2} j\right)}{n^{2}\left(n^{2} n^{2}+u\right)}
\end{aligned}
$$

where

$$
\begin{aligned}
& G=\frac{N}{B / \lambda}=\text { the ratio of non-decayed atons outside the sphere } \\
& \text { at any tine to the total non-decayed atoms in the } \\
& u=\frac{\lambda^{2}}{D} \\
& 5=\frac{D t}{a^{2}} \\
& D=D_{0} \exp (-Q / R T)
\end{aligned}
$$




$$
\begin{aligned}
& \mathrm{D}_{0}=\text { limiting diffusion coefficient, } \mathrm{cm}^{2} \text { per sec, } \\
& Q=\text { activation energy for diffusion, cal per g-mole. } \\
& R=\text { gas constant, cal/(deg) (g-mole) } \\
& T=\text { absolute temperature, deg } K .
\end{aligned}
$$

For reactor operating tines that are long with respect to the half-life of a radioative fission product, $G$ approaches the equilibrium value:

$$
G_{r a}=\xi^{\prime}(1 / u)-\operatorname{coth} v-1 / u !
$$

For stityse fission-product species, the release is expressed in terms of the rutio of the amount released to the anount produced. Thus,

$$
G=I=\frac{\Omega}{\mathrm{B} t}=1-\frac{1}{15 i}+\frac{6}{\pi^{4} \zeta} \sum_{1}^{\infty} \frac{\exp \left(-n^{2} i^{2} r\right)}{n^{4}}
$$

The first five terms of the summation are usually sufficient to obtain an accurate value for $G$.

The diffusion coefficients $D$ are obtined from the Arrhenius expressions as a furction of temperature by specifying the limiting diffusion coefficient $D_{0}$ and the activation energy for diffusion. Of course, these vajues are different for each fission product chemical element. Extensive experimental work has been done over the past two decades, mainly directed at the noble gas elements krypton and xenon, to determine the fundamental $D_{0}$ and $Q$ values for $\mathrm{UO}_{2}$ fuel. Most of the work has involved post-irradiation laboratory heating experiments although some effort has been spent on extracting diffusion coefficients from the results of inpile $\mathrm{UO}_{2}$ irradiation studies. In this model, the basic diffusion parameter data were obtained from fission product release results reported by Parker, et al. (5) for trace irradiated $\mathrm{UO}_{2}$. The fuel temperatures that are needed for the calculation of 
diffusion cocfficients ase obtained by solving a one-dimensional radial heat conduction equation for a representative set of fuel pin positions.

A serjes of calculations was performed in which the values of various paracters were changed to exanine the effect on relcase predicions.

The anges of viriations of parameters were considured to represcht the app rimate degres of uncertainty in the avallable input data is I though the ariation in lo, values could also be interpreted as an estinat: of post he effect of fuel birnup on the release rates. The best ertimate Vall s for the series of parameters are cousicted to bo the followifn:

(a) Gap conductance $=1000 \mathrm{Btu} / \mathrm{hr} \cdot \mathrm{Ft}_{\mathrm{t}}{ }^{2}-{ }^{3} \mathrm{~F}$.

(b) $110_{2}$ thermal conductivity $=1.2 \mathrm{Btu} / \mathrm{hr}-\mathrm{St}+\mathrm{F}$.

(c) Equivalent sphere radius $=0.00613 \mathrm{~cm}$.

(d) The do paracter = The values in Tabl: 10 of reference 6 .

The fission product relcase results olstitined using the kianp code wit] best escimate perameters are lisied in Table A3.1 \& A3.2. 
Appendix 3.3 ANC's model (Aerojet Nuclear Company) (7)

The methods used here are based on a concentration equation for fission product diffusion which assumes that the driving force fir diffusion of fission products is the gradient of the chemical potential of the diffusion particles, ${ }^{(8)}$ H. Yuill has incorporated this idea into his models for calculating fission production diffusion, (9-12)

The concentration balance equation in cylindrical coordinatc is (B)

$$
\frac{d c}{d t}=P(r)-2 C\left(r, t j+\frac{1}{r} \frac{d}{d r} r \frac{D C}{R T} \frac{d u}{d r}\right.
$$

where

$$
\begin{aligned}
& C(r, t)=\begin{array}{c}
\text { concentration at radial position } r \text { at tiac } t \text { of some } \\
\text { particular fission praduct (mols/cc). }
\end{array} \\
& P(r)=\text { production of the fission product at } r \text { (mols/cc-sec.) } \\
& \lambda=\text { decay constant for the fission product } \\
& D=F i c k ' s \text { law diffusion constant for the product }\left(\mathrm{cm}^{2} / \mathrm{sec}\right) \\
& u=\left[\frac{\partial G}{\partial C}\right]_{T}=\text { chemical potential for the fission product. The } G \text { is } \\
& \text { the Gibbs free energy }[\mathrm{Cal} / \mathrm{mol} / \mathrm{cc}] .
\end{aligned}
$$

Evaluation of the expression (DC/RT) $\left(\frac{d u}{d r}\right)$ which appears in equation ( 7 ) necessitates some approximation. First it is assumed tirat it may be approximated by the ideal equation.

$$
u=u^{O}(T)+R T \ln C .
$$

The equation for diffusion current is

$$
J=-D^{\prime} \frac{d u}{d r}=-D^{\prime}\left[\left(\frac{\partial u}{\partial T}\right) c \frac{d T}{d r}+\left(\frac{\partial u}{\partial c}\right) \frac{d c}{d r}\right]
$$


If there were no temperature gradients, this would reduce to Fick's law.

Using (au/ac) $\mathrm{T}$ from equation (8), this yields

$$
D^{\prime}=\frac{D C}{B T} \text {. }
$$

To apply equation (7) requires a knowiedge of (iv/at)e, b and dT/by throughout the pin. The temperature gradient $\mathrm{JT} / \mathrm{dT}$ can be calculated from a knowledge of the heat generation within the pin and the heat conductivity kc(l) as a function of temperature. This is readily accomplished if it is assumed that ke depends only on temperature and is not seriously a zected by such structural changes as may occur within the $\mathrm{UU}_{2}$ pellet due to the marked temperature changes between the boundary and interior.

The diffusion oefficient $D$ is assumed to have a temperature dependeree given by

$$
\mathrm{D}=\mathrm{Do} \exp (-\mathrm{Q} / \mathrm{RT})
$$

Data on Do and $Q$ for noble gases are iucorporated into FPFH code. (12) Data for (au/JT) $c$ are available only for $\mathrm{C}_{S}$ and $\mathrm{Sr}^{(11)}$. Because of this the releases of noble gases and their iodine precursors are calculated using a correlation wich is partly based on equation (7) and partly empirical.

In calculating recase of long-lived noble gases and iodines, Yuill, et. al. (11) developed $e$ uations based on the steady state form of equation ( 7$)$, with $d C / \mathrm{d}:=0$. For stable gases $(\lambda=0)$ they cast their equation into the form (S:). 


$$
\ln (1-F)=-\frac{e^{-Q / R T_{b}}}{b^{2} T_{b}} e^{\left(A+B G+C G^{2}\right)}
$$

where $F=$ release fraction

$\mathbf{b}=$ pellet radius $(\mathrm{cm})$

$\tau_{b}=$ boundary temperature of pellet $\left({ }^{\circ} \mathrm{K}\right)$

$Q=$ activation energy for Fickian diffusion as in equation (10)

$G$ = heat rating $=\int_{T_{b}}^{T_{0}} \quad k_{c} d T=\frac{\bar{z}}{4 \pi}$

$\bar{P}_{z}=$ watt $s / \mathrm{cm}$ in pin

$k_{c}=$ heat conductivity (watts/cm. ${ }^{\circ} \mathrm{c}$ )

A, B, C are constants derived from analysis of capsule data. In cylindrical coordinate, the heat conduction equation is

$$
\frac{\partial}{\partial r}\left(r k_{c} \frac{\partial T}{\partial r}\right)=-\frac{T_{b}}{T b^{2}} \omega(r) \times r
$$

Where $\bar{p}_{2}$ is the average linear rating (watts/cm) and $\psi(r)$ is a function to take account of the variation in production rate with position $\gamma$. Thus in order to apply equation (11) to an actual reactor account must be taken of the lower distribution.

Yuill has shown that the release fractions for short-lived isotopes is proportional to $1 / \mathrm{h}$. Following Yujll's suggestion, the assumption has been made that the release of $8.05 \mathrm{~d} . I^{131}$ is the same as for its $x^{131}$ daughter. Then the release of all other noble gases and iodines wit. half lives shorter than $8.05 d$ are calculated from

$$
F_{m}=F_{x e} 132 \frac{x I^{131}}{\lambda_{m}}=F_{x e^{131}} \frac{t_{m}}{t_{I^{131}}}
$$


In equation (13) $t_{1}^{13]}$ and $t \pi$ refer to the half lives of $I^{131}$ and the species $m$, respectively. The equation is applied for noble gases or iodinc.s for which $t_{n}+t_{1}^{13]}$.

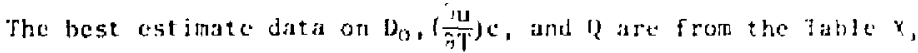
reforence 11 .

$$
\begin{aligned}
& 1_{0}=8.53 \times 10^{-9} \mathrm{~cm}^{2} / \mathrm{sec} . \\
& \left(\frac{\pi u}{j l}\right)_{c}=5 \text { cas } / \mathrm{mol}-\mathrm{deg} \text {. } \\
& Q=6300 \mathrm{cal} / \mathrm{mol} \text {. }
\end{aligned}
$$

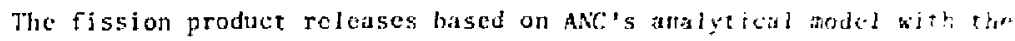
specified input data. (7) describing the phe and thk operating conditzon:, arc listed in tablo A3. I F A.3.2. 
ARpendix 3.4 Parker's model ${ }^{(13)}$ (ORNL)

In ordex to formulate a direct determination of gap release of the various fission products, extersive use was made of both the experimentally determined relative diffusion rates for different elements from early ORNL work, as well as an empirically detemined absolute relation between tenperature and the diffusion paraneter $0_{i}^{\prime}$ (0 prira, empirical) by Lorenz at ORNL (Ref. 14) based on a series of Canadian Capsule experiments in which only xenon and krypton were measured. The ORNC data, like most experimental data, are derived from so called annealing type experiments which roust be critically evaluated for the initial burst contrihution as has been done by $0 i$ and Tajake (Ref. 15) and by Lorenz and Creek (Ref. 16).

Percent release vs. temperature values were taken initially from Fig. 6.3 of ORNL Report 3981 (Ref. 17) and the release values were used to compute $D^{\dagger}$ (D-prime) values according to a method originally derived by Booth and Ryner ${ }^{(18)}$. They write:

$$
F=1-\frac{6}{\pi^{2}} \sum_{n=1} \frac{1}{n^{2}} \exp \left(-\pi^{2} n^{2} j^{i} t\right)
$$

where

$$
\begin{aligned}
& F=\text { fraction release } \\
& t=\text { time in seconds at temperature. }
\end{aligned}
$$

Reliable approximations of equation (14) are possible.

(i) when $F \geq 0.77$

$$
F=1 .-\frac{6}{\pi^{2}} e^{-\pi^{2} D^{\prime} t}
$$

(2) when $\mathrm{F}<0.7$

$$
F=6\left(D^{\prime} \tau / \pi\right)^{1 / 2}-30^{\prime} \tau
$$


The computed $D^{\prime}$ values were plotted as $D^{\prime}$ versus $10^{4} / T$ and fitted to a straight line by the method of least squares. This gave the expression:

$$
\ln D^{\prime}=a+B\left(10^{4} / T\right)
$$

or

$$
D^{\prime}=A e^{B}\left(\frac{10^{4}}{T}\right)
$$

where $T=$ absolute temperature and $\ln (A)=a$. The constant are listed in Tahlo A3.3.The diffusion parameters (D's) were also adjusted for burnup by a correction, $k$, as follows:

$$
D^{\prime}=D_{0}^{\prime} \exp \left[2.303\left(\frac{M W D / T}{25000}-1\right)\right]=D_{0}^{1} K
$$

\begin{tabular}{|c|c|}
\hline$(\mathrm{M} D / T)$ & K \\
\hline 5,000 & 0,158 \\
\hline 15,000 & 0.398 \\
\hline 25,000 & 1.000 \\
\hline
\end{tabular}

where $D_{O}^{\prime}=$ diffusion cocfficient calculated from the reference experimental data,

The D's derived from the ORNL experimental data were empirically normalized to those for $25,000 \mathrm{M} / \mathrm{W} / \mathrm{T}$ burnup, by comparison of the cenonkrypton data from numerous other measurements (Refs. 19,20,21) of the relation between gaseous release and burnup at constant temperature. A simple conputer code, so called DIREL ${ }^{(13)}$, sumarizes the fractional release of twenty principal nuclides using the thermal profile predicted by the thermal analysis code "Little Mamu". (13\} In addition use has been made in DIREL of the following approximations:

(a) The maximum fission product inventory that a reactor may have should reoccur at the end of any equilibrium cycle. In a typical thirdyear fuel replacement scheme, the average time of irradiation would be 
two cycles or about 650 days. This value affects mainly the longlived or stable nuclides.

(b) The average burnups for fuel in the outer, middle, and center thirds of a reactor core are assumed to be about $5000,15,000$, and 25,000 $\mathrm{MHD} / \mathrm{T}$, respectively, at the end of ar equilibriun cycle.

(c) Diffusion coefficients for diffusion products increase by a factor of 10 every $15,000 \mathrm{MhD} / \mathrm{T}$ burnup (Ref. 6).

(d) Thermal conductance across the cladding gap is assumed to range between 500 and $1000 \mathrm{BTU} / \mathrm{hr} / \mathrm{pt}^{2}$. The outer one third and half of the center one third are assuned to be unrestructured and to conform to the Lower conductance.

For thermal analysis, a fuel rod is divided into nine equal lengths. Seven tomperature values are given for seven points along the fuel radius of each length. In the gap release computer progran DIREL:(1) a D-prime for each activity is calculated for each of the seven temperatures using equation (18); (2) F (fractional release) values, at equilibrium, are computed using the $D$ ' values according to:

$$
F=3(\operatorname{HD} / \lambda)^{1 / 2}
$$

when $\mathrm{T} \leq 400^{\circ} \mathrm{C}, \mathrm{F}=\mathrm{D}$ and $W=$ correction factors. If $\lambda$ is less than $2 \times 10^{-8}$, then the isotope is considered to be stable and $F$ is computed according to

$$
F=4\left(k D^{\prime} t / \pi\right)^{1 / 2}
$$

(3) the seven values of "F" are averaged; (4) steps 1 and 2 are repeated for renaining eight lengths of fuel rod in axial directions; (5) the nine "average F" values are averaged to produce the "fuel rod release"; and (6) the average release is computed for the eight regions specified and 
then

$$
\text { Total release }=\sum_{i=1}^{8}(\%) \text { release }{ }_{i} \text { VFi X PFi }
$$

where VF = volume fraction and $P F=$ power factor.

The final release estimates, including effects of the gap release coefficient escape fraction are Iisted in table A.J G A.3.?. 
Appendix 3.5 R. A. Lorenz, et. al's model (ORNL) (22)

Experiments performed at Oak Ridge National Laboratory with fission product simulants and with irradiated light-water reactor (LWR) fuel have been employed ta develop semi -empirical molels of fission product release fron the defected LWR fucl rods. This model has been developed for estimating the source term models required for analysis of cesium and iodine release during a PWR-LOCA.

The models for fission product release in steam are based on tests conducted over the tempexature range $500\left(^{\circ} \mathrm{C}\right)$ to $\left.1200{ }^{\circ} \mathrm{C}\right)$, One series of tests, the Implant Test Series (23 25), employed simulated fission praducts which were coated on unirradiated $\mathrm{UO}_{2}$ fuel pellets; a second series, the Low Burnup Fuel Test Series ${ }^{(26)}$, used fuel caysules irradiated to $1000 \mathrm{MkD} / \mathrm{T}$ at high heat-rating ( 560 to $660 \mathrm{w} / \mathrm{om}$ ); and a third series of experiments, the High Burnup Test Series ${ }^{(27-31)}$, used fuel irradiated to $30,000 \mathrm{MWD} / \mathrm{T}$ in the $\mathrm{H.B}$. Robinson reactor at law-heat rating (175 to $320 \mathrm{w} / \mathrm{cm})$.

The models assume that the release is the sum of two components: burst release (that carried oul with escaping plenum gas when the rod ruptures), and diffusional release (that diffusing from gap spacc after the plenun gas has vented).

The mass of cesium which escapes as "burst release" was found to be equal to the volume of plenum gas vented, multiplied by the concentration of cesium in vapor form. Cesium concentration in the vented gas has been determined to be a function of absolute temperature and the total inventory of cesium in the gap space as estimated from multiplying the radioactive inventory source by the gap release fraction. 
In the temperature range 973 to $1273^{\circ} \mathrm{K}$, cesium burst releasi can be expressed as

$$
M_{B}=V_{B} \frac{C^{0.8}}{7.74} \quad \exp \left(6.06-\frac{7420}{T}\right)
$$

where

$$
\begin{aligned}
\ddot{A}_{B}= & \text { mass of cesium released in the burst, }{ }_{\mathrm{g}} \mathrm{Cs}, \\
v_{B}= & \text { volume of plenium gas vented, } \mathrm{cm}^{3} \text { at } 0^{\circ} \mathrm{C} \text { and system pressures } \\
G= & \text { inventory of cesium in the pellet-cladding gap per unit } \\
& \text { area of cladding, } \mu_{\mathrm{g}} \mathrm{Cs} / \mathrm{cm}^{2} \text {, and } \\
T= & \text { temperature at rupture iscation, } k .
\end{aligned}
$$

A simple depletion equation is used to rodel cesium released by diffusion in stean over the temperature range 500 to $1200^{\circ} \mathrm{C}$,

$$
r_{D}=H_{0} 1-\exp \left(-\frac{R_{0} t}{N_{D}}\right)
$$

where

$$
\begin{aligned}
H_{D}= & \text { mass of cesium released by diffusion, }{ }_{g} C_{s}, \\
M_{0}= & \text { total calculated mass of cesiun initially in the gap, } \\
& \mu_{g} \mathrm{Cs}, \\
t= & \text { time at diffusion temperature, } h r \text {, and } \\
R_{0}= & \text { initial rate of release of cesium by diffusion, }{ }_{g} \\
& \mathrm{Cs} / \mathrm{hr} .
\end{aligned}
$$

The initial rate of release by diffusion, $\mathbb{R}_{0}$ in turn, is given by

$$
\mathrm{R}_{0}=\left[\frac{11}{200}\right]\left[\frac{\mathrm{C}^{0 . B}}{7.74}\right]\left[\frac{0.101}{\mathrm{P}}\right]\left[\exp \left(19.96-\frac{19,810}{\mathrm{~T}}\right)\right]
$$

where

$$
\begin{aligned}
& \bar{W}=\text { width of radial gap, um, and } \\
& \mathrm{P}=\text { system pressure, } \mathrm{MPa} \text {. }
\end{aligned}
$$

The madel for release of iodine follows the same pattern as for cesium. The iodine burst release in the temperature range 973 to $1173^{\circ} \mathrm{X}$ is expressed as 


$$
M_{B}=V_{B}\left[\frac{G^{0.8}}{1.15}\right] \quad \exp \left(1.09-\frac{3770}{T}\right)
$$

The release of iodine by diffusion in the temperature range 500 to 1200 ${ }^{\circ} \mathrm{C}$ is given by Eq. (24), but Ro for iodine is given by

$$
\text { Ro }=\left[\frac{11}{200}\right]\left[\frac{G^{0.8}}{1.15}\right]\left[\frac{0.101}{\mathrm{P}}\right] \exp \left(15.3-\frac{14,800}{\mathrm{~T}}\right)
$$

These modeIs were applied to the analysis of a PWR LOCA in which the reactor characteristics were assumed as follows: 33,000 fuel rods, each containing $2500 \mathrm{~g}$ of $\mathrm{UD}_{2}$ and operated so that equal numbers of rods had average burnups of $10,000,20,000$, and $30,000 \mathrm{khO} / \mathrm{T}$. The fuel rods were divided into six groups, each containing the amount of released fission gas shown in table $\mathbf{3}$.4. Since the fuel rods would rupture near their centers, the cesium and iodine gap inventories were based in peak burnups estimated to be $10 \%$ higher than the above average burnups. It was further assumed that all fuel rods ruptured and experienced a temperature transient to $1200^{\circ} \mathrm{C}$ for an effective time of 10 minutes.

The diffusion equation ${ }^{(1)}$ predicts that the fractional release of radioactive isotopes from the fuel to the plenium and void spaces will be less than for stable isotopes. For small fractional releases, typical of the PWR taken as an example (but not typical of the WASH-1400 PWR), the reduction is inversely proportional to the square root of the decay constant for isotopes reaching production-decay equilibrium. The magnitude of the reduction also depends upon the irradiation time, but release by knockout is essentially independent of half-life.

This model is believed to satisfactorily predict "best-estimate" cesium and iodine release from full length fuel rods in steam provided 
the range of temperatures, times, and gap inventories employed in the tests is not exceeded. This model employed for the estimation of gap inventories is only tentative and has not been verifjed fully by testirg of irradiated fuel rods. But in view of lact of experitiental confirmation, it would be advisable to use these resulta inly is a jover lirni:. Also this okNl. model does not inelude the recent interesting phenomenon like jodine spiking which may tave a significant effect on offsite thyroid dose resulting, from postulated aceident" involving the releise of reactor coolant. There is only a limjact anourst of taita relating to this phenomenon. However, an dpproxjtate estimate of iodine spiking effect for PWR plant can be made in Table $\Lambda 3.5$ by using the data of W. F. Pasedag's repart (32) and his correlation. From this calculation, the iodine release due to iodine spiking for a large fhk plant (1000 lwit: power output) is about 10,000 (Ci). This number is about 3!) percent of the iodine source term of the recent DRliL model. Thus the ORSL model for iodine release has been adjusted by a 30 percent addition due to iodine spiking. A similar lodine spiking estimatc for BiR plant is given at Table A3.6 by using the data of W. F. Pasedag's report and his correlation. It is of interest to compare these release values with those used in WASH-1400. Values for gap inventory and gap escape fraction (the fraction of gap inventory which escapes following rupture) obtained by using these models are listed in Table A3.7. These "best-estimate" predictions of total cesium and iodine release differ from those calculated in WASH-1400 by factors of 200 and 60 , respectively. These Iarge differences are due to two factors: a lower estinate for initial fission 
gas inventory in the gap than used in WASH-1400, and lower estimates of gap escape fractions. 
References: Appendix 3

(1) R. L. Ritzman, "Calculation of Fission Product ReJease to fued Rod Coas fare", WhSll-1400, Appendix VII roci, 1975).

(2) A. 11. Booth, "Methorl of Culculating Fissican ris Diffusion from $\mathrm{UV}_{2}$ and its Application to the X-2-f Loop Test", AECL Report CRUC721 (5ept. 1957).

(3) B. lustinah, "Irradiation Effects in Uo ", chapter 9 in Uranium 11) iuxide: Propertices und Nuclear Applications, edited by J. Belle, USNA:C, 1961 .

(A) S, Beck, "The Diffusion of Radioactive Fission Produets from Porous [uo] fidcmests", BMI-1433 (Apri], 1960).

(5) (i, H. Pitrker, et al., "Out-of-pile Studies of Fission Product Release from Overheated Reactor Fuels at ORNL, 1955-1965", ORN1,-398] $($ July, 1967).

(6) D. L. Morrison, et al., "Ar Evaluation of the Applicability of Existing Data to the Analytical Description of Nuclear Reactor Accident", BMI-1779 (August, 1966).

(7) H. L. McMurry and E. F. Aber, "Release of Fission Products from PlYR and BWR Fuel Pins", WASII-1400, Appendix V1I (Oct. 1975).

(8) K. G. Denbigh, "The Thermodynamics of the Steady Stater, John Wiley, $(1950)$.

(9) V. F. Baston, E. G. Good, and W. A. Yuill, "Fission Product Release Analysis," IDO-17242, May 1969.

(10) K. A. Yuill, V. F. Baston, and J. H. McFadden, "Release of Noble Gases from UO $\mathrm{U}_{2}$ Fuel Rods," 1N-1346, hovember 1969.

(11) W. A. Yuill, V. F. Baston, and J. H. McFadden, "An Analytical Model 
Describing the Behavior of Fission Prodicts in Operating Fue?

Pins," IX-146\%, June 1971 .

(12) V. F. Baston, J. H. McFadden, and K. A. Yuill, "An Analytical Methsd for Calculating Steady-State Fission Gas Release....... Fission Product Fuel Model (FPFM) Code," ANCR-1010, Septembet 1971.

(13) G. H. Parker, "Calculation of Gap ReIcaso of Radioactive Fission Products," WASH-1400, Appendix 7, Oct. 1975.

(14) G. W. Parker and R. A. Lorenz, "Prompt Release of Fission Products from Zircaloy-clad $\mathrm{JO}_{2}$ Fuels', in Nuclear Safety Progran Annual Progress Report for Period Ending December 31, 1967, DRNL-4228, Oak Ridge National Laboratory (April, 1968).

(15) N. Oi and J. Takagi, Zeit Naturf 20a, 673(196S).

(16) R. A. Lorenz and G. E. Creek, unpublished work supplied by personal communication at ORNL (1973).

(17) G. W. Parker, G. E. Creek, W, J. Martin, C. J, Barton, and R. A. Lorenz, "Out-of-Pile Studies of Fission-Product Release from Overheated Reactor Fue1s at ORAL, 1955-1965", ORNL-3981, Oak Ridge National Laboratory (July, 1967).

(1B) A. H. Booth and G. T. Rymer, "Determination of the Diffusion Constant of Fission Xenon in $\mathrm{UO}_{2}$ Crystals and Sintered Compacts", CRDC-720, National Research Council of Canada (August, ]958).

(19) П. M. Evans and A. W. Shilling, "Parameters Sor Estimating the Release of Fission Gases from UO 2 Fuel", TRG Report 1240 (H') (May, 1966) .

(20) R. C. Dariels, et al., "Effects of High Burnup on Zircaloy-clad Bulk UO 2 Plate Fuel Samples", WAPD-263, Westinghouse Electric 
Corp. (September, 1962).

(21) W. L. Baily, C. N. Spalaris, D. X. Sandusky, and E. L. Zebroski, "Effect of Temperature and Burnupi on Fission Gas Release in Mixed Oxide fuel", paper presented at inerican Cerimic socjety iecting, (iva, 1969).

(22) R. A. Lorenz, J. J. Collins, and A. P. Malinauskas, "Fission Product Source Terms for the LiR LOSs-of-Coolant Accident: Sumary geport", NUREG/CR-0091, Oak Ridge Kational Laboratory, June 1978.

(23) R. A. Lorenz, J. L. Collins, and S. R. Manning, Quarterly Progress Report on Fission Product Release from LWR Fuel for the periad Oct.-Dec. 1975, ORXL-TM-5290 (March 1976).

(24) R. A. Lorenz, J. L. Collins, S. R. Manning, and A. P. lalinauskus, Quarterly Progress Report on Fission Product Retease from Lis? Fuel for the period Jar. - Har. 1976, OR:L/NUREC/TM-30 (JuIy 1976).

(25) R. A. Lorenz, J. L. Collins, 5. R. Slanning, O. L. Kirkland, and A. P. Malinauskas, Quarterly Progress Report on Fission Product Release from LWR Fued for the Period Apr..-June 1976, ORNI/NUREG/ TM-47 (Nug. 1976).

(26) R. A. Lorenz, J. L. Collins, and O. L, Kirkland, Quarterly Progress Report on Fission Product Release from LiR Fuel for the Period JuI)-Sept, 1976, ORNL/NUREG/TY-73 (Dec. 1976).

(27) R. A. Lorenz, J. L. Collins, and O. L. Kirkland, Quarterly Progress Report on Fission Product Release from LhR Fued for the Period Oct.-Dec. 1976, ORNL/NGREC/TM-88 (March 1977).

128) A. P. Malinauskas et. al., Quarterly Progress Report on Fission Product Behay ior in LitR's for the Period Jan. March 1977, ORNL/ 
NUREG/TM-122 (June 1977).

(29) A. P. Malinauskas et. al., Quarterly Progress Report on Fission Product Behavior in LWR's for the Period April-June 1977, ORNL/ NUREG/TM-139 (Sept. 1977).

(30) A, P. Malinauskas et. al., Quarterly Progress Report on Fission Product Behavior in LWR's for the Period July-Sept. 1977. ORNL/ NUREG/TM-170 (Jan. 1978).

(31) A. P. MaIinauskas et. al., Quarterly Progress Report on Fission Product Behavior in LWR's for the Period Oct.-Dec. 1977, ORNL/NUREG/ TM-186 (March 1978).

(32) H. F. Pasedag, "Iodine Spiking in BWR and PWR Coolant System," CONF-770708, Inly, 1977. 


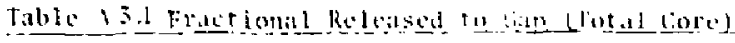

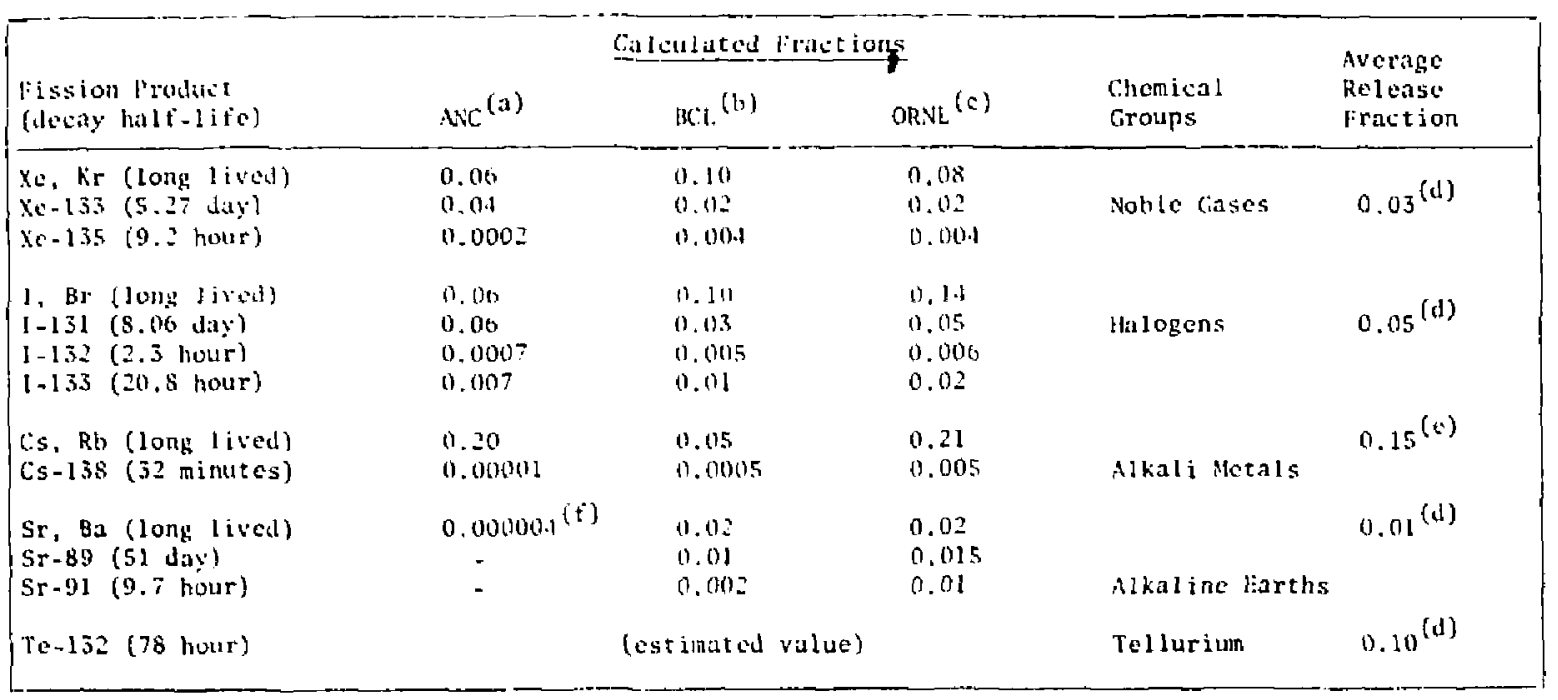

(a) ANC (Aeroiet Nuelear Company) model.

(b) BCL (Battelle's Columbus laboratories) model.

(c) ORNL (OAk Ridige katianal hahoraturyl model.

(d) Values can be higher or lower hy a factor of 4 .

(e) Values can he higher by a factor of 2 or lower by in factor of 4 .

(f) This value results from thermodynanic restrictions ube considered in the other two molels. Sce discussion of the escape fraction for this species. 
Table A3.2 Gap Release Component Values

\begin{tabular}{|cccc|}
\hline $\begin{array}{l}\text { Fission } \\
\text { Product } \\
\text { Species }\end{array}$ & $\begin{array}{l}\text { Gap } \\
\text { Release } \\
\text { Fraction }\end{array}$ & $\begin{array}{c}\text { Gap } \\
\text { Escape } \\
\text { Fraction }\end{array}$ & $\begin{array}{c}\text { Total Gap } \\
\text { Release } \\
\text { Value }\end{array}$ \\
\hline Xe, Kr & $0.03^{(\mathrm{a})}$ & 1 & 0.03 \\
$\mathrm{I}-\mathrm{Br}$ & $0.05^{(\mathrm{a})}$ & $1 / 3^{(\mathrm{c})}$ & 0.017 \\
$\mathrm{Cs}, \mathrm{Rb}$ & $0.15^{(\mathrm{b})}$ & $1 / 3^{(\mathrm{c})}$ & 0.05 \\
$\mathrm{Sr}, \mathrm{Ba}$ & $0.01^{(\mathrm{a})}$ & $10^{-4(\mathrm{~d})}$ & 0.000001 \\
Te, Se, Sb & $0.10^{(\mathrm{a})}$ & $10^{-3(\mathrm{~d})}$ & 0.0001 \\
Others & - & - & NegIigible \\
\hline
\end{tabular}

(a) Values can be higher or lower by a factor of 4 .

(b) Value can be higher by a factor of 2 or lower by a factor of 4 ,

(c) Values can be higher ot lower by a factor of 3 .

(d) Values can be higher or lower by a factor of 100 .

[e] While no humerical value was developed for these various species, the number should not exceed that used for strontium-barium.

Tavle 43.3 Values Por Constagts in the Arrhezius Equation

\begin{tabular}{|c|c|c|}
\hline Radioel ement & Constant A & Constant B \\
\hline Xenon-krypton & 232.3 & -4.00534 \\
\hline Iodine & 2.936 & -2.95177 \\
\hline Cesium & 1.369 & -2.62966 \\
\hline Strontium & $3.37 \times 10^{15}$ & -11.2368 \\
\hline Ruthenium & 3.8495 & -7.01379 \\
\hline Tellurium & 53.27 & -3.3510 \\
\hline
\end{tabular}




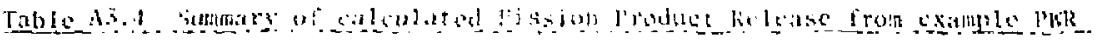

\begin{tabular}{|c|c|c|c|c|}
\hline $\begin{array}{l}\text { Number of ronds } \\
\text { in s roup }\end{array}$ & $\begin{array}{l}\text { Fissiug gits in plonum } \\
\text { (s of toial in rod) }\end{array}$ & $\begin{array}{l}\text { Cosium amb iodine } \\
\text { in gan space } \\
(8 \text { of total in rod) }\end{array}$ & $\begin{array}{l}\text { Total } \\
\text { from } \\
\text { g. Cs }\end{array}$ & $\begin{array}{l}\text { ased } \\
\text { roup } \\
\end{array}$ \\
\hline 390 & 8 & 10.6 .5 & 1.80 & 0.38 \\
\hline$\therefore, 7,0$ & $\therefore$ & $9,6.5$ & $7.5=$ & 1.48 \\
\hline 5,970 & $=$ & .5 .65 & 8.90 & 1.73 \\
\hline 10,550 & 1 & 2.13 & 8.10 & 1.59 \\
\hline 7,920 & 0.5 & 0.88 & 3,01 & 0.59 \\
\hline 5.610 & 1). 25 & 0.25 & 0.78 & 0.15 \\
\hline $3.3,000$ & - & - & $30.11^{b}$ & $5.92^{c}$ \\
\hline
\end{tabular}

${ }^{4} \mathrm{An}$ equal number of rods it eidel group hibs inventories sorsesponding to average burnups of 10,000 20,000 , and 30,000 , ind $/ \mathrm{MT}$.

bon released at time of rupture; 20 s released by diffusion.

$c_{72^{n}}$ released at time of rupture; $28^{c}$ released by diffusion. 
Table di.5 lodine hing data for rof phants

\begin{tabular}{|c|c|c|c|}
\hline $\begin{array}{l}\text { plant } \\
\text { name }\end{array}$ & $\begin{array}{l}\text { design } \\
\text { power (Mgie) }\end{array}$ & $\begin{array}{l}\text { Total equilibrium } \\
\text { release rate }(i t / \sec )\end{array}$ & $\begin{array}{l}\text { Equilibrium rolease } \\
\text { jate per power (1/ei/kno/sec) }\end{array}$ \\
\hline Ginna & 490 & 364 & 0.743 \\
\hline Haddam & 575 & 242 & 0.421 \\
\hline Main Yankeo & 790 & 1285 & 1.626 \\
\hline O'Conee & 819 & 680 & 0.830 \\
\hline
\end{tabular}

Table 33.6 lodine spiking data for QUR plants

\begin{tabular}{|c|c|c|c|}
\hline $\begin{array}{l}\text { plant } \\
\text { name }\end{array}$ & $\begin{array}{l}\text { design } \\
\text { power (Awe) }\end{array}$ & $\begin{array}{l}\text { Total equilibrium } \\
\text { release rate ( } u \text { il/sec) }\end{array}$ & $\begin{array}{l}\text { Fquilibriun release } \\
\text { rate per power (uci/awe/sec) }\end{array}$ \\
\hline Dresden 2 & 809 & 70 & 0.0865 \\
\hline Dyster Creok & 640 & 85 & 0.133 \\
\hline 9 Mile Rt. & 625 & 65 & 0.104 \\
\hline Millstone Rt. 1 & 652 & 43 & 0.066 \\
\hline
\end{tabular}


Table A3, 7 Comparison of WASH-1400 and ORNL Nodel Calculations

\begin{tabular}{|c|c|c|c|c|c|c|}
\hline \multirow[t]{3}{*}{ Elemert } & \multicolumn{2}{|c|}{$\begin{array}{l}\text { Gap inventory } \\
(\% \text { of total inventory })\end{array}$} & \multicolumn{2}{|c|}{$\begin{array}{l}\text { Gap escape fraction } \\
\text { (\% of gap inventory) }\end{array}$} & \multirow{2}{*}{\multicolumn{2}{|c|}{$\begin{array}{l}\text { Total Felease } \\
\text { [\% of total } \\
\text { inventory] }\end{array}$}} \\
\hline & \multirow[t]{2}{*}{ WASH-1400 } & \multirow[t]{2}{*}{ Mode 1} & \multirow[t]{2}{*}{ WASII- 1400} & \multirow[t]{2}{*}{ Model } & & \\
\hline & & & & & WASH - 1400 & Model \\
\hline $\begin{array}{l}\mathrm{Ke} \text { and } \\
\mathrm{kr}\end{array}$ & 3 & 1.27 & 100 & $100^{\mathrm{b}}$ & 3 & $1.27^{b}$ \\
\hline $\mathrm{Cs}$ & 15 & 2.79 & 3.3 & 0.89 & 5 & 0.025 \\
\hline I & 5 & 2.79 & 33 & 1.91 & 1.4 & 0.053 \\
\hline
\end{tabular}

(A) Calculated for stable and long haff-life isotopes. The gap invencory and total release of 131 I and 13.3 xe would be 3 to 9 tines lower.

(b) An additional amount of fission gas, approximately $1.5 \%$ of the total inventory, would be released during heated up. 
Appendix 4. Nature of Realistic leakage Calculation

Appendix 4.1 Introduction

The nature of the leakage, including the equations that define its rate as a function of its driving forces, is dependent upon a number of factors. The major factors of importance are whether or not the critical pressure is exceded, the diameter, length, and roughness or tortuosity of the leakage path, and the mean free path and viscosity of the escaping gas.

A brief revief of the parameters that govern the flow characteristic of a gas passing through a small restriction wili help to clarify the problem of leakage behavior. Experimental determinations of the flow rate of gases through leaks have been made by Nerken ${ }^{(1)}$ for the size of leaks of interest in vacuun work and leak detection. Since some leaks of interest in containment structures approach the size of leaks investigated by Nerken, the results of his experiments and comparison with theoretical equations can be applied to evaluate the magnitude and significance of leakage. These investigations emphasize, however, the fact that the effects of pressure on the flow rate of leakage (at atmospheric pressure) are not always simply apparent, because a given leak can exhibit several types of flow.

For the particular characteristic geometry of a leak in a vessel, it is desirable to recognize the type of flow that may occur. Since, in turn, it defines the expected leakage rate in terms of the follawing controlling conditions: 
(I) Geometry of the leak and roughness of passage

(2) Pressure difference across the leak

(3) Physical properties of the gas (1.e.,viscostty, molecular we1ght, dens1ty)

(4) Composttion of baseous mikture (alr-steam mixtures).

In formulating the leakage parameters for each type of flow, leakage from a containment structure is preferably expressed as the fraction (or percentage) by welght of the contained atmosphere escapling per unit of time. Accordingly, all equations that define flow race will be expressed In terms of the welght of gas escaping through the leaks.

Appendix 4.2 Molecular Elow: The molecular flow regime is defined by mean free path, 1.e., as the average distance that a gas molecule will travel between collisions with another molecule. The mean free path varies inversely as a IInear function of the pressure. Molecuitr flow occurs when the mean free path of the gas exceeds the largust dimension of the cross-sectional flow area of the leakpassage. linder this condition the molecules will collide more frequenty with the walls of the leak passage than wth each other. At atmospheric pressure, the mean free path of air is exceptionally small. The average value of mean free path of atr molecules $(3)$ at standard condictons of 1 atmosphere and $70^{\circ} \mathrm{F}$ is of $2.6 \times 10^{-6}$ fnch and decreases to approximately $2.6 \times 10^{-7}$ inch at 10 atm. Molecuiar flow occurs shen the mean free path of the gas exceeds the largest dimension of the cross-sectional flow 
area of the leak passage. Under this condition the molecules will collide more frequently with the valls of the leak passage than with each other.

This mean free path of air may be roupared with the size of the leaks that exist in a containment wall. The smallest dimensions of Ieak size that is significant with respect to flow rate is considered to be approximately $3 \times 10^{-4}$ inch. This might be compared with a leak size of $1 \times 10^{-2}$ inch, which under constant pressure of 40 psig, would leak at a rate of $0.1 \%$ per day based on orifice flow leakage frota a containnent structure with a free containment volume of $2.5 \times 10^{6} \mathrm{ft}^{3}$. Hence, single leaks below $1 \times 10^{-4}$ inch diancter do not contribute significantly to the loss of the containment atmosphere.

Obviously, molecular flow does not play a major rolc in contributing to containment leakage because of the exceedingly small leak dimensions required in this flow regime. However, molecular flow may occur in portions of jrregular leak passages where considerable dimensional changes occur, such as in tight eracks in weld seams. If a substantial number of these snall leaks existed in a welded containnent structure, some slight contribution to the overall leakage might be expected as a result of molecular flow. In the field of vacuum technology, a convenicht parameter frequently used to determine the type of flow is the knudsen number, $a / h$, where $a$ is the radius of the leak with a circular cross section, and $k$ is the mean free path of gas molecules flowing through the leak passage. This parameter, as discussed by 
by Dong and Bromley ${ }^{(2)}$, affords a convenient means to arbitrarily divide the flow regimes into the various types of flows that characterize the gradual transition between molecular and laminar flow.

The flow regimes have arbitrasily been divided into a range expressed by the value of the Knudsen number:

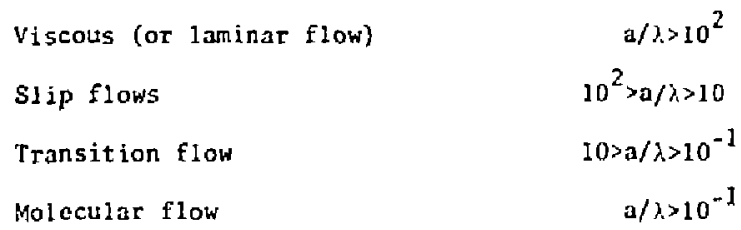

To provide o more comprehensive exposition of other parameters that are important in the molecular flow regime and to enable comparisons to be made with other types of flows, the molecular flow equation for the simplest of leak geometry (circular section) is selected. The molecular flow equation was originally derived by knudsen fand aliscussed by nong and Bromley (2) and by Dushman (3), for a finite cylindrical leak path; in the case of ais flow from il higher nressure, ris rentainment pressure), to atmosphere, J'o, thus equation is

$$
n=x_{1}^{\prime} \frac{D^{3}}{L} \frac{I^{\prime}}{(M R T)^{\frac{1}{6}}}
$$

where $W=$ mass flow rate in terms of weight of gas flowing through leak per unit of time $(1 \mathrm{bm}-\mathrm{ft} / \mathrm{sec})$, $D=$ diameter of circular cross-section leak $(f t)$.

$L=$ length of leak path (between pressure zones $P_{a}$ and $\left.P_{0}\right)(f t)$. $M=$ molecular weight of gas,

$R=$ gas constant

$T=$ temperature of gas, $k_{1}^{\prime}=$ the constant of proportionality, 
Equation (1) may be further simplified by expressing the containment pressure as a ratio of the downstream absolute pressure at the end of the leak path, which is equal to atmospheric (barometric) pressure

$$
H=K_{1}^{\prime \prime} \quad \bar{D}^{3} \frac{\overline{P_{a}-1}}{(\overline{M R T})^{1}-\frac{5}{2}}
$$

where $\overline{\mathrm{P}_{\mathrm{a}}}$ is the ratio of the upstream absolute pressure to the atmospheric pressure.

The leakage rate, $I_{F}$, of the system is the fractional loss of contaimment atmosphere during time $\Delta t$ :

$$
L_{r}=\frac{W_{0}-W_{1}}{-\frac{N_{0}}{\Delta t}}
$$

where lio $=$ weight of gas in the free volume of containment vessel it initial selected state,

$w_{1}=$ weight of gas in free volume of containmert remaining after the loss sustained through leaks for the selected interval of time.

The most commonly selected time interval, $\Delta t$, is $24 \mathrm{hr}$. Since the containment atmosphere weight difference $\left(v-w_{1}\right) / \Delta t$ is the weight loss per interval of time, or the flow rate o escaping gas, $w$, the leakage rate can be expressed as:

$$
\mathrm{L}_{\mathrm{r}}=\frac{\mathrm{L}^{\mathrm{N}}}{150}
$$

The initial weight of contained atmospher to, is determined from the equation of state for a perfect gas, ass aing uniform conditions through out the containment volume fnot necessarily valid for noncirculated atmosphere) : 


$$
w_{0}=\frac{P_{a} V}{A T}
$$

By substitution, the leakage rate, $L_{r}$, is then conveniently expressed in terms of defined parameters:

$$
L_{r}=\frac{R T}{P_{a} V}
$$

In order to find leak rate as a function of pressure for molecular flon, substitute equation (2) into equation (6).

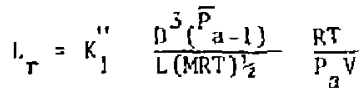

$$
\begin{aligned}
& =k_{m}\left(t-\frac{I}{\bar{p}}\right)
\end{aligned}
$$

Where $k_{\mathrm{m}}=$ dimensionless constant in leakage rate for molecular flow. The dependence of lcakagc rate upon the absolute air pressure in tio containment vessel for molecular flow is shown in Figure A4.1. Appendix 4.3 Haminar Elow

For gas flowing through leaks at Iow velocities and with a low differential pressure across the leak, the flow may be considered as incompressible. However, with increased velocitics, long leak paths, and significant meesure differentials, the gas density is no longer canstant between the entrance and the exit of the Icak passage. Then the Hagen-Poiseuille equation (4), (5), for the viscous flow of a gas through a straight leak passage of circular section must be modificd to treat the flow of a compressible fluid with its accompanying density changes. By substituting the average density of the gas flowing through the leak into the Hagen-Poseuille equation, the laminar flow equation for a compressible fluid becomes

$$
W=\frac{g \pi D^{4}}{128+L} \quad P_{a v}\left(P_{a}-P_{o}\right)
$$


where $u=$ gas viscosity

However, for the condition at the leak $P_{a y}$ may be approxinated ( $T$ constant) by

$$
\sigma_{\mathrm{aV}}=\frac{\mathrm{P}_{\mathrm{aV}}}{\mathrm{RT}}=\frac{\mathrm{P}_{\mathrm{a}}+\mathrm{P}_{\mathrm{O}}}{2} \times \frac{1}{\mathrm{RT}}
$$

and thus

$$
w=\frac{g \prod D^{4}}{256 \mu L} \times \frac{1}{R T} \times\left(\mathrm{P}_{\mathrm{a}}^{2}-\mathrm{P}_{\mathrm{D}}^{2}\right)
$$

Equation (10) is in the form commonly referred to as the barcy formula. A typical application of this equation by Shapiro ${ }^{(6)}$ is illustrated by a problem of seepage of gas through a tuhe, this condition may be similar to il leak in containment vessels.

In terms of leak area, $A$, and a constant of proportionality, $k_{2}$, the equation (10) becomes

$$
W=K_{2}^{1} \frac{A D^{2}}{\mathrm{HL}} \times \frac{1}{\mathrm{RT}} \times\left(P_{\mathrm{i}}^{2}-\mathrm{P}_{\mathrm{a}}^{2}\right)
$$

To further simplify eq. (11), the pressure $P_{a}$ may be expressed in terms of atmospheric pressure Po

$$
W=K_{2}^{+} \frac{\mathrm{AD}^{2}}{\mu \mathrm{L}} \times \frac{1}{\mathrm{RT}} \times\left(\overline{\mathrm{P}}_{\mathrm{a}}^{2}-1\right)
$$

and $\bar{P}_{a}$ is written for $P_{a} / P_{o}$.

The leakage rate, $\mathrm{L}_{\mathrm{y}}$, for laminar flow can be obtained by substituting equation (12) into equation (6).

$$
\begin{aligned}
\mathrm{L}_{\mathrm{t}} & =\mathrm{K}_{2}^{\prime} \frac{\mathrm{AD}^{2}}{\mu \mathrm{L}} \frac{1}{\mathrm{RT}} \times\left(\overline{\mathrm{P}}_{\mathrm{a}}^{2}-1\right) \times \frac{\mathrm{RT}}{\mathrm{P}_{\mathrm{a}} \mathrm{V}} \\
& =K_{\mathrm{p}}\left(\overline{\mathrm{P}_{\mathrm{a}}}-\frac{1}{\overline{\mathrm{P}_{\mathrm{a}}}}\right)
\end{aligned}
$$

Where $K_{Q}=$ dimensionless constant in the leakage rate for laminar flow. The dependence of leakage rate upon the absolute air pressure in the containment vessel for laminar flow is shown in Figure A.4.2. 
Appendix 4.4 Turbulent Flow

Although the majority of significant leaks in a containment vessel nay well be in the laminar flow regime at the pressures which are of interest, it is concejvable that turbulent flaw conditions will be attained in some cases, particularly if the leak passages are irregular. The region of transition between laminar flow and turbujent flow may be conservatively estinated to begin with a Reynolds number. Re, greater than 2000. If the leak path in a containment structure is of a nature to permit the developrent of turbulent flow, the mass flow rate, $k$, may be derived from the Darcy-liseisbach equation ${ }^{(7)}$, assuming that the leak cross section approaches the geometry of a small diameter tube. The equation commonly appears as

$$
\mathrm{P}_{\mathrm{a}}-\mathrm{P}_{\mathrm{O}}=\mathrm{f} \frac{\mathrm{L}}{\mathrm{D}} \times \frac{y^{2}}{2}
$$

where $f$ is friction factor whose value is a function of the leak passage roughness and the Reynolds number for the flow conditions through the leak.

$A$ gas flowing through a leak pass. ge where $L / D$ and $\Delta P$ may be appreciable would not only encounter wall friction losses but also would expand. A]though under such conditions, the behavior may change from incompressible to compressibie flow, an approximation may be made by treating the problem as incompressible and assigning avorage values for the variables in Eq. (14). Thus,

$$
P_{a}-P_{0}=f \frac{L}{D} \frac{P_{\text {av } V S}{ }^{2}}{2}
$$

where

$$
f_{\mathrm{av}}=\frac{\mathrm{P}_{\mathrm{a}}+\mathrm{P}^{\mathrm{p}} \mathrm{o}}{2} \times \frac{1}{\mathrm{RT}(g)}
$$


and

$$
V s=\frac{W}{P_{a v^{g A}}}
$$

which, when substituted in Eq. (15), yield

$$
H=g A\left[\frac{\mathrm{D}}{\mathrm{fL}} \times \frac{1}{\mathrm{RT}} \times\left(\mathrm{P}_{\mathrm{a}}^{2}-\mathrm{P}_{\mathrm{O}}^{2}\right)\right]
$$

or, If pressures $\mathrm{Pa}$ is expressed in terns of atmospheric pressure Po,

$$
W=K_{3} A\left[\frac{D}{\mathrm{fL}} \times \frac{1}{\mathrm{RT}}\left(\bar{P}_{\mathrm{a}}^{2}-1\right)\right]^{\frac{1}{2}}
$$

For $\left[1\right.$ wis with Reynolds Numbers $4 \times 10^{3}$ to $10^{5}$, it may be assumed that the profile of flow through the leak approaches that of a smooth tube for which the empirical expression of Blasiss' law, ${ }^{(8)}$ may be applied in the determination of a conservative friction factor. For circular leak paths,

$$
f=\frac{0.0791}{\operatorname{Re}^{\frac{1}{4}}}=\frac{0.0791}{\left(\frac{\gamma D_{\rho}}{\nu}\right)^{\frac{1}{4}}}
$$

and for noncircular Jeali paths,

$$
f=\frac{0.0791}{\left(\frac{4 \mathrm{VR} \mathrm{H}^{\rho}}{\mu}\right)^{\frac{1}{4}}}
$$

Where hydraulic radius $R_{1}$ is defined by $R_{H}=\frac{2 S}{2}, S=$ the flow arez, $z=$ wetted peritheter of flow. Substituting Eq. (18) in the Darcy-lieisbach equation (16) and rearranging terms yields

$$
W=K_{4} A \frac{D^{5 / 7}}{i 1 / 7} \times \frac{1}{(\text { LRT })^{4 / 7}} \times\left(P_{a}{ }^{2}-P_{0}^{2}\right)
$$

or, if pressure $P_{a}$ is expressed in terns of atmospheric pressure $P_{0}$,

$$
W^{\prime}=K_{4}^{\prime} A \frac{D^{5 / 7}}{L 1 / 7} \quad\left(\frac{\overline{\mathrm{p}}^{2}-1}{\operatorname{LRT}}\right)
$$

The relationship defined by Eqs. (17) and (21) should be recognized as indicative of the influence of pressure, temperature, and viscosity on 


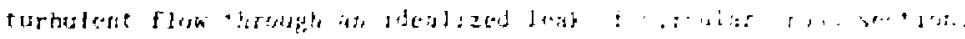

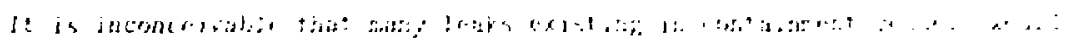

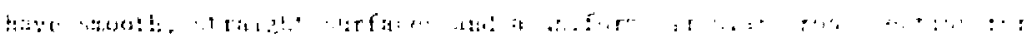

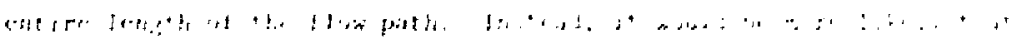

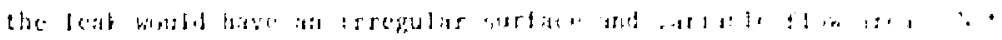

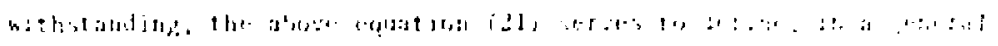

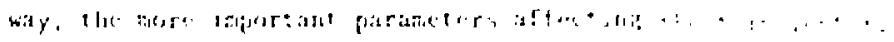

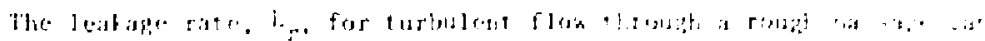

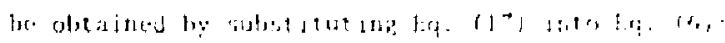

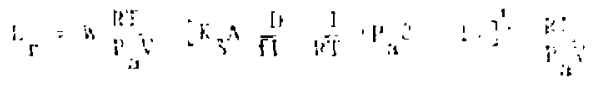

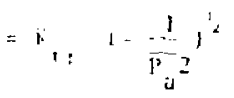

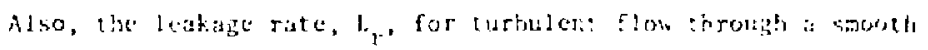
passage can be obtained by sulstitliting lq. ralf into ta te?:

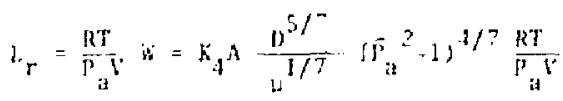

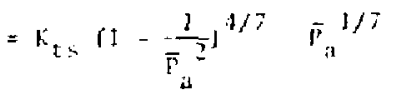

Whete $k_{t r}$ and $k_{t s}$ itre dimensionless constants for curbuleni flow through

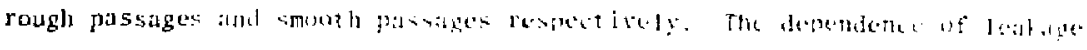
rate upon the absolute air pressure in a contojngent vessel for turbulent

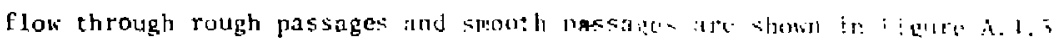
and $A, 4.4$ respectively. 
Apendix 4.5 Conpressible :10x through comergeni passages ar orifices

Leaks with cancrgent passagrs may be considered as soziles, whith leaks whose length is relatively short compared with the dianeter may the cansidered as orifices. Significant changes in gas densiti oceur with

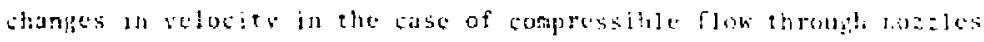

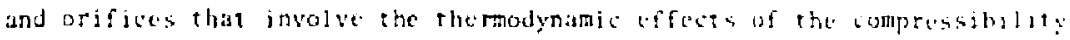
of the fits. The flow behavior depend:s on the velocity attained in the

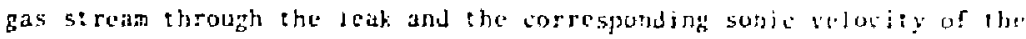
gas is the flow conditions.

For air, the sonic velocity is given by the relutiot. $C=49.025^{\frac{1}{2}}$ (2.4)

It is noted that the containment atmosphere in the everet of at

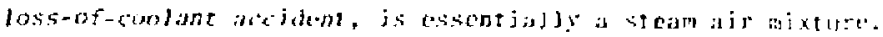
In such a case. the sanic velocity will be modiricd both by the temperature and the composition of containment atmosphere. The value of the Mach number, Ma, that determines the effect of downstream pressure on flow will be correspondingly modified.

When a compressible flow is at subsonic velocity, Mar, the flow through a leak is always influenced by the downstrem pressure conditions. On the other hand, at velocitics Na>1, the downstream pressure conditions cannot affect the leakage, assuming orifice geometries exist. The pressures in a containment structure are, respectively, the inside pressure, $F_{d}$, and the outside ambient atmospheric pressure, $P_{D}$. At flows corresponding to $M_{a}=1$ (sonic flow), the $P_{0} \cdot P_{i j}$ becomes to the critical pressure ratio, which, for air at nomal conditions with $\left.i=c_{p} / c_{r^{\prime}}\right)=1,4$, attains a value of 0.528 . (For saturaced stean, the eritical pressure 


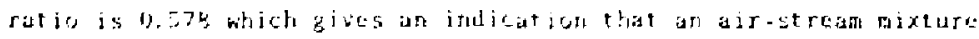

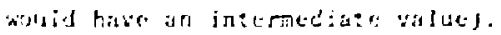

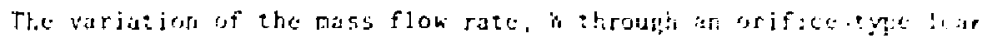

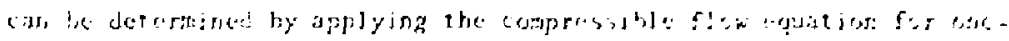

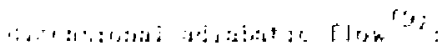

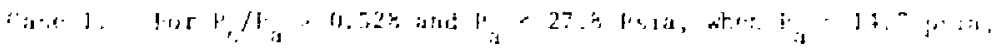

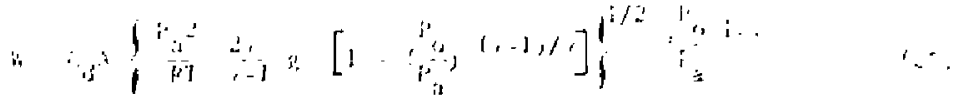

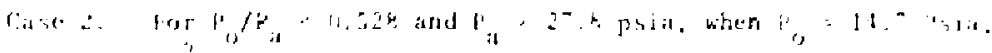

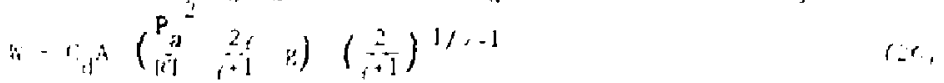

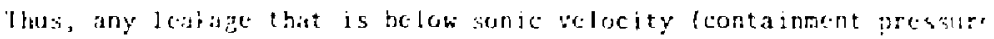
less that 27 . g plat is dependent upon both upstream ( $p_{\text {a }}$ and downse reath (1) pressures, while, leakuge that attains sonic velocity foutainmeat pressure greater than 27.8 psial is independent of the domst rearn pressurt. $\left(\mathrm{P}_{\mathrm{D}}\right)$. Lquations (25) and $(26)$ may be expressed in terms of atmospheric pressurc and a constant of proportionality. For Case 1:

$$
w=k_{5} \wedge\left[\frac{1}{M T} \times \frac{2 y}{\gamma-1}\left(1-\frac{1}{\bar{p}_{a}(r-1) / \gamma}\right)\right]^{1 / 2} \bar{p}_{a}(r-1) / \gamma C_{p}
$$

and for Calse 2:

$$
n=K_{5} \lambda\left(\frac{1}{R T} \times \frac{2 \gamma}{i+1}\right)^{1 / 2} \quad\left(\frac{2}{\gamma+1}\right)^{1 /(r-1)} \quad i_{a} c_{i} .
$$

Since the orifice leak geometry is indeterainate for the majit of such leaks in containment structures. the value of the coefficicrt of discharge Cd can ondy be estimated. The range of this variation is approximately 0.55 to 0.99 from the experimental work of Graze and Lapple $(10)$; it is dependent upon the specifis orifice geometry. For an 
assumed orifice flow behavior of leaks in a containgent structure, the discharge coefficient that is applicable js, at best only a guess because of the mat:y undefjned orifice leak geonetries possible in such structures.

The leak rate, $L_{t}$, for compressible flow through orifice, when

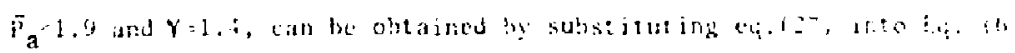

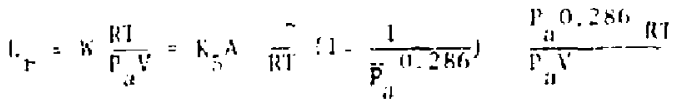

$$
\begin{aligned}
& =x_{0}\left(1-\cdots \frac{1}{11.58 n}\right)^{3 / 2} \quad-\frac{1}{\bar{p}_{i 1}^{0.715}}
\end{aligned}
$$

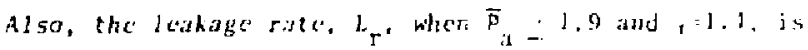

$$
L_{r}=0.259 \times 5
$$

From equation $(\bar{x} 0)$. orifice flow in the sonic velocity latge is independent of the pressure. The depefifence for leakige rate upon the absolute air pressure in the containment vessel for comprossible flow through orifice is shawn in Figure A.4.5.

To compare the rejatjve magnitude of ajr flow through cont: ment leak paths, as governed by the relationships of equations $(\bar{i} ;,[1, \overline{3}),(22)$, (23), and (6) for the flow regimes investigated, it is assuted :hat a containment structure contains a number of leak paths whose total flow area is equivalent to that of an urifice having a diameter of 0.12 inch [0.01 fi.). The tota] flow, $w$, through the leak paths is cal..iated on the basis of the pounds of air escaping per day from the containgent vessel as a function of the containment pressure. It is further assuned

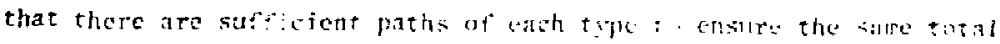
flow area. The resulting Fig. A.4.6 elearly shows that the leak paths which behave as orifices wilu allow the largost flow of air when 1 a 


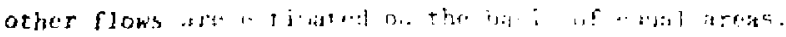

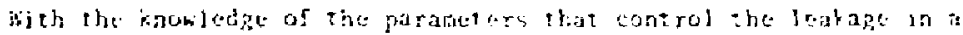

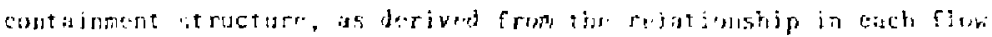

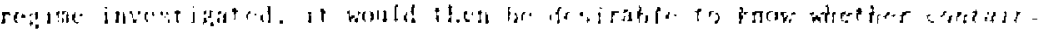

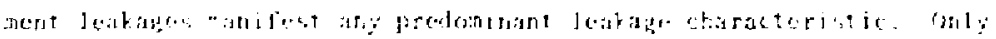

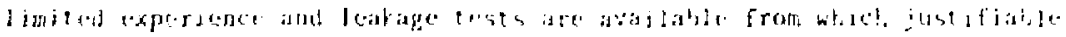

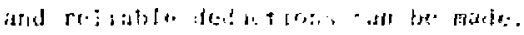

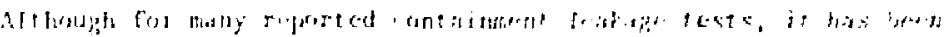

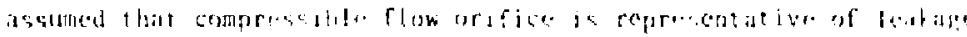

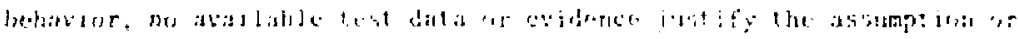
staport this conclusion. Aach contentent st ructure should preferably

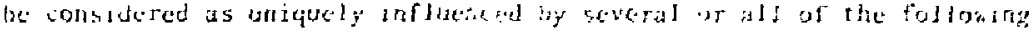
factors that latimately determine the leakage rate:

1). The pressure and temperature conditions of the conta intait at rowphere.

3). The compositias and physical properties of the containment at mosphere (in the case of aceident conditions).

3) The number of potential leakage parhs.

1) The dissimilarity of flow churacteristits among the oxjsting leak paths.

5) The variation of leak geometry with variations of internal containment neasures.

6) The extent of the containnent boundary linits beyond the containgent sholl.

From a practical stanjpoint, the containment total leakage should be recognized as nerely representative of a composite average of the above-ment ioned pricets, and no actemp: should be made to analyze the 
leakage dependence of the individual contributing factors.

In practice there it no means of determining. prior co construction, what proportion of the leakage will be atfributable to each type of fion. Conseusently, it has to be assumed in design that the relationship between leak rate and pressure will be the least favorablo fi. s. orifice flowj. [t will be seen from fig. A.4.7 that the leak rate for orifiec ilon would not be changed until it reaches the critical pressure $(=1.9$ atm. $)$ and woulil be reduced by 50 percent when the absolute pressure has fallen to 1.1 at in. from an initial value of atout 5 atm.: whereas if the flow werc entirely laminar flow, it would bave falien to 50 percent at about 2.7 at in. Using; the data given by Bechtel in Ref. 1] for the pressure response vis. time relatjonship for a typical "dry" containment, it was found that the average leak rate over the first 24 hours is 84.3 percent of the initial value (with assumption that all the leakage is due to orifice flow); the rate at 24 jours is about 75 percent of the initial value. 


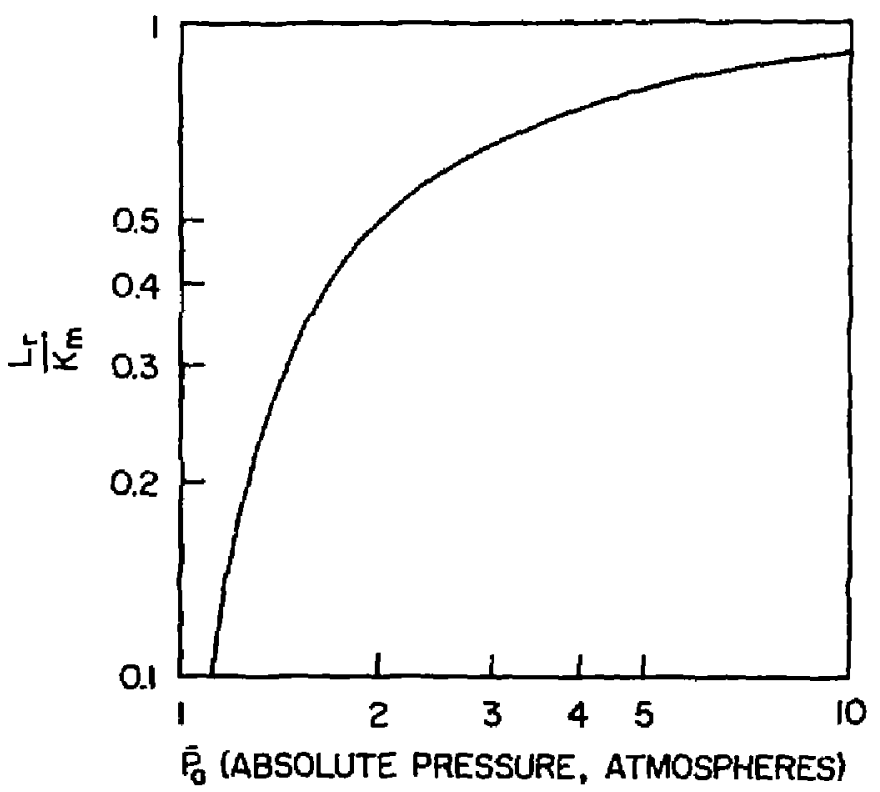

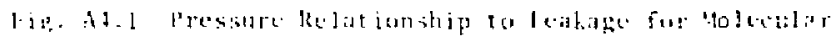
1.] 


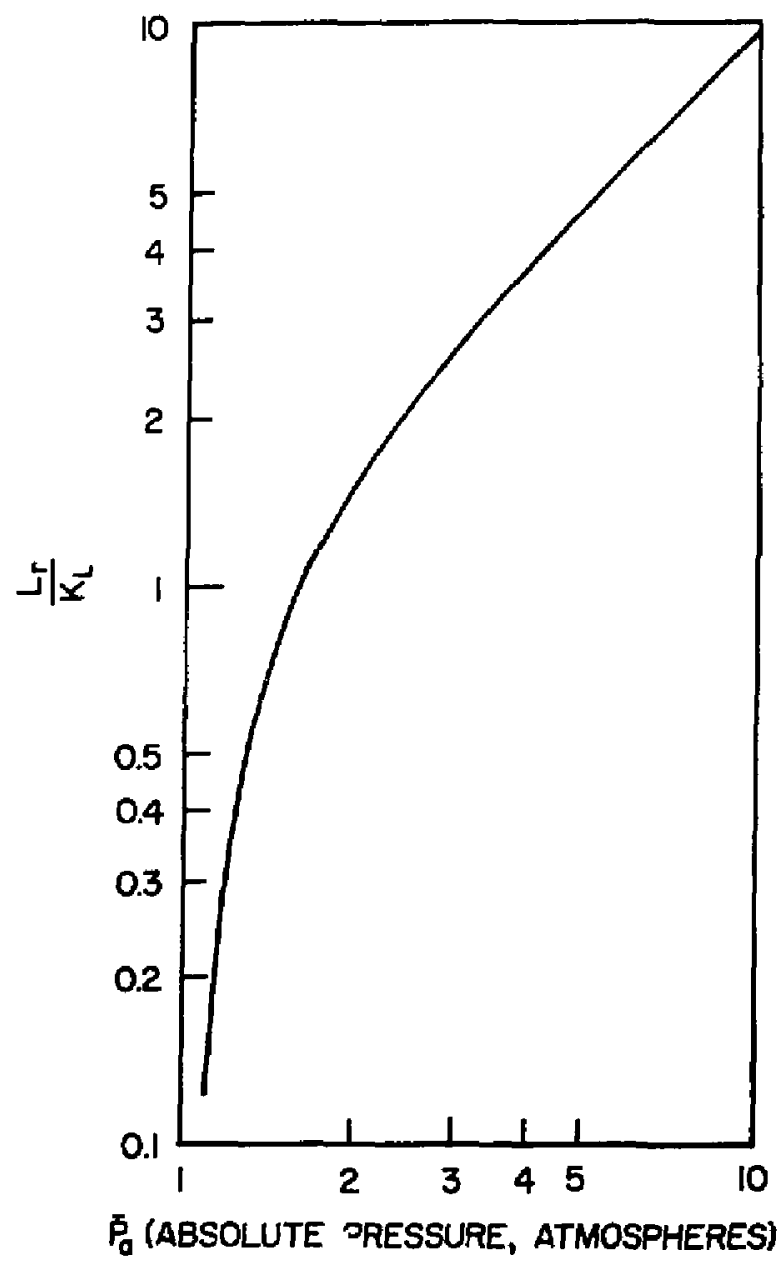

Fig. A.4.2. Pressure Relationship to leakege for Laminar (viscous) filow 


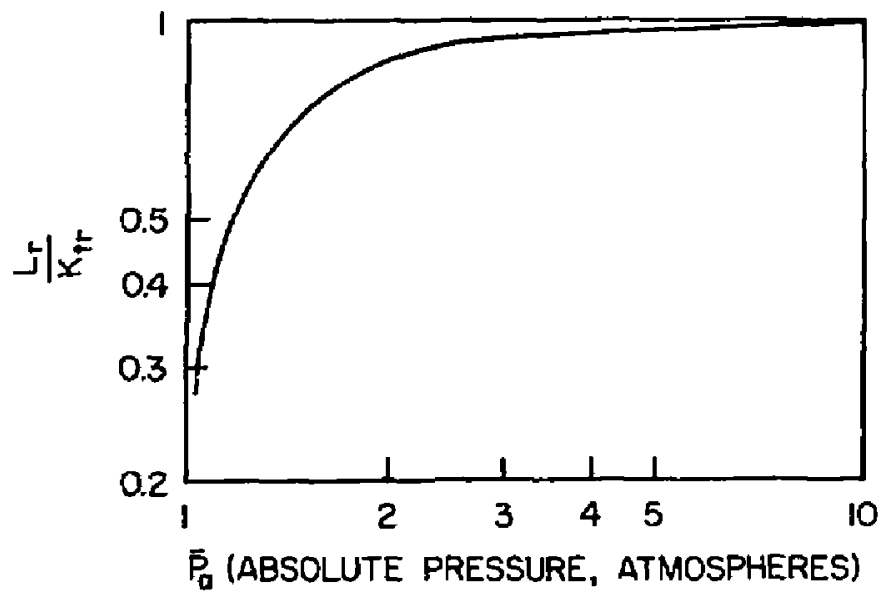

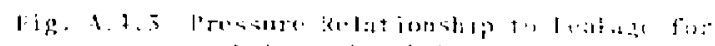

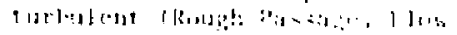




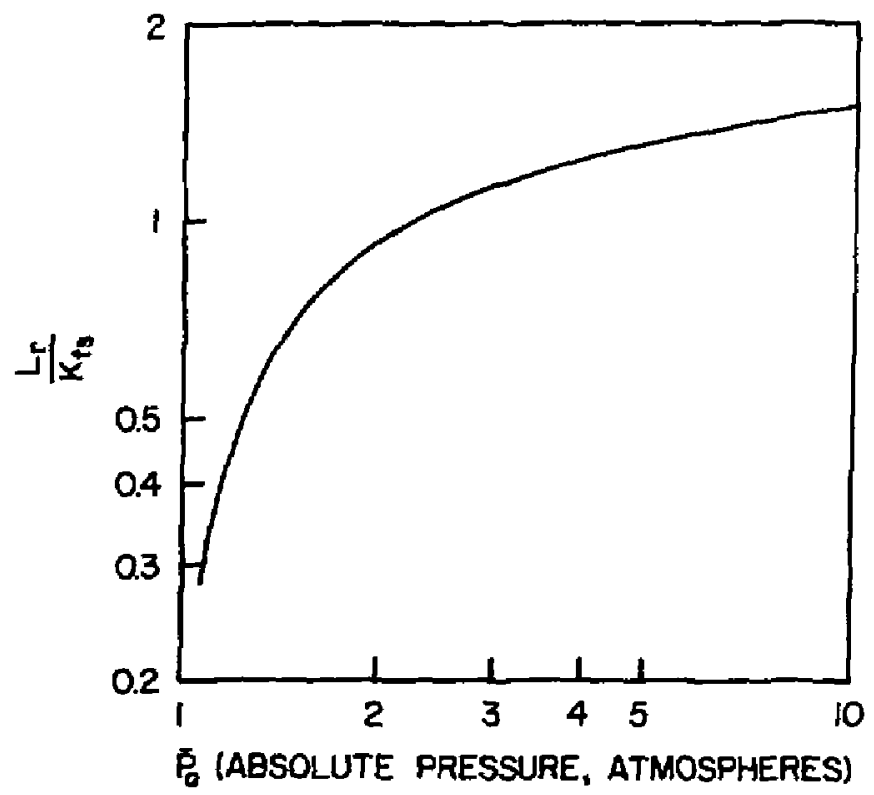

Fig. Ad. 4 Pressure Relat lonship to lookagle for tarhulent rimooth passige/ flok 


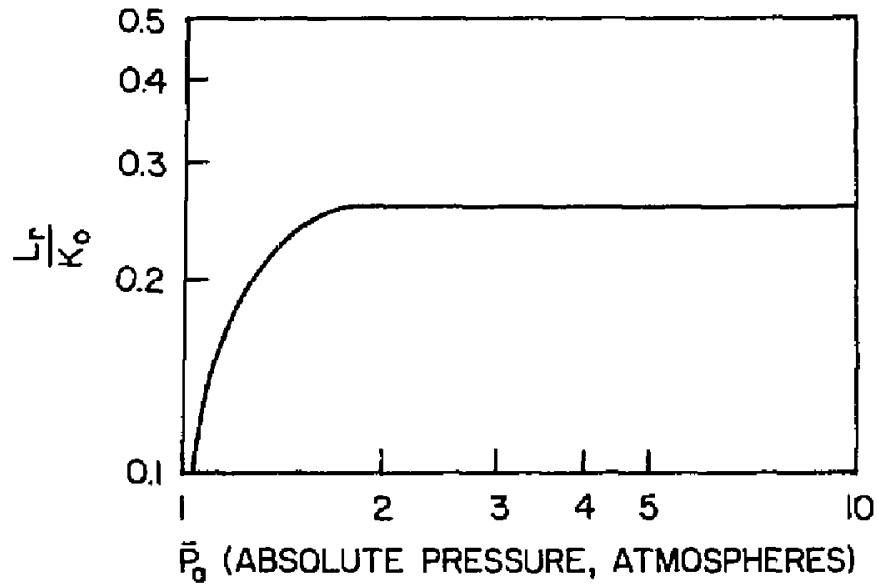

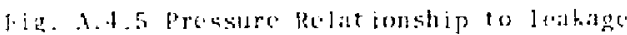
rur arifice rlow 


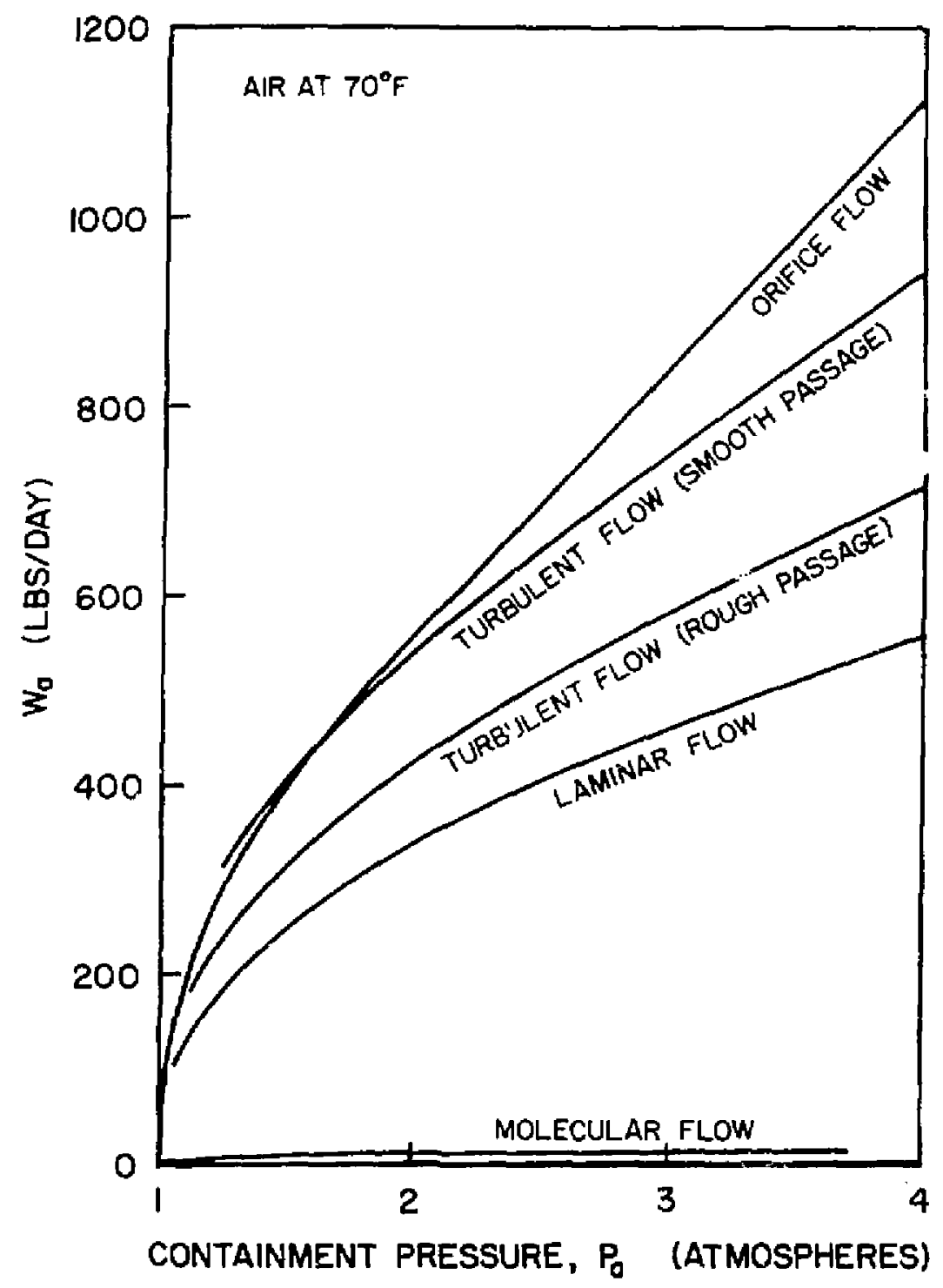

E:ig. A.4.6 Comparative How through Leak Paths Based on Assumptions of Equal Area at a Selected Containment l'ressure 


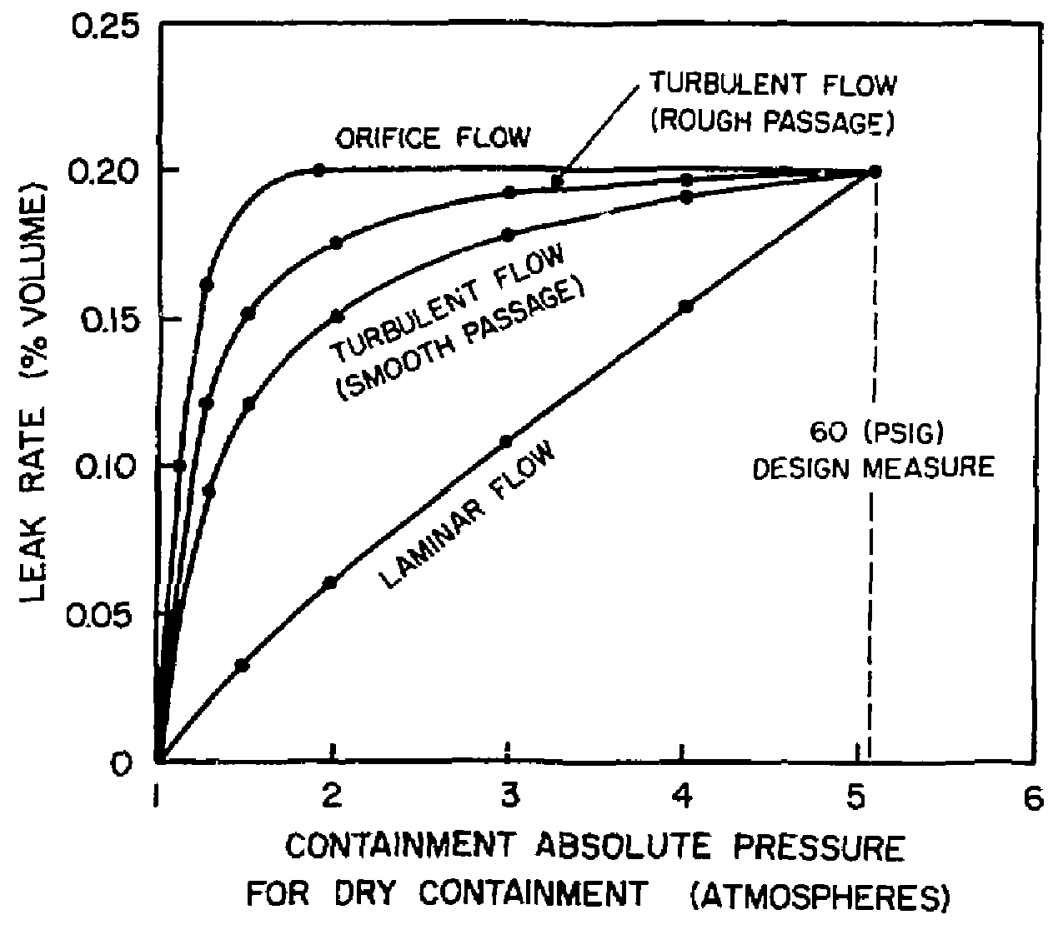

Fig. A.4.7 Jeak Rate vis. Containment Pressure for various flok renias 
(1) A Nerken, "Experiments on the flow of Gases through Leaks," National Symposium on Vacuum Technology Transactions, Pergamon Press, 1956.

(2) K'. Dong and L. A. Bromley, "Vacuum Flow of Gases through Channels with Circular Annular and Rectangular Cross Sections, 1961 Transactions of the 8th Vacuun Symosiun, 2nd Internat 1 nal Congress, Vol. 2 .

(3) 5. Dushman, Scientific Foundations of Vacuum Techniques, 2nd Ed., Table 1.6, Wiley, 1962,

(4) R. Bird, W. Stewart, and E. Light foot, Transport Phenomena, p. 46, Niley, Niew York, 1960 .

(5) H. Schlichting, Boundary-Layer Theory, p. 11, NcGraw-lill, i. York, 1968.

(6) A. H. Shapiro, The Drnamics and Themodynamics of Compressiblc Fluid Flaw, Vol. 1, p. 189, Ronald Press, New York, 1953.

(7) J. J. Duderstadt and L, J. Hamilton, Nuclear Reactor Analysis P. 484, Wiley, New York, 1976.

(8) R. Bird, W. Stewart, and E. Lightfoot, Transport Phenomena, p. 187, Wiley, hew York, 1960.

(9) M. J. Zucrow and J. D. Hoffman, Gas Dynamics, Vol. 1., p. 160, Wiley, New York, 1976.

(10) R. H. Bradley, J. W. Thiesing, and P, 5. Lowery, "Performance and Sizing of Dry Pressure Containments," BN-TOP-3, (Revision 4). Bechtel Corporation, October, 1977. 
Append Lx 5. Theoretical and experimental models of spray washout of alrborne contalnments.

\section{Append ix 5.1 Introduction}

To assess the external hazard it is necessary to est mate the amounc of any particular isotope which might be released to the contafrment atmosphere and the rate of leakage of the contalnment contents to the outsfde. Much of the various fisston products under accldent conditions miaht deposit or condense in the cooler parts of the reactor cifcuit, but with sases and low bollingpoint substances such as fodine, it is possible that the majority of the release will reach the containment boundary.

Spray systens are installed in the containment vessels of water reactors to reduce contafnthent pressure, remove heat from the containment and remove fission products whtch could be released from the core as a result of a postulated deslgn basis loss of coolant accident (toCA).

The maxinum thyrold dose which an ind fuidual could recelve following LOCA is reduced by engineered safety features such as spray systems and by plate-out on containment surfaces. The extent to which potential doses are reduced hy a spray system depends on how fast alrborne fisslon products are washed from the containment atmosphere.

As early as 1965, several reactor deslgns were pronosed (1)(2), (3), (4) in which containmenr sprays were destgned to remove both heat and alrborne fission priduces from the contalnment atmosphere in the 
unlikely event of a lass of coolant accident. Spray systems represent a class of gas scrubbers. Aqueous scrubbers simllar to contafnment sprays are widely used in industrial applications and have been studied extensively over a period of mare than 40 years. (5), (6), (7), (8)

It is important to recognize that there are differences as well as similarities between industrial scrubbers and containment building sprays. These are: (1). In a typlcal industrial scrubber the gas and liguld are in countercurrent flow and each makes one pass through the device, whereas in the containment building the same bady of atr remains in the bullding for the entire time. (2). In the findustrial absorber the contact time for gas is normally in the range of a few seconds, whereas in the containment buflding the contact $t$ ime between gas and liquid is comparatively long and the liquid is recycled continuously. (3). In the contafnment buflding the mass of material to be absorbed is relatively small, and one can eas 1 ly afford to use overwhelming excess of chemical reagents to assu. complete absorption. (4). In the contalment butiding there are some problems unique to highly radfoactive environments, such as radiolysis of the spray solution.

As applications of sprays have developed, spray solutions of several chemical compositions have been ised. These include boric actd, borlc acld made basic with sodium hydroxide (caustic spray), sodfum hydroxide/sodlum thiosulfate, and borlc acid contalning hydrazine at trace level concentrations. 
Iodine washout by sprays is complicated by the fact that it may exist in three states: elemental lodine, arganic ladides, and particulate lodine. The most persistent of these forms, organte lodines, was show by Jiggleton and Alkins in $1964^{(9)}$ to be composed mainly of thethyl foulde. The fractional abundance of each of these three forms would vary with acrident conditions. For a site sultabl11ty source term rejeasel into the cantainment vessel, the percent of each of three spectes of iadine is conservatively estinated to be $91: 4: 5 .(24)$

Appendix 5.2 Models For spray washout (10)

Fission product washout in a contafment vessel can be described mathematically by a first order differential equation which equates the rate of the mass accumulation in the contalntant atmosphere to the difference between source and removal rates:

$$
\frac{\mathrm{d} C_{j}}{\mathrm{dT}}=\mathrm{G}-\mathrm{R}_{i j} \mathrm{G}_{i}
$$

where $\quad v=$ volume of gas space, $m^{3}$

$C_{j}=$ concentration of 1 th fission product in gas phase, $\mathrm{kg} / \mathrm{m}^{3}$

$G_{1}=$ ith fission product input rate, $\mathrm{kg} / \mathrm{hr}$ $R_{i j}=j^{t h}$ removal rate constant for the $i^{\text {th }}$ fission product ( $R_{i j}$ is assumed to be first order with respect to colicentration), $\mathrm{m}^{\tilde{3}} / \mathrm{hr}$.

For realistic calculations both time-dependent source and 
removal terms should be considered in modelling the spatial and temporal fission product distributions in multicompartment containment buildings. However, for a conservative analysis of the design basis LoCA an instantaneous source term may be assumed. For an instantaneous saurce, the time-dependent generation terms, $G_{i}$, in eq. (1) as replaced by an initial condition on $C_{i}$ at time zero. The washout equation may then be written as

$$
\frac{d C_{i}}{d t}=-\Sigma \lambda \text { ij } C_{i}
$$

where $\lambda_{i j}=\frac{R_{i j}}{V}=$ the $j^{\text {th }}$ removal rate constant for the $i^{\text {th }}$ fission product specie, hr

The first order renoval process defined in Eq. (2) applies until equilibrium between fission product concentration in the containment atmosphere and the containment 1 iquid mass is approached. At this point Eq. (2) is no longer valid and $\frac{\mathrm{dc}}{\mathrm{dt}}$ appraaches zero. A simple and conservative method of handling the approach to equilibrium is to use the first order washout equation until a cut-off concentration Ievel is reached. After the cut-off concentration level is reached, washout is neglected.

The washout model based on an instantaneous source term and a cutoff concentration to account for equilibrium effects may be obtained by integrating eq. (2) with respect to time:

$$
c_{i}=c_{i 0} e^{-\lambda_{i} \tau}
$$

where $\lambda \mathbf{i}=\sum \lambda_{i j}$

$$
c_{i o}=c_{i} \text { at time }=0
$$

and imposing the condition $\lambda_{i}=0$, for $c_{i} \leq c_{i}$ cut-off. In eq. (3) 
$i_{i}$ is the total removal constant resulting from all removal mechanisms for the $i^{\text {th }}$ fission product specie.

Fach fission product specic wauld have its own $;$ and cut off concentration level. Conscquently, eq. (3) must he solved for each iodine specic jndependently. The following sections describe the calculational thethods used to predist ' ${ }_{j}$ 's for particular containment systems and fission product species.

Appendix 5.3 Models for absarptions of elemental iodine

lilemental iodine is the dominant iodine specic in post-accident atmospheres. It is removed at an appreciable rate by both spray drop absorption and by wall deposition. For simplicity, subscripts indicating the iodine species are dropped in the development of equation in this sectjon.

\section{IPpendjx 5.3.1 kbsorption by Spray Drops}

The removal rate of any absorbable specie may be equated to the prodict of concentration increase and spray flok rate:

$$
R_{c}=F\left(C_{c o}-C_{e i}\right)
$$

where $\mathrm{R}_{\mathrm{c}}=$ removal rate, $\mathrm{Kg} / \mathrm{hr}=\mathrm{RC}$ :

$c=$ airborn iodine concentration, $\mathrm{Kg} / \mathrm{m}^{\overrightarrow{3}}$.

$R=$ spray removal rate constant, $\pi^{3} / h r$,

$\Gamma=$ spray flow rate, $\mathrm{s}^{3} / \mathrm{hr}$

$C_{\text {eo }}=$ concentration of solute in spr.y drops leavina atmosphere, $\mathrm{kg} / \mathrm{ru}^{3}$,

$\mathrm{C}_{\text {io }}=$ concentration of solute in 1 iquid entering atmosphere $\mathrm{kg} / \mathrm{m}^{3}$.

For spray liquid which has not been exposed to the containment atmosphere previously (i.e. during the injection phase of spray operation), $C_{e}, i=0$ 
and $C_{e 0}$ may be related to the equilibrium partition coefficient, $H$. though the use of an absorption efficiency, $E$, defined by:

$$
c_{c o}=H E(C)
$$

where $H=$ equilibrium partition coefficient applicable to spray absorption.

$E=$ fractional approach to cquilibrium by spray drops during a single pass,

$\mathrm{C}=$ concentration of solute in gas phase, $\mathrm{Kg} / \mathrm{m}^{3}$.

Eq. (4) and (5) may be used together with eq. (2) to related $\lambda$ to the spray parameters:

$$
\lambda_{\mathrm{s}}=\frac{\mathrm{FHE}}{\mathrm{V}}
$$

where $\lambda_{s}=$ washout + due to the spray, $\mathrm{hr}^{-1}$.

$v=$ volume of sprayed region, $\mathrm{m}^{3}$.

The absorption efficiency, E, may be computed by several models. The models differ in degrees of conservatisma and simplicity, and hence represent alternatives useful in specific applications.

\section{Stagnant film madel}

The stagnant film model is based on absorption through both a gas film and liquid film. This model is conservative because it neglects mixing within the drop. In this model, $E$ is computed by

$$
E=1-\exp -\left[\frac{6 k_{g} t_{e}}{d\left(H+\frac{\left.k_{g}\right)}{k_{e}}\right.}\right]
$$

where $k_{g}=$ gas film mass transfer coefficient, (m/sec).

$t_{e}=$ drop exposure time, sec. 
$d=$ drop diamter, cm.

$k_{e}=1$ iquid film mass transfer coefficient, $\mathrm{cm} / \mathrm{sec}$.

The gas phase mass tranafer coefficient, $k_{g}$, may be computed from the Ranz-Marshall approximation (11) to the Frossling equation $(12)$ :

$$
k_{g}=\frac{D}{d}\left(2+0.6 R e^{0.5} \mathrm{Sc}^{0.33}\right)
$$

where $D=$ diffusivity of solute in gas phase, $\mathrm{cm}^{2} / \mathrm{sec}$.

Re= Reynolds number for fall drop.

$\mathrm{Sc}=$ Schmidt number for solute in gas phase.

On the liquid side of the drop interface, the film coefficient is predicted by Griffiths $(13)$ approxigation to the rigid drop $\{14\}$ alssorption equation:

$$
k_{e}=\frac{2 \pi^{2} n}{3} j^{5}
$$

where $D=$ diffusivity of solute in liquid, $\mathrm{cm}^{2} / \mathrm{sec}$.

F.q. (9) is a conservative formulation of the rigid drop equation in that it predicts lower rates of absorption than the rigid drop equation. (15)

\section{Rigid drop mode]}

The rigid drop model is similar to the stagnant film model in that it represents a mathematical solution to absorption by a stagnant sphere, accounting for gas phase and liquid phase mass transfer resistance.

Dankwert's ${ }^{(14)}$ equation for drop absorption can be written in tems of the abscrption efficiency, $E$, as ${ }^{(15)}$ :

$$
\begin{aligned}
& E=1-\sum_{n=1}^{\infty} \frac{6 s_{h}^{2} \exp \left(-n^{2} j\right)}{a_{n}{ }^{2}\left[a_{n}{ }^{2}+s_{h}\left(s_{h}-1\right)\right]} \\
& s_{h}=\frac{k_{g} A}{H D_{e}} \\
& \theta=\frac{D_{e}^{t} e}{a^{2}}
\end{aligned}
$$


$\mathrm{a}=$ drop radius, $\mathrm{cm}$.

$a_{n}=N^{\text {th }}$ roat of $\alpha_{n} \cot \alpha_{n}+\left(3_{h}-1\right)=0$

Numerical comparisons of the stagnant film and rigid drop models (15) show that the stagnant film model typically under predicts the E values as compared to the rigid model by less than $16^{\circ}$.

Well-mixed drop model

In the wel1-mixed urop model, mass transfer resistance inside the drop is neglected. The solute concentration on the liquid side of the gas/liquid interface is equated to the average concentration in the drop. While the liquid phase mass transfer resistance is neglected, gus/liquid equilibrium are properly accounted for in this model. The drop efficiency may be expressed as (15)

$$
E=1-\exp -\left[\frac{6 k g^{t} c}{d H}\right]
$$

By comparison with the stagnant film E, Eq. (7), Eq. (11) would apply where $k_{e}$ was large [small drops or circulating drops) or where H was large compared to $\mathrm{k}_{\mathrm{g}} / \mathrm{k}_{\mathrm{e}}$ (reactive liquid).

Numerical values of E predicted from eq. (11) are as much a factor of two higher than values of E predicted from stagnation fj!m model. For 4 values larger than $10^{5}$, a 11 thrce models yield similar predictions. Appendix 5.3.2> Deposition of iadine on interior containment surfaces

Surface deposition of iodine occurs as the result of several transport processes which occur in series. Regimes of trensport include: the bulk gas phase, the gas boundary leyer, the liquid film, and the solid wall surface. Of these, transport in the gas boundary layer has heen show:" to be the controliting step. (16)

Several models have been proposed to describe fission product removal due to surface deposition. Of these, the Knudsen-Hilliard (17) 
and the Yuilie-Baston ${ }^{(18)}$ model appear to be $j n$ good agreement with available experiments. The knudsen-Hilliard model views deposition as a gas film transport process to vessel surfaces. The gas film mass transfer coefficient is predicted from natural convection heat transfer corrclations by a mass-heat transfer analogy. The Yuille-Baston nodel is based on the penetration theory for mass transfer, and uses il natural convection heat transfer model to estimate gas flow velocitas.

In the Knudsen-Hilliard model, the bulk gas in the containment atnosphere is assuned to be well-mixed by natural convection, by stearn flows, and by spray operation. A gas boundary Jayer is established adjacent to containment surfaces. For laminar boundary layer the mass transfer coefficient ucross the gas boundary layer is predicted by the equation $\quad \frac{k_{g} l}{D}=0.59(\mathrm{GrSc})^{i}$

whore

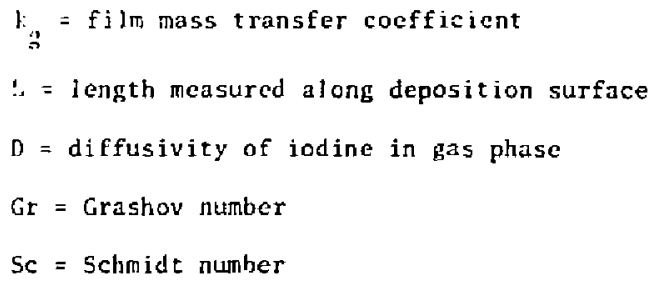

For turbulent boundary flow, the mass transfer coefficient is predicted using the equation

$$
\frac{k_{g} L}{D}:=0.13(\mathrm{CrSc})^{i / 3}
$$

The transition from laminar flow to turbulent flow occurs at a critical Grashov number. Ir.-portant variables in Grashov number include length $L$, and temperature difference between the gas and the wall surface. 
Therefore the plate length at which the flow transition occurs depends on thermal conditions in the cortainment vessel.

The iodine removal rate constant for a particular compartment in the cantainment is given by

$$
\lambda_{n}=\frac{k^{n}}{v}
$$

where $\lambda_{n}=$ removal rate constant duc to surface deposition

$$
\begin{aligned}
& k_{B}=\text { average mass transfer coefficient } \\
& x=\text { surface area for wall deposition } \\
& V=\text { volume of contained gas }
\end{aligned}
$$

Appendix 5.3.3 overall absorption rate

The overall rate is the sum of that due to spray operation and natural convection plate-out:

$$
\lambda=s^{\prime}+n
$$

Thus the airborne concentration at any time, $t$, after the release of an instantaneous source term is:

$$
\left.c=c_{0}{ }^{*}-()_{s}+\lambda_{n}\right) t
$$

\section{Appendix 5.4> Models for absorption of organic iodides}

Methyl iodide is slightly soluble in water, and reacts slawly with pure water. Therefore its absorption rate is governed by mass transfer resistance in the 1 iquid phase. This is different from elenental iodine which is more soluble in water, and undergoes very rapid hydrolysis through ionic reactions.

For slightly soluble gases which are relatively inert chenically, the absorption rate is strongly influenced by the presence of reactive additives which destroy the dissolved solute. Sladels for the absorption rates of drops, wall films, and sump pools will be described in detail. 
<Appendix 5,4,1> Absorption by a stagnant drop

Absorption by a stagnant drop with a surface resistance nay be predicted from a solution of the diffusion equation written in spherical coordingtes

$$
\frac{\partial C}{\partial t}=\frac{D}{r^{2}}\left[\frac{\partial}{\partial T}\left(r^{2} \frac{\partial c}{\partial r}\right)\right]-R
$$

subject to the surface condition

$$
D \frac{\partial C}{\partial N}=k_{g}\left(C_{B}-C_{g i}\right)
$$

where $N=$ autward directed normal at the surface of the drop.

$\mathrm{D}=\mathrm{diffusivity}$ in the liquid,

$R=$ destruction rate per unit volume by chemical reaction.

A solution to sq. (17), subject to the boundary condition (18) and assuning $C$ is initially zero within the drop, has been given by Danckwerts. (14) The total amount of absorption in time $t$ is obtained by integrating the flux over the area and time. The final equation for the amount of solute gas absorbed by a drop is

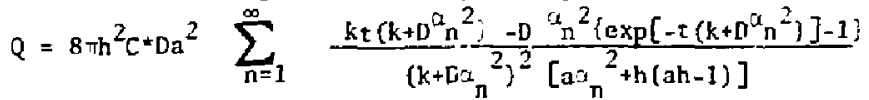

where $h=\frac{k}{\mathrm{HD}^{\prime}}, \mathrm{cm}^{-1}$

$$
\begin{aligned}
& \mathrm{C}^{*}=\mathrm{HC}=\text { solute concentration on liquid side of interface, } \mathrm{K}_{\mathrm{g}} / \mathrm{cm}^{3}, \\
& a_{\pi}=\mathrm{N}^{\text {th }} \text { root of }(\mathrm{ac}) \operatorname{Cot}(\mathrm{ar})+a \mathrm{~h}-1=0, \mathrm{~cm}^{-1} \\
& t=\text { first order reaction rate constant, } \mathrm{sec}^{-1} \\
& a=\text { drop radius, cm } \\
& D=\text { diffusivity of solute in liquid, } \mathrm{cm}^{2} / \mathrm{sec} \text {. } \\
& Q=\text { total anount of solute absorbed during exposure time } t, \mathrm{k}_{\mathrm{g}},
\end{aligned}
$$


The roundary condition, eq. (19), has been assumed to apply at all points on the surface of the drop. Also the reaction rate, $R$, was taken to be that for a first order reaction, $k C$,

If gas phase resistance is snall, $h$ becomes large. In the Jimit as $h$ approaches infinity, aq. (20) becomes

$Q=8 \pi a D C * \sum_{n=1}^{\infty} \frac{k a^{2}+\frac{D n^{2} r^{2}}{k+D n^{2} \Pi^{2} / a^{2}}-\left(1-\exp \left[-t\left(k+\frac{D n^{2} n^{2}}{a^{2}}\right)\right]\right\}}{k a^{2}+D n^{2} n^{2}}$

This equation would be expected to apply for absorption of slightly soluhle substances such as methyl iodide unless the reaction rate constant $k$, were very large. For very large values of the reaction rate gas phasc resistance is applicable.

Both eq. (19) and eq. (20) can be written in terms of absorption efficiency, E. Since $E$ is equal to the attained solute concentration divided by the equilibritm concentration, $E=\frac{30}{4 \pi a^{3} c^{*}}$ SAppendix 5.4.2) Wall film absorption (10)

The flow characteristics and absorption by liquid fjlms have been extensively studied during the past 25 years. Based on theoretical and experimental studies, the general characteristics of wetted wall flow may be stated as follows. At low flow velocities, laminar flow persists, the velocity profile is parabolic, and the free surface velocity is $3 / 2$ the zverage velocity. At Reynolds numbers in the range $5-25$, waves liegin to appear on the surface, though the flow is substantially laminar. At Reynolds number of 250-500 the flow becomes turbulent.

Absorption into a wetted wall film is described mathematically by eq. (21): 
$\frac{\partial C}{\partial t}+v_{x} \frac{\partial C}{\partial x}+v_{y} \frac{\partial C}{\partial y}+v_{z} \frac{\partial C}{\partial z}=D\left(\frac{\partial^{2} C}{\partial x^{2}}+\frac{\partial^{2} C}{\partial y^{2}}+\frac{\partial^{2} C}{j z^{2}}\right)-R$

where $C=$ concentration of solute in 1 iqujd, $k_{g} / \pi^{3}$.

$t=\operatorname{tine}, \sec$.

$v_{x}, v_{y}, v_{z}=$ rlujd velocities in $x, y, z$ directions, m/sec.

$n=$ diffusion coefficient of solute in liquid, $m^{2} / \mathrm{sec}$.

$R=$ destruction rate per unit volume by chemicaj reare ion = kc: $\mathrm{k}_{\mathrm{Bg}} / \mathrm{m}^{3}-\mathrm{sec}$,

$k=$ first order reaction rate constant, sec -1

The total absorption rate for methyl iodine is obtained by integraing the absorption rate per unit area over the surface area. Analytical solution is possible only for relative simple flow regines. $A$ simple fluw regime of practical use is that corresponding to fully developed one dimensional flow. For this ease, the velocity profile can be witten

$$
\begin{aligned}
& \left.v_{z}=v_{\max }\left[1-r_{y}^{x}\right]^{2}\right] \quad y: . \\
& v_{x}=0 \\
& v_{y}=0
\end{aligned}
$$

Where $V_{\text {max }}=$ velocity at gas/liquid interface,

$\Xi \quad=$ distance paralle] to plane of film, measured in direction of liquid flok,

$x$ = distance measured perpendicular to plar of film measured froth surface of film taward solid sirface,

$=$ thickness of liquid rilm.

Using this velocity profile, and neglecting diffusion in the Y-direction eq. (21) becones 


$$
V_{\max }\left[I-\left(\frac{x}{5}\right)^{2}\right] \frac{\partial C}{\partial z}=D \frac{\partial^{2} C}{\partial x^{2}}-k C
$$

For short length of laminar film, the solute does not have time to penetrate far inta the film, and hence absorption takes place as though the film were infinite in thickness. The differential equation for this case involving the penetration thcory approximation, is obtained from cq. (25) by setting $x$ equal to zero.

$$
v_{\operatorname{mix}} \frac{\partial c}{12}=n \frac{\partial^{2} c}{\partial x^{2}}-k C
$$

Fia. (3) anay be writien in terds of exposure time,

$$
t=\frac{z}{i_{\max }} \text {. }
$$

The solution to eq. (2.1) is given by Danckwerts (20) as

$$
q=d \cdot \frac{j}{k}\left[(k t+1 / 2) \cdot \operatorname{erf}(k t)+\frac{k t}{\Pi !} e^{-k t}\right]
$$

whers $C^{*}=$ concentration in liquid at the gas-liquid interface $q=$ anount atsorbed per unit area up to time $t$.

Sost experiment data obtained for laniner flow in short wetted wall Lolumns agree with prediction based on the penetration theory. Serious discrepancies however may be encountered if the absorption process causes interfacial turbulence. (19) Interfacial turbulence enhances absorption compared to predictions based on the penetration theory.

Appendix 5.4.3; Absorption by sunp pool liquid (10)

Uptake of methyl iodide in sumps in a PHR containment system can be important compared to spray and wall film absorption for spray solutions which react slowly with methyl iodide. For the slow reaction regime, expasure of liquid in the form of sprays and wall films merely cause it to atzain saturation with respect to the gas phase. If no additional reaction occurred, recirculated liquid would re-enter saturated in methyl 
iodide, and no further absorption would occur. However, the residence tine of liquid in the pool is relatively Jong, perajting relatively slow reactions to destroy absorbed methyl jodide.

A material balance made on the spray liquid can be used to rejate the methyl iodide washout rise to the peol reartion ride. For the pros, the followilg call ${ }_{3}$ anaterial balance can be written

$$
\begin{aligned}
& \text { Input rate }=\text { FIIC } \mathrm{g}_{\mathrm{g}} \quad(27 \mathrm{a}) \\
& \text { Output rate }=\mathrm{FC}_{t}+\mathrm{kv} \mathrm{C}_{\xi} \quad \text { (27bj } \\
& \text { Accunulation rate }=0 \text { for steady statc ahsorption } 12701
\end{aligned}
$$

and

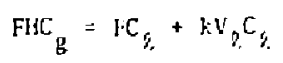

where

$F=$ volumetric spray flow rate entering pool. $\mathrm{m}^{3} / \mathrm{sec}$.

$k=$ reaction rate constant, $\sec ^{-1}$

$\mathrm{C}_{\mathrm{q}}=\mathrm{CH}_{3} \mathrm{l}$ concentration in pool $1 \mathrm{iquid}, \mathrm{kg} / \mathrm{m}^{3}$,

$v_{p}$. volume of pool liquid, $\mathrm{m}^{3}$.

A similar material balance made for the gas phase leads to

$$
F C_{\ell}=F l C_{g}+V_{g}\left(\frac{d C g}{d t}\right)
$$

If eq. (2g) is solved for $C_{2}$, the methyl iodide concentration in the liquid, and the result substituted into eq. (2J) and the resulting equation solved for $\mathrm{C}_{g}$, the result is

$$
c_{g}=c_{g o} \exp -\left[\frac{F k H t}{V_{g}\left(F / V_{g}+k\right)}\right]
$$

where $\mathrm{C}_{\mathrm{go}}=$ airborne methyl iodide concentration at time zero, $\mathrm{kg} / \mathrm{m}^{3}$,

$$
\begin{aligned}
F & =\text { spray flow rate, } \mathrm{m}^{3} / \mathrm{sec}, \\
V_{B} & =\text { volume of gas phase, } \mathrm{m}^{3},
\end{aligned}
$$




$$
\begin{aligned}
v_{k} & =\text { volume of liquid, in containment pump, } \mathrm{m}^{3}, \\
k & =\text { first order reaction rate constant, } \sec ^{-1}
\end{aligned}
$$

Eq. (29) would be applicuble for cases where $k$ is too low to appreciably enhance absorption during a single pass of spray drops or wall films through the contoinment atmosphere. This case obtains for water sprays which contain ro special additive for methyl iodide, hence would apply to boric acid, huffered boric acid, and sprays made basic bith sodium hydroxide.

\section{sAppendix 5.4.4> Effect oi spray solution conposition}

Pure water reacts very slowily with methyl iodide, and wethy iodide is only slightly soluble in water. Therefore, the spray removal rate is small unless reactive chemicals are added to the spray solution.

Methyl iodide reacts in aqueaus solution by substitution icactions (26) in which a nucleophylic agent replaces the methyl radical. Schwendiman et. al. ${ }^{(20)}$ have sumarized reaction rates available prior to 1968. These are reproduced in Table AS.1.

of the reactants listed in Table A5.1, only four, the two forms of hydrazine, sodium thiosulfate, and perhaps sodium sulfate, appear to be practical additives for enhancing methyl iodide absorption. The others react too slowly to give an appreciable enhancement compared to water alone.

<Appendix 5.4.5> Qverall absorption rate

A model formulated from absorption theory for stagnant drops and stagnant wall films is described as follows. The overall washout for reactive sprays is

$$
\lambda=\lambda_{\text {drops }}+\lambda_{\text {wall } f \dot{z} 1 m}
$$


The washout rate constant for spray drops, 'drops' may be witten as

$$
\lambda_{\text {drops }}=-\frac{\text { Fllt }}{v}
$$

whore $\quad l=$ spray flow rite. $\mathrm{m}^{3} / \mathrm{sc}=$.

$H=$ methyl iodide partition caefficient,

I: = fractional saturation achieved daring single pass,

$y=$ volume of contaimicnt gus space, $\mathrm{m}^{3}$.

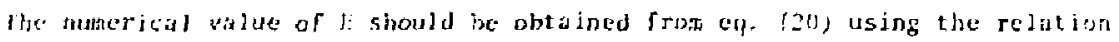
I. = 3n/4id ${ }^{3} \mathrm{C}^{*}$. In selecting a drop size, it would be best to break the drop size spectrum into increments, and integrate eq. (3i) aver the spect rum.

If a mean drop size is to be used, the volume median diameter is recomended insuse it will provide a conservative estimate of washout rate. (21)

Hie wasiout rate constant for wall films, twall film may he cxpressed :15

$$
\lambda_{\text {wall }} \mathrm{film}=\frac{\mathrm{gi}^{3}}{\mathrm{rc}_{\mathrm{g}}}
$$

where $g / C_{g}=\frac{\text { absorption }}{\text { gas phate per un it area }}$, m/ $/ \mathrm{sec}$.

$$
\begin{aligned}
& \therefore=\text { surface area of kall film, } \pi^{2} \\
& V=\text { volume of gas space, } m^{3}
\end{aligned}
$$

The numerical value of $q / C_{g}$ can be abtained fram eq. (23) with a lower limit to absorption of $\frac{\partial C}{\partial z}=0$, then eq. (23) becomes

$$
0=0 \frac{d^{2} c}{d x^{2}}-k c
$$

For this steady state nodel, the boundary conditions are

$$
\begin{aligned}
& C=C^{*} \text { at } x=0 \\
& \frac{d c}{d x}=0 \text { at } x=\xi
\end{aligned}
$$


The second of these boundary values is based on the assumption that there is no net transfer of methyl iodide to the solid wall. The absorption rate per unit area of interface is

$$
q=C * \sqrt{k \bar{D}} \tanh \left(\sqrt{\frac{k}{D}} \delta\right)
$$

From eq. (34), $4 / \mathrm{C}_{\mathrm{g}}$ is given by

$$
q / C_{g}=1+\overline{k D} \tanh (\sqrt{\mathrm{k} / \bar{D}} \neq)
$$

where

$$
\begin{aligned}
& H=\text { partition coefficient }=\mathrm{C}^{*} / \mathrm{C} \\
& k=\mathrm{first} \text { order reaction rate constant, ste } \\
& D=\text { diffusivity of methyl iodide in water, } \mathrm{m}^{2} / \mathrm{sec} \text {. } \\
& \vdots=\text { thickness of wall film, } \mathrm{m} .
\end{aligned}
$$

Film thickness, $\because$, ray be predicted from Iaminar flow theory, which relates the film thickness to the filn flow rate and fluid viscosity. The $f i$.n thickness is ojven by (21).

$$
\therefore=\left[\frac{3 i^{2}}{6}\right]^{1 / 3}
$$

whete $\quad \hat{i}=$ film thickness on vertical wal

$y=$ kinematic viscosity of water film,

- = film flow rate per length of perimeter,

$\mathrm{g}=$ acceleration due to gravity

For slowly reacting sprays, a simple model may be used because the reaction race is too slow to enhance absorptions during a single pass. Solutions which fit this category are pure or buffered boric acid, and basic borax solutions contuining sodium hydroxide. Eq. (29) applies for these sprays. The spray lambda implicity defined by eq. (29) is

$$
\begin{gathered}
\lambda=\frac{F}{V_{g}\left(F / V_{Q}+k\right)} \\
F=\text { total spray rate, } \pi^{3} / \mathrm{sec},
\end{gathered}
$$




$$
\begin{aligned}
& v_{g}=\text { volume of gas space, } \pi^{3} \\
& v_{l}=\text { volume of spray liquid in containment vessel sump, } \pi^{3}, \\
& k=\text { rirst order reaction rate constant, sec }
\end{aligned}
$$

Appendix 5.5. Models for herosol particle wishout

Appendix 5.5.12 hashout by spray drops

The removal of nerosol particles by sprays is a notc complex process than guscous absorption because a number of mechanisms contributc siznificantly to capture. In a review of particle washout by containent sprays, Ritzman et. al. (16) list the following mechanisas.

- Broknian diffusion

- Diffusiophoresis

- Interception

- Inertial impaction

The relative importance of each of the contribution mechanisns depends on spray and aerosal properties. Ritzman, et. al. (16) hate evaluated cach of these mechanisms for typical LkR contaigment conditions fot a 1,210 micron diameter spray drop.

The dominant mechanisms for capture of particles in the 0.1 inicron to 1.5 micron range are diffusionophoresis and interception. For particles with diameters larger than about two microns, incrtial impaction becomes the dominant mechanism. Brownian diffusion controls capture of particles smaller than 0.1 micron diameter.

The spray removal rate for aerosols can be related to spray parameters and to the single drop collection efficiency by considering the spray to b; an assembly of single drops. The relevant equation is (22):

$$
-\frac{d c}{c}=\lambda_{s} d t=\frac{3 h F E}{2 d V} d t
$$


where $\mathrm{C}=$ aevosol concentration, $\mathrm{kg} / \mathrm{m}^{3}$

$\lambda=$ spray removal rate constant. $\sec ^{-1}$.

$h=$ drop fall height, $m$.

$F=$ spray flow rate, $\mathrm{m}^{3} / \mathrm{sec}$,

$E$ = single drop sollection efficiency,

$d=$ mean spray drop djancter, $m$

$V=$ volume of contained gas phase, $\mathrm{m}^{3}$

The quantities $h, F$, and $V$ are parameters of the containment system design. The drop diameter, $d$, is deternined by the spray nozzle design and operating conditions, and is subject to direct experiment measurement. The most difficult-to-determine parameter in en. (38) is the single drop collection efficiency, E.

From a review of available large scale test results on acrosal washout, a conservative estimate of particulate iodine washout can be obtained by choosing $(E / d)=0.1 \mathrm{Cm}^{-1}$ for $\mathrm{C} / \mathrm{C}_{\mathrm{o}}$ values from 1 to 0.01 , and $0.01 \mathrm{Cm}^{-1}$ for $c / C_{0}$ value smaller than $0.01^{(22)}$. Mathematically this can be stated in $t$ 'sns of washout $\lambda$ 's

$$
\begin{aligned}
& \left.\lambda=\frac{3 h F}{2 V}\left(0.1 \mathrm{~cm}^{-1}\right) \text { for } 0.0\right] \leq C / C_{0} \leq 1.0 \\
& \lambda=\frac{3 h F}{2 V}\left(0.01 \mathrm{~cm}^{-1}\right) \text { for } c / C_{0} \leq 0.01
\end{aligned}
$$

\section{SAppendix 5.5.2> Deposition of particles on surfaces}

Airbome particles are known to be removed by a number of mechanisms even if sprays do not operate. (2z) Daminant among these is gravity settling ${ }^{(23)}$ onto horizontal surfaces. Hall plating occurs by diffusion, by thermophoresis, by diffusiophoresis, and by turbulence in the wall boundary layer. All of these mechanisms lead to removal rates which are small compared to the spray removal rate, and therefore surface deposition 
of particles had usually been neglected in site craluations.

Append ix 5.6> Summary and Conclusions

Spray systems may be included in containment vessels as an enginecred sufety feature to reduce pressurc and scrub aitborne containments in the unljkely event of a loss-of-coolant accident. The effectiveness of spray scrubhing is jmportant in the sjting of power reactors, because the spray runoval rate directly affects the calculated radiation dose from the design basis loch which nould be received by people in the plant's vicinity.

Specific conclusions and sumaty starements are 1 isted as follows:

a) Wathematical rodels are arailable to conservatively predict washout for the several physicochenical forms of iodine.

2) For elemental iodine, the most abundant airborne iodine spesies, a stagnant film model has been adoptcd by the NRC staff. This nodel is a simplified form of the equation for absorption by a rigid sphere accounting for a mass transfer resistance in both the gas and liquid phase.

3) Absorption of methyl iodide, the most persistent iodine form expected to be present in postaccident atmospheres, is prodicted by a ncdel in which it is assused that both falling drops and wall films are stagnast. For most spray solutions methyl iodide absorption is too slow to appreciably affett two hour dose calculatjons.

4) Aerosol particle washout is predicted using a simple model in which conservative estimates of the single drop collection efficiency are obtained from large scale experiments. 
5) The composition of spray solutions plays an important role in the absorption rate of elemental iodine because the fiunerjcal value of the partition coefficient applicable to the spray washout depends on solution reactions. Experimentally derived partition coefficients are available for plain-boric acid, for sodium hydroxide solutions, for trace level hydrazine solutions, and for solutions of sodium thiosulfate.

6) Nethyl iodide is absorbed only slowly by spray solutions which do not contain special additives. Of the spray solutions currently in use, anly sodiun thiosulfate at 1 wt. percent enhances the absorption rate to an appreciable extent. For thiosulfate solution, absorption by wall liquid films is typically morc inportant than that by falling spray drops.

7) Surface deposition of elemental iodine can be predicted using a model in which it is assumed that the 1 imiting transfer resistance resides in the gas phase boundary layer. Predicted surface deposition rates are small compared to spray washout rates. 
References of Appendix 5

(1) "Indian point Nuclear Generating Station Unit No. 2 Prelininary Safety Analysis Report," Consolidated Erison Company of Stw York, Inc., Vol. III, Docket No. 50-247, 1965.

(2) "Zion Station, "reliminary Safoty Analysis Report," Commontealth Edison Company, Vols. I and It, Docket : $10.50-205$, June J 1067 .

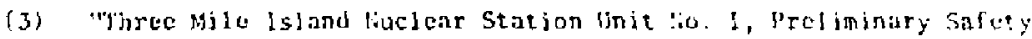
Aualys is Report," Met ropolitan Edison Company, Vols. I, II, ami II, Docket No. 50-289, May 1967.

(4) "Diablo Canyon Preliminary Safety Analysis Report," Patific Cais and Electric Company, vols. I and I1; bocket so. 50-275, . bamusy 1967.

(5) Norman, W.S., Absorption, Djstidjatjon and Cooling Towers." loongmins, Greene and Company, London, 1961.

(6) Bird, R. B., Stewart, H.E. and Lightfoot, E.2., "Transport Phenonenis." John Wiley and 5ons, Inc., New York, 1960.

(7) Sherwood, T.K. and Pigford, R.L., "Absorption and extraction," Second Edition, McGraw-11ill Book Company, Ine., New York, 1952.

18) Gobler, T. "Mass Transfer and Absorbers" Fergamon Press, New York, 1966.

(9) Egge]ton. A.E.J, and Atkins, D.H.F., "The Identification of Trace Quantities of Radioactive Iodine Compounds by Gas-chromatographic and Effusion Methods," Radiochen. Acta., 3(3), PP. 151-158(1964).

(10) Pastma, A.K., Sherry, R.R., and Tam, P.S., "Technological Bases for itodels of Airborne Contaninants in Containment Vessels, "WHREG/ CR-0009, Detober 1978. 
(11) Ranz, W. E., and W. R. Marshall, Jr., "Evaporation from Drops, Parts I and II" Chemical Engineering Progress, 48, pp, $141-146$ and pp. $173-180$ (1952) .

(12) Frossling, N., Gerlants Beits. Geophys., 52, p. 170 (1938), as referenced by R. B. Bird, W. E. Stcwart, and F. N. Lightfoot, Tranport Phenomena, John Wilcy and Sons Inc., New York, 1960, p. 409.

(13) Griffiths, V., "The Removal of Iodine from the Atmosphere by Sprays" AlisB(S)R 45, UKNEA, 'uthority and Safety branch, Risloy, Lancs, England, January, 1963.

(14) Dankwerts, P.V., "Absorption by Simultaneous Diffusion and Chemical Reactions into Particles of Various shapes and into Falling Drops", Trans. Faraday Soc., 47, pp. $1014-1023$ (1951).

(15) Postma, A. K., and W. F. Pasedag, "A Review of Mathematical lodels for Predicting Spray Removal of Fission Products in Reactor Contain ment Vessels" WASH-1329, U.S. AEC, Washington, D.C., 20545, June 1974.

(16) Postma, A. K., R. L. Ritzmas, J. A. Gieseke, and E. W. Schnidt, Models for Predicting the Removal of Airbome Contaminants by Reactor Containment Sprays", BNWL-B-417, Battelle Pacific Northwest Labs, Richland, Washington, 1975.

(17) Knudsen, J. G., and R. K. Hilliard, "Fission Product Transport by Natura1 Processes in Containment Vessels" BNwL-943, Battelle Pacific Northwest Labs., Richland, Washington, 1969.

(18) Yuill, W. A., Jr., and V. F. Bastor, "A Model for Fission Product Deposition Under Natural-Response Conditions in Containment Buildings" Nuclear Safety, 10 , pp. 492-498 (1969).

(19) Lynn, S., J. R. Straatemeier and H. Kramers, "Absorption Studies 
in the Light of the Penetration Theory", Chem. Engr. Sci., 4, pp. $49-57$ (1955).

(20) Schwendiman, L. C., R. A. Hasty, and A. K. Postma, "The llashout of Nethyl Iadide by Hydrazine Sprays-Final Report" BNliL-935, Battelle Pacific Northwest Labs, Richland, Washington, 1968.

(21) Postma, A. K., "Absorption of Methyl Iodide by Aqueous Hydrazine Solutions within Spray Chambers" Ph.D. Thesis in Chemical Enginecring. Oregor State Univ., Corvallis, Oregon, 1970.

[22) Postma, A, K., "Removal of lodine Aerosol by Containment Sprays" BCT-101, Benton City TechnoJogy, Benton City, Washington, November, 1976 .

25) Hilliurd, R. K., and L. F. Coleman, Matliral Transport Effects on Fission Product Behavior in the Containment System Experiments", BNiL-1457, Battelle Pacific Morthrest Iabs., Richland, Washington, June 1973.

(24) NRC Regulatory Guide I.4, "Assumptions Used for Evaluating the Potential Radiological Consequences of a LOCA for Pressurized fiater Reactors". 


\begin{tabular}{|c|c|c|c|c|}
\hline \multicolumn{5}{|c|}{$\begin{aligned} \text { Table A5+1 Summa : of Reaction } & \\
& \text { in Aqueous Solution }\end{aligned}$} \\
\hline Reactant & $k^{* \star}$ & $\begin{array}{l}\text { Activation } \\
\text { Energy } \\
\text { (kCal/mole) } \\
\end{array}$ & $\begin{array}{c}\text { Temperature } \\
\text { Range } \\
\text { Studied }\left({ }^{\circ} \mathrm{C}\right) \\
\end{array}$ & $\begin{array}{c}k \\
\text { Extrapolated } \\
\text { at } 120^{\circ} \mathrm{C} \\
\end{array}$ \\
\hline $\mathrm{H}_{2} \mathrm{O}$ & $1.4 \times 10^{-9 *}$ & $>24.8$ & $30-93$ & 0.00006 \\
\hline $\mathrm{F}^{-}$ & $7.08 \times 10^{-8}$ & 25.2 & - & 0.002 \\
\hline $\mathrm{Cl}^{-}$ & $3.3 \times 10^{-6}$ & 21.97 & - & 0.025 \\
\hline$B x^{-}$ & $4.16 \times 10^{-5}$ & 19.31 & - & 0.11 \\
\hline $\mathrm{OH}^{-}$ & $6.36 \times 10^{-5}$ & 22.22 & $30-70$ & 0.55 \\
\hline $\operatorname{scN}^{-}$ & $3.58 \times 10^{-4}$ & 19.95 & $25-35$ & 1.2 \\
\hline $\mathrm{I}^{-}$ & $4.71 \times 10^{-4}$ & $17.5 B$ & - & 1.6 \\
\hline $\mathrm{CN}^{-}$ & $5.76 \times 10^{-4}$ & 20.47 & $20-55$ & 2.5 \\
\hline $\mathrm{N}_{2} \mathrm{H}_{4}$ & $1.1 \times 10^{-3}$ & 20.2 & $25-65$ & 10 \\
\hline $\mathrm{A}_{\mathrm{g}}^{+}$ & $2.61 \times 10^{-3}$ & 19.4 & $15-45$ & 7 \\
\hline 1,1 & & & & \\
\hline $\begin{array}{l}\text { dimethyl } \\
\text { hydrazine }\end{array}$ & $7.7 \times 10^{-3}$ & I 8.4 & $25-35$ & 13 \\
\hline $\mathrm{s}_{2} \mathrm{O}_{3}^{--}$ & $3 \times 10^{-2}$ & 18.88 & $10-25$ & 70 \\
\hline $\ln _{3}-$ & $3.5 \times 10^{-2}$ & - & 25 & - \\
\hline $\begin{array}{r}\text { Cal } \\
\text { cor } \\
* * \quad \mathrm{Bir}\end{array}$ & $\begin{array}{l}\text { ated fron } \\
\text { tration }= \\
\text { cular rea }\end{array}$ & $\begin{array}{l}\text { first order } \\
55 \text { moles } / 1 i \\
\text { tion rate c }\end{array}$ & $\begin{array}{l}\text { constant usin } \\
\text { at } 25^{\circ} \mathrm{C}\end{array}$ & mole $e^{-1} \sec ^{-1}$ ) \\
\hline
\end{tabular}




\section{Appendix 6. Atmospherje Dispersion}

Append ix 6.1 The Cicneral Atmospheric Transport Model

an atmospheric transport model is an important link which connect an

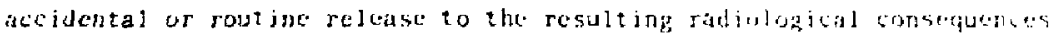
for a fixcd release guantity, the magnitude of the dose and duratere we exposure to deliver a gajer dose, depend apon the tharacteristics of the

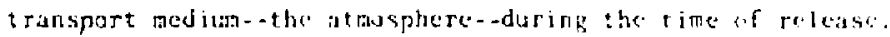

An appropriate starting point for describing tho turbulant deforitu

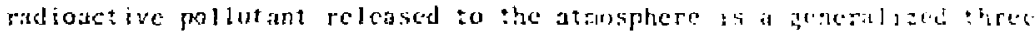
dimensional, : ime dependent diffusion equat jon ameluding sourtes,

$$
\frac{t x(\vec{r}, t)}{\vec{i} t}=i \cdot \dot{i}(\dot{r}, t)+S(\dot{r}, t)
$$

where

$$
\begin{aligned}
& x(\vec{T}, t)=\text { consentration of the gives misterial at positjon r, ind } \\
& \text { time, t, jst curjes/min. } \\
& j(\dot{r}, t)=d j f f u s i t^{2} \text { mass flux of the airhornc materlal is } \\
& \text { curies/n }{ }^{2} / 5 \text {, and } \\
& S(t, t)=\text { souret function in curie } / m^{3} / s
\end{aligned}
$$

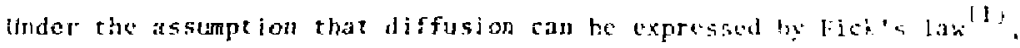

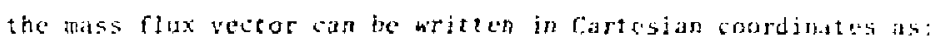

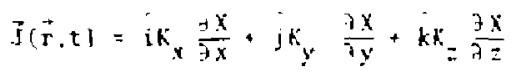

whers the $K^{\prime} s$ are spoce and time dependent diffusion coefficient $(2,2)$. If the source is an instantaneous point source at $\vec{r}=\left(x_{0}, x_{0},{ }_{0}\right)$ and $t=1$, the source tern becomes 


$$
S(x, y, z, t)=Q \delta\left(x-x_{0}\right) \delta\left(y-y_{0}\right) \delta\left(z-z_{0}\right) \delta(t)
$$

where

$Q=$ nagnitude of the instantaneous release in curies.

$\dot{s}=$ Dirac delta function.

With the source thus defined, and the further restriction that the $K_{i}^{\prime}$ 's are each space and time independert it is possible to solvo Equation (I) by means of Laplace Transforms and obtain the solution presented by Roherts ${ }^{(3)}$.

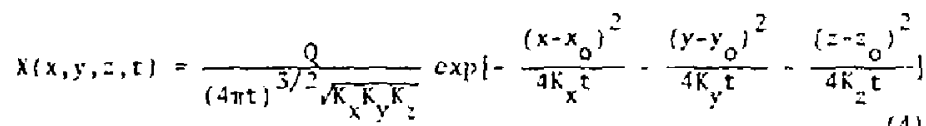

This is the fundamental equation of diffusion in the atmosphere and is completely valid for an infinite static air mass or an infinite ajs mass in which the coordinate system follows the trajectory of the wind vector. The concept of applying tquation (4) to atmospheric problems by developing expressions for the k's is referred to as " $k$ Theory". This theory has anly been applied successfully to diffusion problens in the free atmosphere and has provided useful theoreica! results, as described by Gifford (l).

Most workers in the area of airborne dispersion make use of statisticat theory put forth by Taylor ${ }^{(4)}$. In statistical theory, the form of Equation (4) as a solution to the diffusion equation is rctained. However, it is postulated that a quantity of matroial instantaneously released to the free static atmosphere assumcs a Gaussian distribution along the $x, y$ and $z$ axes. 
Under this assumption the basic dispersion equation for an instantaneous point source is

$$
x(x, y, z, t)=\frac{Q}{(2 \pi)^{3 / 2}{ }_{D_{x} \sigma \sigma_{z}}} \exp \left[-\frac{\left(x-x_{0}\right)^{2}}{20_{x}^{2}}-\frac{\left(y-y_{0}\right]^{2}}{2 c_{y}^{2}}-\frac{\left(z-z_{0}\right)^{2}}{2 o_{z}^{2}}\right]
$$

The $\sigma^{\prime}$ s are tlic mean square deviations of the spreading plume which are $t$ ime depencient parameters. By comparing Fquatian (5) to liquation (1), it is observed that they are exactly the same if one makes the substitution $k_{i}=: 2 / 2 t$, However, Equation (5) cannot be obtained from [aquation (I) by making this substitution. An operating chordinate systom cas be chosen so that the origin is at ground level at or beneath the point of emission, with x-axis cextending horizontal$1 y$ in the direction of the mean wind velocity $\bar{u}$. The $y$-axis is in the horizontal plane perpendicular to the $x$-axis, and the $z$-axis extends vertically. H is the height of the plume centerline when it fecomes essentially level, and is the sum of the physical stack lieight, $h$, and, the plume rise, $\Delta H$.

When the expanding eloud reaches the ground surface, some or all of the suspended thaterial will he reflected. The resulting higher concentration at ground level can be accounced for by assuming an inage source located at $z=-11$. With these modifieations [equation (5) becomes:

$$
\begin{aligned}
x(x, y, z, t) & \left.=\frac{Q}{(2 \tau)^{j / 2} c_{x y y^{\sigma} z}} \exp !-\frac{(x-\bar{u} t)^{2}}{2 \sigma^{2}}-\frac{y^{2}}{2 \sigma^{2}}\right] \\
& \times\left(\operatorname { e x p } \left(-\frac{(z-H)^{2}}{2 \sigma^{2}}+R_{f} \exp \left[-\frac{(z-H)^{2}}{2 \sigma_{z}^{2}}\right] !\right.\right.
\end{aligned}
$$


$R_{f}$ is the fraction of the total cloud concentration at ground level reflected back into the atmosphere.

Appendix 6.2 A Continuous Uniform Release

A continuous plume may be considered as made up of an infinite number of instantaneous or puff releases sequentially arranged with a vanishingly small time interval between puffs. The quantity of material released is expressed as a relcase rate $\dot{p}$ (curies/sec). The instantaneous increase in ground level concentration of a pollutant, $d_{x}(x, y, 0, t)$, at any downwind position can be viewed as resulting from an instantaneous source of magnitude $Q=\dot{Q} d t$. This allows one to rewrite Equation (6) as

$$
d_{x}(x, y, 0, t)=\frac{\dot{Q} d t}{(2 \pi)^{3 / 2} \sigma_{x} \sigma_{y} \sigma z}\left[1+R_{f}\right] \exp \left\{-\left[\frac{(x \bar{u} \tau)^{2}}{2 \sigma_{x}^{2}}+\frac{y^{2}}{2 \sigma_{y}^{2}}+\frac{H^{2}}{2 \sigma_{z}^{2}}\right]\right\}
$$

The average steady state ground level concentration is obtained by integrating the Equation (T) from $t=0$ to $t=\infty$. This could be a formidable task because of the time dependence of the $\sigma$ 's. However, it has been pointed out $(1,5)$ that diffusion along the $x$-axis can be igmored relative to wind transport. This allows $x$ to be treated as constant and $\sigma_{z}$ and $\sigma_{y}$ to become function of $x$, since $t=x / \bar{u}$. Removing this troublesome time dependence allows Equation (7) to be integrated giving:

$$
x(x, y, 0)=\frac{\dot{Q}\left(1+R_{f}\right)}{2 \pi \sigma_{y} \sigma_{z} \mathrm{~d}} \exp \left[-\frac{y^{2}}{2 \sigma_{y}^{2}}-\frac{H^{2}}{2 \sigma_{z}^{2}}\right]
$$

The spreading plume is constantly depleted at ground level by such processes as dry deposition and rainout. Because of these pro- 
cesses, a ground level observer at a downwind location $x$ sees a modi fied source $Q(x)$. In order to account for these effects $R_{i}$ is replaced by

$$
\mathrm{R}_{\mathrm{f}}=2 \frac{\dot{\phi}(\mathrm{x})}{\dot{\mathrm{Q}}}-1 .
$$

Then Equation (8) for a cont inuous uniform relcase becomes

$$
x(x, y, 0)=\frac{\dot{Q}(x)}{\pi \sigma \sigma_{y} \bar{u}} \exp \left[-\frac{y^{2}}{2 \sigma_{y}^{2}}-\frac{\mathrm{H}^{2}}{2 \sigma_{z}^{2}}\right]
$$

Briggs (14) has developed a sot of empirical correlations for $c_{y}$ and $\sigma_{z}$ as functions of downwind position which corresponds to liasquill's categories on open terrain. These farmulations are listed in Table Al. I.

\section{Appendix 6.3 Instantaneous Release}

The instantancous or "puff" release is an approximation to the type of enission associated with a very rapid venting of matcrial to the atmosphere. The puff, once formed, moves away from the source with a speed and direction determined by the wind at the moment of release. The instantaneous ground level concentration due to an instantaneous source can be obtained by the time-integral fron Equation (b) in the same way as Equation (9).

$$
x(x, y, o)=\frac{Q(x)}{\pi \sigma_{y} \overline{\bar{u}}} \exp \left[-\frac{y^{2}}{2 \sigma_{y}^{2}}-\frac{\mathrm{H}^{2}}{2 \sigma_{z}^{2}}\right]
$$

where $Q(x)$ is the source modified for deposition and $R_{f}=2 Q(x) / Q-1$.

Instantaneous release processes are frequently assaciated with an explosion or a short and rapid burning. For this reason, the puff will have an initial volume of dilution $v_{0}$, in the atmosphere. Taking 
this into consideration, the expression for the ground level exposure

from the instantaneous source is:

$$
x(x, y, o)=\frac{Q}{\pi\left(\sigma_{y} \sigma_{z} \bar{u}+V_{0}\right)} \exp \left[-\frac{y^{2}}{2 \sigma_{y}^{2}}-\frac{\mathrm{H}^{2}}{2 \sigma_{z}}\right]
$$

This initial dilution increases the effective exposure time by an amount $D_{o} / \bar{u}$ where $D_{o}$ is the initial ground level diameter of the puff.

slade (14) has pointed out that dispersion coefficients correlated to continuous enissions are not acceptable for puff releases. He has shawn that the Gaussian model is acceptable, as long as the empirical correlations for $\sigma_{y}$ and $\sigma_{z}$ are modified. Slade's formulation is given in Table A6.2. Brigg's correlations, which allow for more plume spread due to longer sampling time, are used only to estionate average sector doses from continous releases while Slade's correlations are used to determine the maximum exposure from an instantaneous release along the plume centerline.

If the concentration is to be calculated along the centerline of the plume $(y=0)$, the Equation (10) can be simplified as follows:

$$
x(x, 0,0)=\frac{Q}{\pi \sigma_{y} \sigma_{z} \bar{u}}
$$

\section{Appendix 6.4 Effecis of Stability}

The value of $\sigma_{y}$ and $\sigma_{z}$ vary with the turbulent structure of the atmosphere, height above the surface, surface roughness, sampling time over which the concentration is to be estimated, wind speed, and distance from the source. For the parameter values given here, the sampling time is assumed to be about 10 minutes, the height to be the lowest several hundred meters of the atmosphere, and surface to be relatively open country. The turbulent structure of atmosphere and 
wind speed are considered in the stability classes, and the effect of distance from the source is embodied in the graphs determining the parameter values. Mean square deviations, $z_{y}$ and $z_{z}$, used in the dispersion equations are ostimated from the stability of atmosphere, which is in turn estimated frot the wind speed at height of about 10 meters and, during the day, the incoming solur radiation or, during the night, the cloud cover ${ }^{(6)}$. Pasquil ${ }^{(6)}$ proposed a series of six atmospheric stability categories, which are shown in Table Ad.t, cach having a different ampirical correlation for $\sigma_{y}$ and $\sigma_{z}$. Class $A$ is the most unstable, class f the most stable class considered here. Note that the neutral class II can be assumed for overcast conditions during day or night, reguruless of wind speed.

"Strong" incoming solar radiation corresponds to a solar altitude greater than $60^{\circ}$ with clear skics; "slight" insolation cortesponds to a solat: altitude from $15^{\circ}$ to $35^{\circ}$. Table 170 , Solar Altitude and Azimuth, in Smithsonian Metcoroligical Tables (List, i951) can be used in determining the solar altitude. Cloudiness will decrease inconing solitr radiation and should be considered together with solar altitude in deternining solar radiation. Incoming radiation that would be strong with clear skies cin be expected to be reduced to moderate with broken $13 / 8$ to $7 / 8$ cloud cover and to 5 light with broken low elouds. An abjective system of classifying stability from hourly meteoroligical observations based on the above method las been suggested ${ }^{(7)}$. Appendix $\quad 6.5$ Plume Depletion

In order ta accurately mode] the diffusion of radioactive material in the atmosphere, the rate at which contaminants are deposited from 
air to ground must be known. Processes by which materials are removed from the air are classified as either wet or dry deposition.

Dry deposition occurs by gravitational settling, molecular exchange, surface impaction, electrostatic attraction and chemical interaction at ground level. Gravitational fall is insignificant for gaseous sptcies and is neglected in the present evaluation. Wet deposition is the removal of species from atmosphere to ground by rainfall.

In general, wet and dry deposition cannot be specified precisely. However, it is possible to determine the limiting effects of these processes on consequences of radiactive release. Lower limits are obtained by ignoring deposition completely. Upper limits are dictated by the limited capacity of the atmosphere to carry material to ground Ievel. Maximum deposition quantities have been estimated by experinent ${ }^{(8)}$.

Dry deposition rates are proportional to the immediate ground level concentration. Chamberlin ${ }^{(9)}$ has defined the dry deposition rate $w$ (curies $/ \mathrm{m}^{2} / \mathrm{s}$ ) as the product of the average ground level concentration $\bar{x}(x, y, 0)$ and the deposition velocity $v_{d}$ as:

$$
w(z, y)=v_{j} \bar{x}(x, y, o)
$$

If the depletion of the plune is to be allowed for, $Q$ or $Q$ must be replaced by an effective source strength $\dot{Q}(x)$ or $Q(x)$ which is a function of $x$.

Application af a mass balance to a cantrol volume surrounding the plume shows that $Q(x)$ is just: 


$$
\frac{\partial Q(x)}{\partial x}=-\int_{-\infty}^{+\infty} H(x, y) d y
$$

Substituting liquations (10) and (14) inta l:quation (15) gives

$$
\frac{Q(x)}{\dot{y} x}=\sqrt{\frac{2}{\pi}} \frac{Q(x)}{\sigma_{z}(x)} \frac{v_{d}}{\bar{u}} \exp \mid-\frac{u^{2}}{2 \sigma_{z}^{2}} l
$$

lloarranging and integrating laquation $(16)$ with respect to $x$ yiclds

$$
Q(x)=\eta \operatorname{cxp}\left[-\sqrt{\frac{2}{\frac{2}{\pi}}} \frac{\mathrm{d}}{\frac{1}{4}} 1(x)\right]
$$

Where

$$
f(x)=\int_{0}^{x} \frac{d x}{v_{z}(x) \operatorname{cxp}\left[1^{2} / 2 \sigma_{z}^{2}(x)\right)}
$$

Equations (10), (14), (17), (18) are used to determine surface level concentrations and dry deposition rates when the deposition velocities are giver.

Wet deposition can be described by a simple removal rate, $r$, per unit air volume, as:

$$
\mathbf{r}=1 \cdot \bar{X}(x, y, z)
$$

where

$$
\begin{aligned}
& r=\text { washout coefficient }\left(\sec ^{-1}\right) \\
& \bar{X}=\text { concentration in washout area. }
\end{aligned}
$$

For precipitation that is just beginning at a downind position $x_{0}$, the deposition rate at that position is:

$$
n_{0}=A \int_{0}^{A} x\left(x_{0}, y, \pm\right) d z
$$

The upper limit for this integral is the altitude from which the rain 
falls. If it is assumed that the plume is contained below this level, then

$$
w_{0}=\frac{n Q}{4 \sigma} \sqrt{\frac{2}{\pi}} \exp \left[\cdot \frac{y^{2}}{2 \sigma^{2}}\right]
$$

The Equation (2l) assumed that the plume profile docs not chanpe with elevation because of wind shear. The comeentration can be madificd for tret removal up to some distance $x$, greater than $x_{a}$, by an attenuation term. With this modification the wet deposition rate at $x, y$ from a cloud which originates at $x_{0}$ is

$$
r=\frac{\Lambda Q \sqrt{2}}{\overline{\mathrm{u} g} \sqrt{\pi}} \exp \left[-\frac{y^{2}}{2 \tau_{y}^{2}}\right] \exp \left[-\frac{\Lambda\left(x+x_{0}\right)}{\bar{u}}\right]
$$

Typical washout coefficients ate given in Table A6, 2 .

Appendix 6.6 Effective Height of Emission

In most problems one aust estimate the effective stack height, H, at which the pluae becomes essentially level. If the plume is caught in the turbulent wake of the stack or of the buildings in the vicinity of the stack, the effluent will be carried rapidly dowaward towarl the ground (aerodynamic downwash). If the piume is emitted fice of these turbulent zones, a number of enission factors and meteorological factors influence the rise of the plume. The enission factors are: velocity of the effluent at the top of the stack, $v_{s}$; temperature of the effluent at the top of the stack, $\tau_{s}$; and diameter of the stack opening, d. The meteorological factors influencing plume rise are wind speed, $\bar{u}$; temperature of tha air, $T_{a}$; shear of the wind with height, dü/dz; and atmospheric stability. No theory on plume rise 
takes into account all of these variables; even if such 3 theory could be devised, mensurements of all of the parameters would seliom be available. Most of the equations that have been formulated for ovilwating the effect of height of emission are semi-empirical.

The floldand's ${ }^{(10)}$ equation was developed with experigental dita from larger sources than those of Moses and Strom (11) fstact diameters from 1.4 to 4.3 metors and stack tomperatures from $82^{\circ}\left(\mathrm{C}\right.$, to $\left.204^{\circ} \mathrm{C}\right)$; ffis equation frequently underestimates the effective beight of epission; therefore its use orten provides a sight safety fitetor. Hol hand's oquation is:

$$
\Delta E=\frac{v_{5} d}{\bar{d}}\left(1.5+2.68 \times 10^{-3} r \frac{T_{s}-T_{d}}{T^{2}} d\right)
$$

wher:

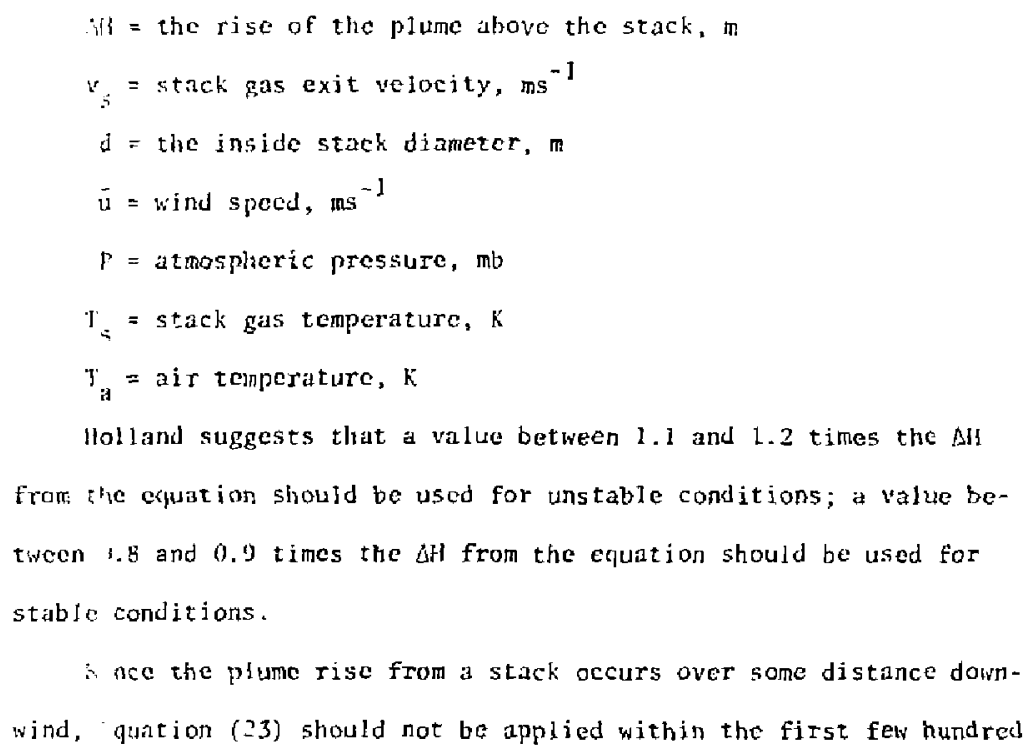


meters of the stack.

If the effective heights of emission were the same under all atmospheric conditions, the highest ground-level concentrations from in given source hould occur with the lightest winds. Generally, however, enission conditions are such that the effective stack height is an inverse function aind speed as indicated in Equation (23). The maximunl ground-leve mecrtration occurs at some intermediate wind speed, at which a balance is reached between the dilution due to wind speed and the effect of height erission. The critical wind speed will vary with stability. In order to determine the critical wind speed, the effective stack height as a function of wind speed should first be determined. The maximum concentration for each wind speed and stability can be ohtained as a function of effective height of emissian and stabilitr.

The influence of mechanical turbulence around a building or stack can significontly alter the effective stack height. This is especially true with high winds, when the beneficial effect of high stack gas velocity is at minimum and the plune is emitted nearly horizontally. The region of disturbed flow surrounds an isolated building, generally to at least twice its height and extends downwind 5 to 10 times its height. Building the stack 2.5 times the height of the highest building adjacent to the stack usually overcomes the effects of building turbulence (12). Ensuring that the existing velocity of the stack gas is more than 1.5 times the wind speed will usually prevent downwash in the wake of the stack. 
The Regulatory Guides 1.3 and 1.4 suggest use of the building wake correction model presented by slade $(13)$. This madel is to be applied only to ground level releases of eight hours or less duration. The dispersion correction factor is 1 imited to the range of $1 / 3$ to 1 . The classic way of handling the turbulenee-enhancement effect in the conterline diffusion equation in Regulatory Guides 1.3 and 1.4 has been to add to the r! ine size parameters a term that accounts for the enhanced mixing in the lee of the building:

$$
x / Q=\frac{1}{\pi \bar{\Sigma} y^{2} z^{\bar{u}}}
$$

there

$$
\begin{aligned}
\Sigma_{y}= & \left(0_{y}^{2}+C N / \pi\right)^{1 / 2} \\
E_{z}= & \left(\sigma_{z}^{2}+C N / \pi\right)^{1 / 2} \\
A= & \text { the minimum cross sectiona } i \text { area of the reactor building }\left(\pi^{2}\right) \\
C= & \text { the fraction of the area over which the plume is dispersed } \\
& (-0.5 \text { in Reg. Guides } 1.3 \text { and } 1.4) .
\end{aligned}
$$

The exact numerical value for $C$ will have to be determined by suitalie experiments. Gifford ${ }^{(15)}$ suggested that, as a reasonable estithate, $1 / 2 \leq \mathrm{C} \leq 2$. The reason for choosing these particular bounds, which were actually no more than a guess, was to provide, in absence of suitablc experimental data, usable numbers for concentration estimation. Accolding to Barry ${ }^{(16)}$, who made an interesting and useful sumary of the results of a number of experiments, studies with wind-tumel models have suggested values of $C$ near the lower of these timits, namely, $C=0,5$ to 0.67 . Thus, NRC has chosen conservatively jower bounds of $C$. of course, it is sot inpossible that larger values of $C$ may be found 
if suitable full-scale atmospheric experiments are performed, particularly in unstable 1 ight-wind conditions. A further potential source of conservatism in the dispersion model is the absence of any consideration of the relief offered by "radioactive buoyancy" of a plume containing a high concentration of radioactive raterial. If the concentration is sufficiently high, the temperature of the air in the pluse becomes high enough to make the plume buoyant with respect to the surrounding air. Thus, even for a ground-level release, the axis of the plume is no longer at the surface, so that the concentration there is reduced, thereby decreasing doses due to inhalation, and there is some "shielding-by-distance" from the gasuma radiation responsible for the whole body dose due to external radiation. A good summary of the effects of this phenomenon was provided by Beattic in Ref. 17. His estimates have been confirmed to a large extent by later work in other establishments.

However, in the case of accidents of the type visualized in Regulatory Guides 1.3 and 1.4 , the rate of release of active material would be so slow, if the requirements of the gujdes were met, that the radioactive buoyancy would be negligible, i.e., if the otjectives of the Regulatory Guides are met, these would, in practice, be no factor of conservatism on account of radioactive buoyancy. 


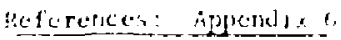

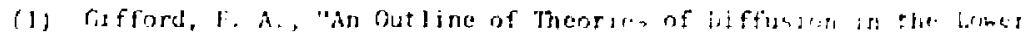

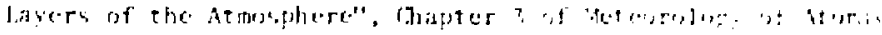

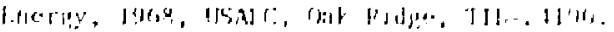

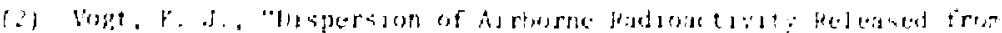

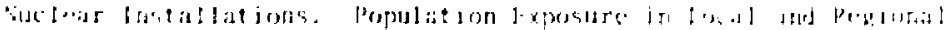

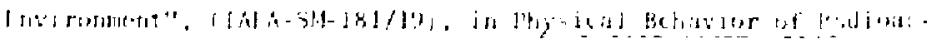

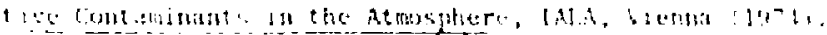

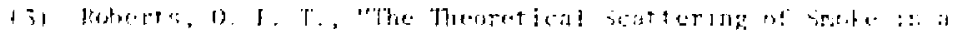

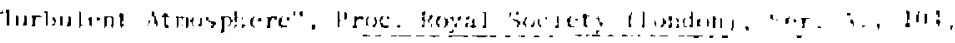

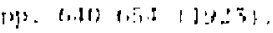

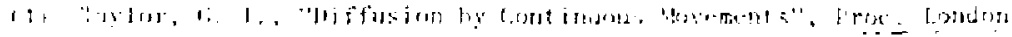
$\sec , 211,51,111,80213$

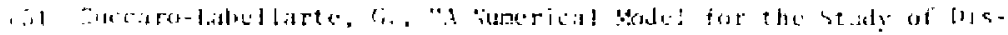

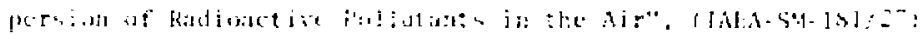

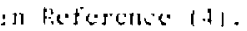

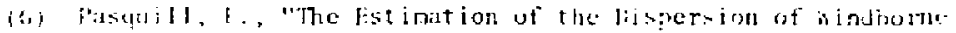

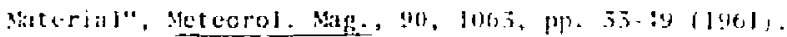

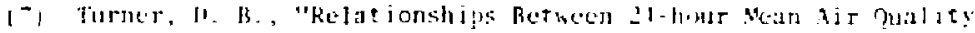

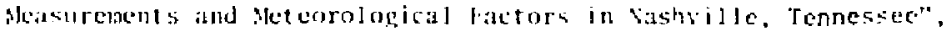

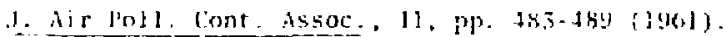

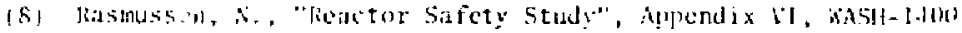
$\{$ (X)

(b) Processes beher that satural Turiulent iffecting liffluent Concentrations", Chapter 5 uf Meteorology of Atomic Energy, 1968, USALC, Oak Ridge, TII)-24190. 
119; Holland, 1. Z., "A Meteorological Survey' of the Oak Ridge Rrea", ISSIC Report ORO-99, p. 548, Nashington, D.C. (1953).

(II) Soses, 11., and (;. if. Strom, "r Comparison of obserted plute Rises

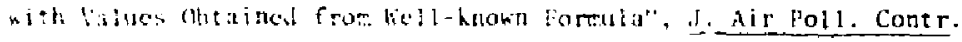
$1500,11,11$, Pp. 1:-16), (1!10!).

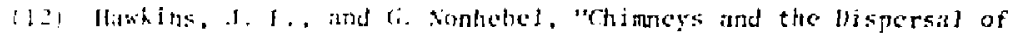

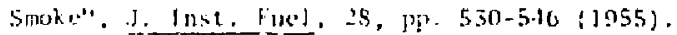

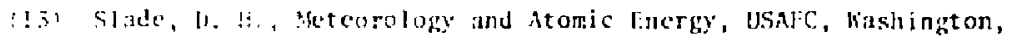
$[1,1 .(19)(1,6)$

191 rifford, 1. A., "Turbulent Diffusion--Typing Schemes: A Reviek",

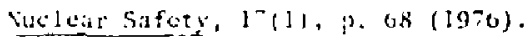

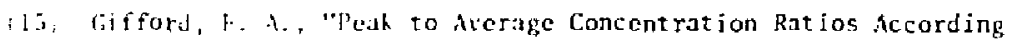

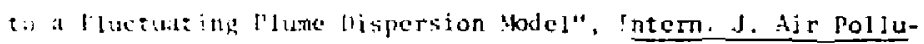
tion, $3(1),[1] .253-260)(1960)$.

(1t) Riarry, P. I., "Estimaticn of llownind Concent ration of Airbarme I.ffluents lischarged in the veighborhood of Buiddings", ACEL-2045, Iu] 1964.

1:" Butcte, 3. K., paper given at British Nuclear Energy Society Symposium on "Safety and Siting", London, March 1969. 
Table 46,1 Briggs' Formulas for $G_{y}(x)$ and

$\sigma_{z}(\bar{x})$ for oper Terrath

\begin{tabular}{|c|c|c|}
\hline $\begin{array}{l}\text { Pasquill } \\
\text { Condition }\end{array}$ & $\sigma_{y}(\mathrm{x}), \mathrm{m}$ & $g_{z}(x)$, in \\
\hline$\lambda$ & $0.22 \times(1+0.0001 x)^{-1 / 2}$ & $0.31) \times$ \\
\hline$n$ & $13.16 \times(1+0.0001 x)^{-1 / 2}$ & $0.12 x$ \\
\hline c & $0.11 \times(1+0.0001 x)^{-1 / 2}$ & $0.08 \times(1+0.0002 x)^{-1 / 2}$ \\
\hline$[1$ & $0.08 \times(1+0.0001 \times)^{-1 / 2}$ & $0.06 \times(1+0.0015 x)^{-1 / 2}$ \\
\hline$E$ & $0.06 \times\{1+0.0001 x\}^{-1 / 2}$ & $0.03 \times r 1+0.0003 \times 1^{-1}$ \\
\hline I: & $0.04 \times(1+0.0001 x)^{-1 / 2}$ & $0.016 x ! 1+0.0003 x)^{-1}$ \\
\hline Table AG.2 & Slade's Formulas for $\sigma_{y}(x)$ & and $\sigma_{z}[x]$ in Puff Relcases \\
\hline Condition & $\sigma_{y}(x), \pi$ & $a_{2}(x), \pi$ \\
\hline Unstable & $0.14(x)^{0.92}$ & $0.55(x)^{0.75}$ \\
\hline Neut ral & $0.06(x)^{0.92}$ & $0.15(x)^{0.70}$ \\
\hline Very Stable & $0.02(x)^{0.89}$ & $0.05[x)^{0.61}$ \\
\hline
\end{tabular}


Table 26.3 Relation of Turbulence Types to

Weather Conditions (13)

\begin{abstract}
A - Extremely unstable conditions
$B$ - Moderately unstable conditions

C - slightly urtstable conditions
\end{abstract}

D - Meutral conditions*

E - Slightly stable conditions

F. Moderately stable conditions

\begin{tabular}{|c|c|c|c|c|c|}
\hline $\begin{array}{l}\text { Surface wind } \\
\text { speed, } \mathrm{m} / \mathrm{sec}\end{array}$ & \multicolumn{3}{|c|}{ Daytime insolation } & $\begin{array}{c}\text { Nhighteime } \\
\text { Thin overcase } \\
\text { or } \geq 4 / 8 \\
\text { cloudinesst }\end{array}$ & $\frac{\text { glitions }}{c 3 / 8}$ \\
\hline$<2$ & A & $A-B$ & $B$ & & \\
\hline 2 & $A-B$ & B & C & E & $\mathrm{F}$ \\
\hline 4 & B & $\mathrm{B}-\mathrm{C}$ & C & D & E \\
\hline 6 & $c$ & $C-b$ & $D$ & $D$ & D \\
\hline$>6$ & $c$ & $\mathrm{D}$ & D & D & D \\
\hline
\end{tabular}

Applicable to heavi: overcase, day or night.

The degree of cloudiness is defined as that fraction of the sky above the local apparent horizon which is covered by clouds. 


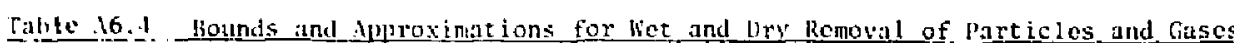

\begin{tabular}{|c|c|c|c|}
\hline 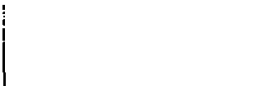 & $\begin{array}{l}\text { Minimula } \\
\text { lixpected (a) }\end{array}$ & Average Expected $(b)$ & $\begin{array}{l}\text { Maximum } \\
\text { Expectod }\end{array}$ \\
\hline$\left\{\begin{array}{l}\text { hiet removal } \\
\text { rate }\left(5 \mathrm{~s}^{-1}\right)\end{array}\right.$ & $10^{-5}$ & Stable $(d): 10^{-4}$. Not stable $e^{(c)}: 10^{-3}$ & $10^{-2}$ \\
\hline $\begin{array}{l}\text { II. Uloposition } \\
\text { velociry (n/sec) }\end{array}$ & $111^{-5}$ & $10^{-2}$ & $10^{-1}$ \\
\hline
\end{tabular}

(i) Fxeept for sases bately soluble in water (e.g., the noble gases); then use zero.

(b) Based on field experimentil diatil for mieron-size particles and soluble gases.

(c) Mhitiply tabulated mmerieal values by $\left(p / l \mathrm{mrl} h \mathrm{r}^{-1}\right)$, where $\mathrm{p}$ is the precipitation rate in manwater coluivalent

(d) li:trm front:1l storm.

(c) Convertive storm. 
Appendix 7. Review of estimated doses for Class 8 accidents

Various applicants for licenses have endeavored to demonstratc the degree of conservatism in the Reg. Guide 1,4 assumptions by calculating the whole body anri thyroid doses the the $E A B$ and $C P Z$ using assumptions of their own, which they have deseribed as "conservative", "realistic" and "Environnental Report Model".

In order to compare these estimates on a common basis it is convenient to derive a "Relaxation Factor" for each case, where this factor is defined as follows:

Relaxation Factor $=\frac{\text { Retention factor for Reg. Guide } 1.4 \text { analysis }}{\text { Retention factor for Applicant's analysis in }}$

"Retention Factor" in this expression is defined for each analysis model as

Retention factor $=\frac{\text { Amount of Radioactive material relea:ed to containment }}{\text { Mnount of Radioactive material released to atmosphere. }}$ The Retention Factor has been calculated by working back from the Applicant's estimated $E A B$ and LPZ doses, using his stated atmospheric dilution factors, to abtain the denominator of the expression; the numerator is simply the Applicant's source term. 
Table A7, I Review of Estimated Doses for Class A Accideris

\section{Palaxation Factoss for Coniajnacen iresign}

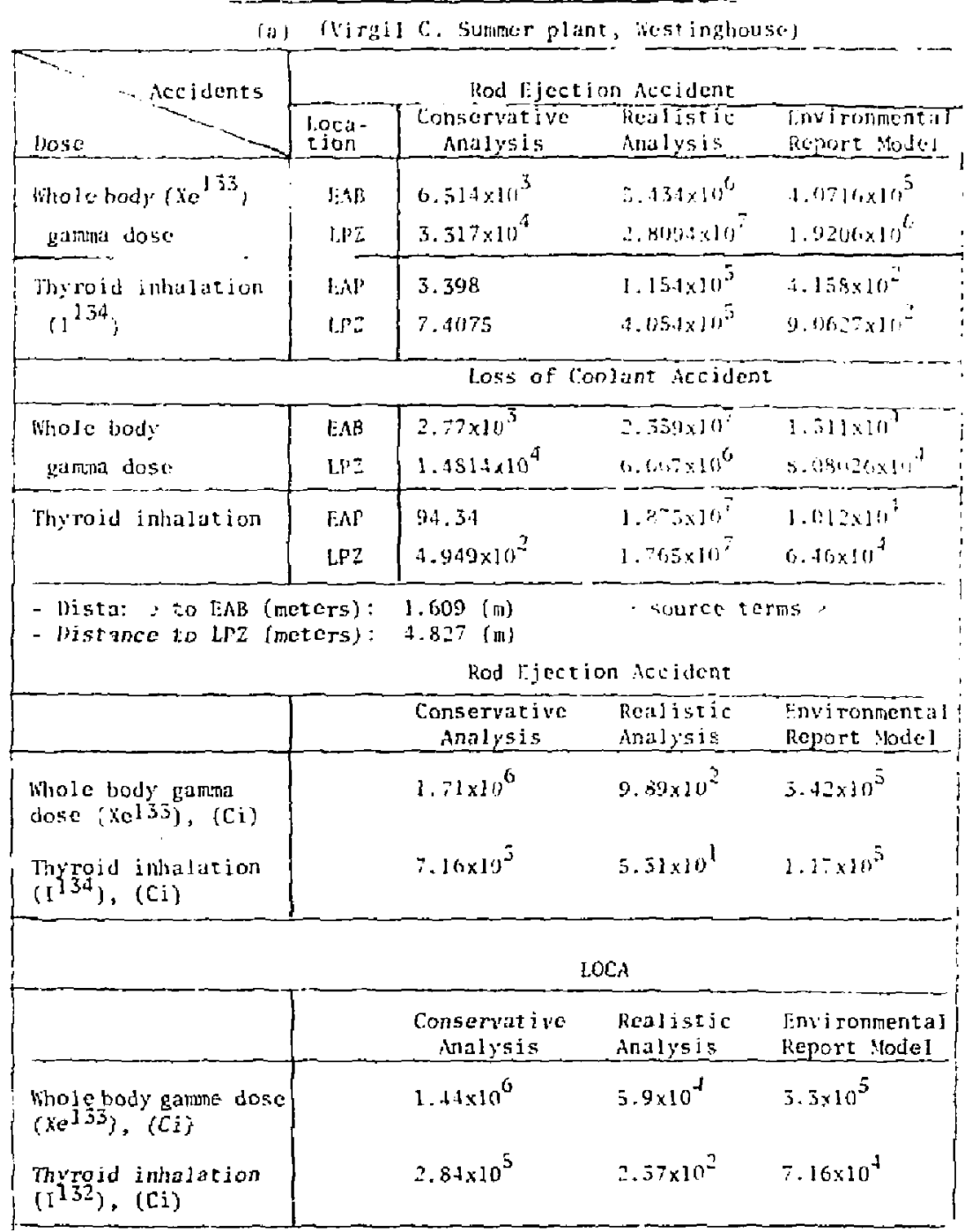




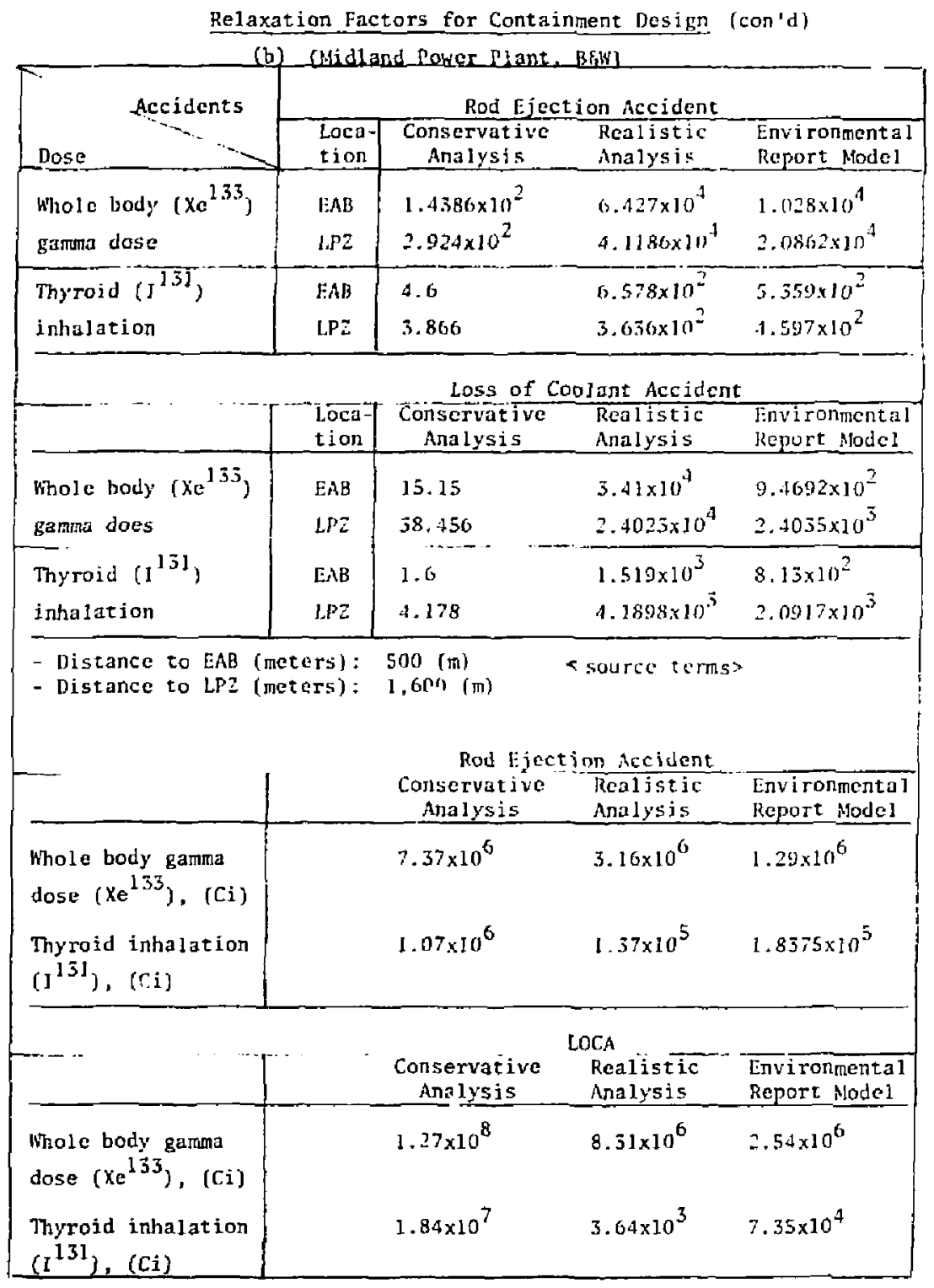


Relaxation Factors for PWR Dry Containment liesign

() (San Onofre 2d3 Plant, Combustion ing.)

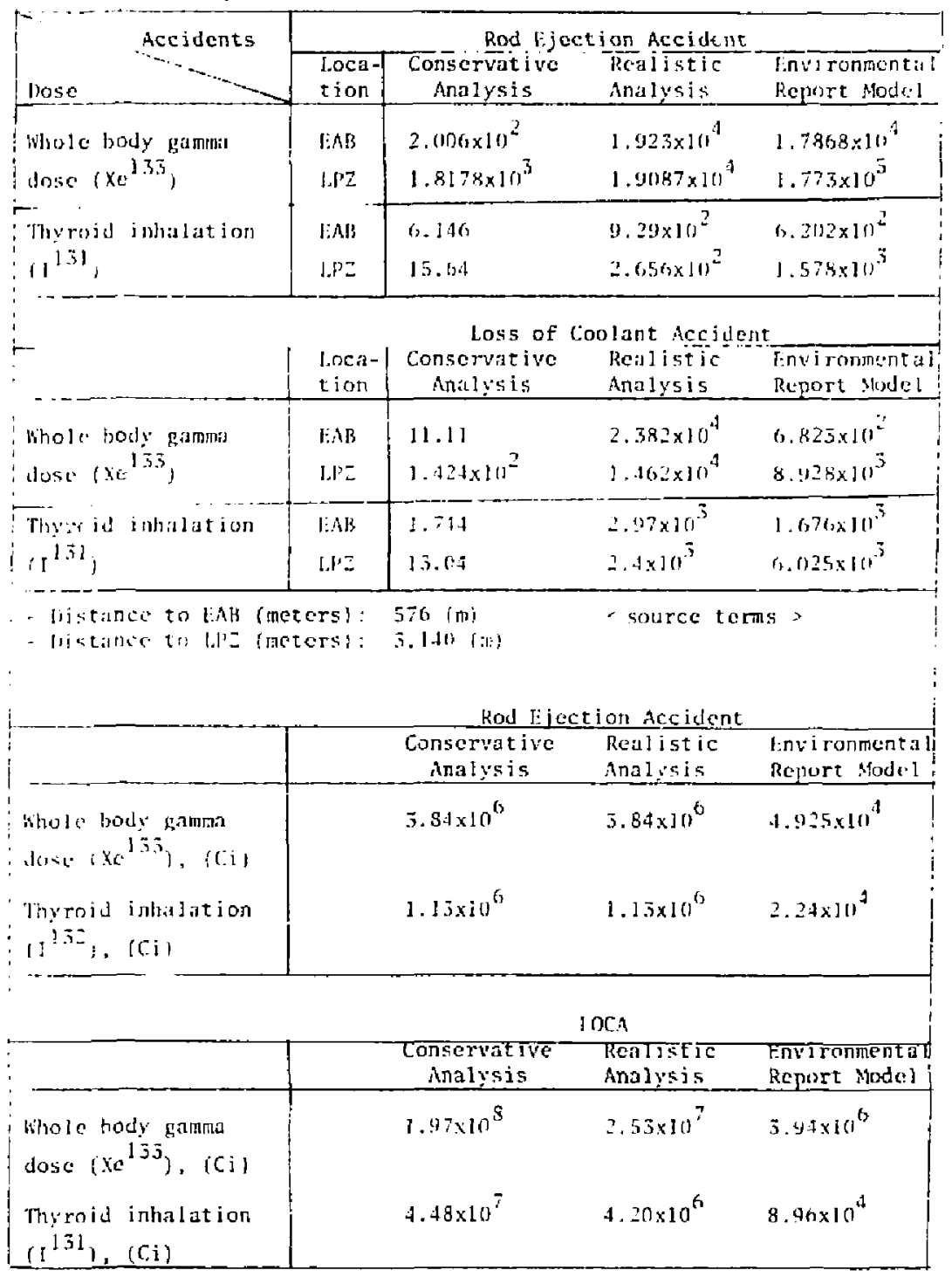


Appendix B. The Effect of 1nternal Diameter and Design Pressure on Containment Cost

Approximate relationships between internal diameter and cost of containment structures for stecl lined and for unlined containment are derived in this Appendix.

As discussed in section $S$ of the main text, the major components of cost which are particularly sensitive to the internal diameter are:

(i) the steel used to resist the pressure load in the shell and dome,

(ii) the cost of the mild steel liner.

For a thin steel vessel we have the relationships:

$\mathrm{t}=\frac{\mathrm{P}}{\mathrm{s}} \mathrm{r}$, for a cylinder

and

$$
t=\frac{P}{5} \frac{r}{2} \text {, for a spherical vessel }
$$

where

$$
\begin{aligned}
& t=\text { minimum design thickness of plate } \\
& p=\text { design pressure } \\
& s=\text { design stress } \\
& r=\text { radius of vessel }
\end{aligned}
$$

The surface area, $A$, of a cylindrical or spherical vessel is proportional to $r^{2}$.

The volume of steel required, $v_{s}$, is proportional to tA. Thus we can wirite $v_{s}=k r^{2}$ Tp $=k r^{3} p$ for either cylindrical or spherical vessels. In the case of a containnent vessel, $p$ is inversely proportional to the contained volume and thus to $1 / \mathrm{r}^{3}$. 
Cunstequently the volume of steel required is, to a first apjroximation, independent of the radius of the containment vessel. In the case of a $r$ nforced or prestressed vessed, the equatity of stecel required to res th the design pressure is also approximatejy proportioras to ta and the, as in the case of the steel vessel, is virtually indejentent of the :adjus.

It iever, in the case of a reinforced or prestressed concrete

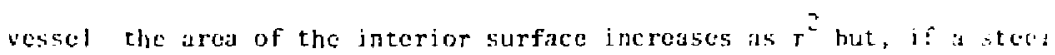

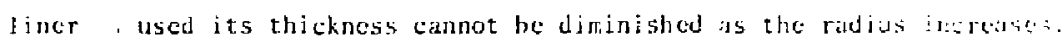
thus tl $\because$ inount of material required for the liner increases is $r^{2}$ and, morco: the total length of helds is also proportionel to $\mathrm{r}^{2}$. is shown t the main toxt, the cost of the liner pless the penetedion: js abo. 3n per cent of the total cost of the containnent serteture (inclus ng the interior concrete rorkj. Thus a 10 per ect incruse in rati is of a steet-lined containgent vessel woulal add aboul it per vent i the cost of the structure.

l's.ssure suppression provides a means of reducing design pressure, thus il view of the relationship derived above,

$$
i=k r^{3} \mathrm{P}
$$

a prop rtional decreise in $V_{5}$ can be obtained, witlout decreasing the ridius of the structure. In addition, if the structure is a 1 ined concre one, a saving in liner costs proportional to $r^{2}$ would also be witain 1 by reducing the radius of the structure.

T 2 greater thiekness required for a cylindrical vessel, for the same design pressure, makes it worth while to examine the relative 
costs of spherical and cylindrical vessels containing the same rolume.

Consider a typical cylindrical vessel, with a hemispherical done

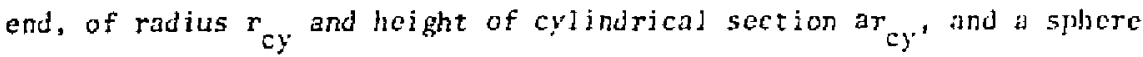
of radius $\mathrm{r}_{\mathrm{sp}}$. The following relationships can be derived:

(i) Volume of containgent

Cyl inder $\frac{\pi r^{3} y}{3}(y+2)$, spherc $\frac{4}{3} \pi r_{s p}^{3}$

Thus for $y_{c y}^{\prime}=v_{s h}$, we reepire $r_{c y} / r_{s p}=\left(\frac{1}{3 a+2}\right)^{1 / 3}$

(ij) Surface area of contaiment structure

Cylinder (cxcluding base) $2 \pi r_{c y}^{2}(a+1)$, sphere $4 \pi r^{2}$

Thus $A_{c y} / A_{s p}=\frac{(a+1)}{2}\left(\frac{4}{5} \frac{4}{+2}\right)$

(jii) Comparison of volume of steel for pressure retention purposes

Cylinder $2 \pi r_{c y}^{2} t(2 a+1)$, sphere $4 \pi r_{s p}^{2} t$

Thus $v_{\text {sicy })} / v_{s(s p)}=\left(\frac{2 a+1}{2}\right)\left(\frac{4}{3 a+2}\right)^{2 / 3}$

The values of $A_{c y} / A_{s p}$ and of $V_{s(c y)} / V_{\text {s(sp) }}$ as functions of a are shown in Table 48.1 .

Table A8.1 Variation in ratios of surface area and of quantities of pressure retaining steel for cylindrical and spherical vessels of the sane volume, as function of "a".

\begin{tabular}{|c|c|c|c|}
\hline $\mathbf{a}$ & $r_{c y} / r_{s p}$ & Ratio of surface area & $\begin{array}{l}\text { Ratio of quantities of } \\
\text { steel }\end{array}$ \\
\hline 1 & 0.928 & 0.862 & 1.20 \\
\hline 2 & 0.794 & 0.945 & 1.575 \\
\hline 3 & 0.714 & 1.02 & 1.783 \\
\hline 4 & 0.659 & 1.08 & 1.952 \\
\hline
\end{tabular}




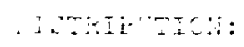

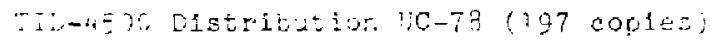

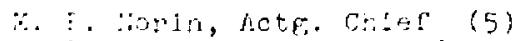

$\therefore \therefore$ :

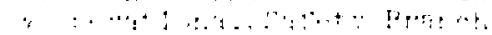

$-$

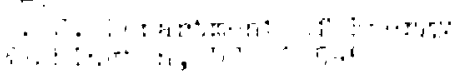

$\therefore 2 \pi+3$

$\because-i$

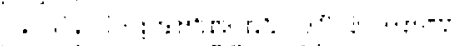

$\therefore \therefore, \therefore, \cdots, \square$

. $\therefore \therefore \mathrm{i}$

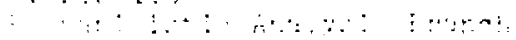

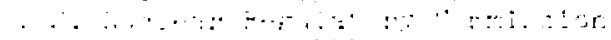

$\therefore \therefore \quad \cdots \quad \cdots, \quad \because \quad \cdots$

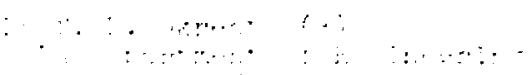

$\therefore \quad \therefore \quad \because \cdots$

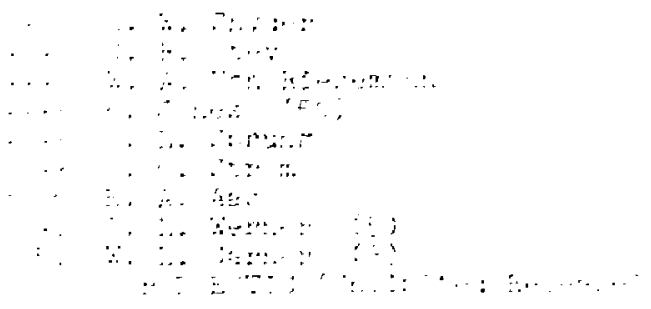

